\title{
DISTRIBUTED GENERATION: \\ ISSUES CONCERNING A CHANGING POWER GRID PARADIGM
}

\author{
A Thesis \\ presented to \\ the Faculty of California Polytechnic State University, \\ San Luis Obispo
}

\author{
In Partial Fulfillment \\ of the Requirements for the Degree \\ Master of Science in Electrical Engineering
}

by

Scott G. M. Therien

May 2010 
(C) 2010

Scott G. M. Therien

ALL RIGHTS RESERVED 


\section{COMMITTEE MEMBERSHIP}

TITLE:

Distributed Generation: Issues Concerning a Changing Power Grid Paradigm

AUTHOR:

DATE SUBMITTED:

COMMITTEE CHAIR:

COMMITTEE MEMBER: Ahmad Nafisi, Professor

COMMITTEE MEMBER: Bill Ahlgren, Associate Professor
Scott G. M. Therien

May 2010 


\begin{abstract}
Distributed Generation:

Issues Concerning a Changing Power Grid Paradigm

Scott G. M. Therien
\end{abstract}

Distributed generation is becoming increasingly prevalent on power grids around the world. Conventional designs and grid operations are not always sufficient for handling the implementation of distributed generation units; the new generation may result in undesirable operating conditions, or system failure. This paper investigates the primary issues involved with the implementation of distributed generation and maintaining the integrity of the power grid. The issues addressed include power flow, system protections, voltage regulation, intermittency, harmonics, and islanding. A case study is also presented to illustrate how these issues can be addressed when designing distributed generation installation on an existent distribution system. The case study design is performed on the campus distribution system of California Polytechnic State University, San Luis Obispo, with the design goal of implementing renewable energy sources to make the campus a net zero energy consumer. 
TABLE OF CONTENTS

Page

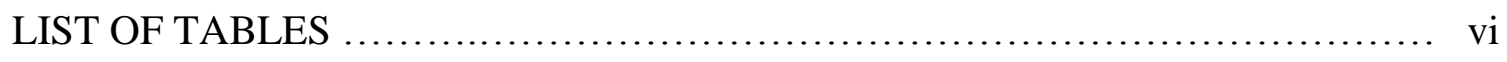

LIST OF FIGURES …....................................................... vii

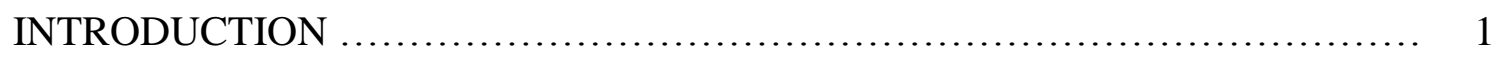

I. DISTRIBUTED GENERATION: IDENTIFICATION \& EVALUATION ......... 4

II. RADIAL DISTRIBUTION VS. NETWORKED DISTRIBUTION ............... 15

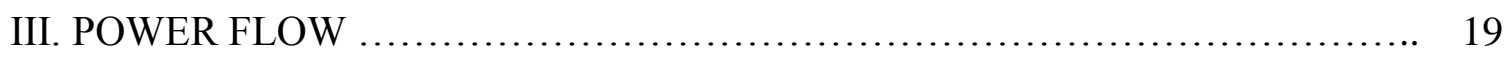

IV. PROTECTION SYSTEM DISTURBANCES ............................ 22

V. VOLTAGE REGULATION ................................................ 36

VI. INTERMITTENCY / FLUCTUATING SOURCES .......................... 42

VII. HARMONIC DISTORTION .......................................... 47

VIII. ISLANDING …...................................................... 54

IX. CASE STUDY - CAL POLY DISTRIBUTION SYSTEM .................... 68

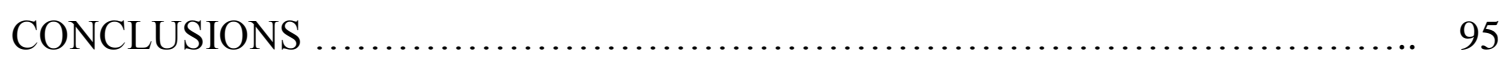

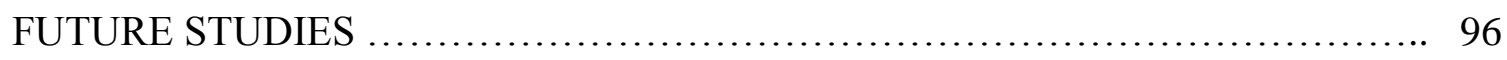

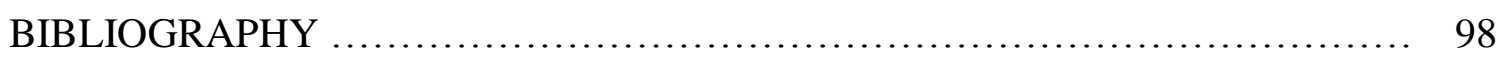

APPENDICES

A. Cal Poly Yearly Metering Data, 2008-2009 ......................... 102

B. Conductor \& Transformer Modeling Data ............................ 105 


\section{LIST OF TABLES}

$\begin{array}{lll}\text { Table Page } & \text { Pag }\end{array}$

VII.A IEEE 519 Current and Voltage Distotion Limits ....................... 49

IX.A System Branch Load Flows (in kW) at Various Loading \& Generation Levels 71

IX.B Feeder Interties .................................................. 71

IX.C Possible Bus Generation Capacities without Load Flow Reversal ........... 73

IX.D Maximum Fault Current due to Amount of Added Generation ............... 76

IX.E Source Currents (in A) for New System ............................. 86

IX.F System Currents and Necessary Relay Settings for Protection .............. 88 


\section{LIST OF FIGURES}

Figure

Page

II.1 General Radial Distribution System ............................... 16

II.2 General Low Voltage Network Distribution System ................... 16

III.1 Example Distribution System ..................................... 19

IV.1 Radial Distribution System with Fuse Protection $\ldots \ldots \ldots \ldots \ldots \ldots \ldots \ldots \ldots \ldots . . \ldots \ldots$

IV.2 Fuse 2 and 3 Characteristic Curves ................................ 25

IV.3 Altered System with Fuse Protection ................................ 28

IV.4 Radial Distribution System with Relay Protection ........................ 28

IV.5 Relay Coordination for System of Fig. IV.4 f......................... 29

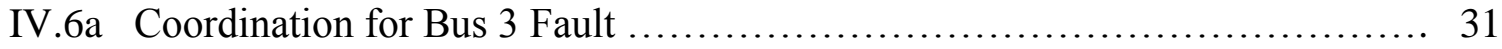

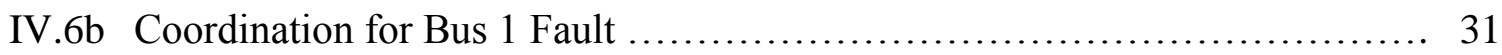

IV.7 Radial Distribution System with Recloser/Fuse Protection . ............... 33

V.1 Distribution Line with LTC and LDC Voltage Regulation ................. 37

V.2 Radial Distribution Line for Investigation of Voltage Level Effects from DG 38

V.3a Full Load Voltage Profile w/o DG ................................ 39

V.3b Full Load Voltage Profile w/ DG ................................... 39

V.4a $30 \%$ Load Voltage Profile w/o DG ................................. 39

V.4b $30 \%$ Load Voltage Profile w/ DG ................................ 39

V.5 Voltage Profiles at Various Points of DG Connection .................... 40

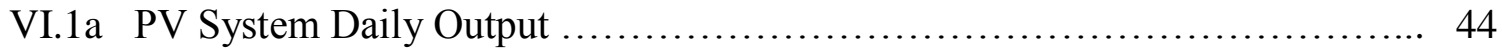

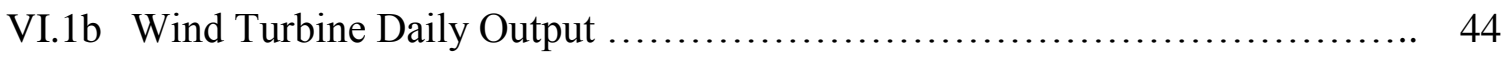

VI.2 Radial Distribution System with DG, Protected by Relays ................ 45 
Figure

VII.1 Distorted Current Waveform and Harmonic Components ................... 48

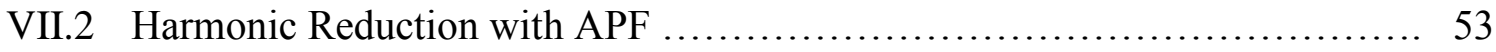

VIII.1 Distribution System that is Susceptible to Islanding $\ldots \ldots \ldots \ldots \ldots \ldots \ldots \ldots \ldots .54$

VIII.2 Non-Detection Zone ........................................... 59

IX.1 Nominal High-Level System of Cal Poly Distribution Network ............. 70

IX.2 Feeder Z Distribution and Fuse Protection Ratings ...................... 75

IX.3 Proposed Upgrades to Cal Poly Distribution Network .................... 84 


\section{INTRODUCTION}

At increasing rates, various influences within the energy market are posing new challenges to traditional methods of delivering electrical energy. In today's energy market, it has become far more economically sound for many homeowners, businessowners, and even grid operators to produce their own energy with small generators than it has previously been [1]. The reasons for this are numerous and debatable but include such motivations as environmental concerns, increases in cost to traditional energy sources, reductions in cost to new technologies, political incentives, and many other factors. While there have been utility customers producing their own energy for a very long time, the increasing quantity and changes in methodologies of this production pose many new challenges.

The standard power grid infrastructure has generally been comprised of largescale power plants feeding a high voltage network, from which substations drop the voltage and feed distribution networks at lower voltages. With this paradigm, generation has been connected almost exclusively to the high voltage network while the distribution networks have fed almost exclusively to loads. Therefore, the supportive and protective equipment used to maintain the power grid has often been implemented under assumptions dependent on the framework of this model. Unfortunately, modern developments are making these assumptions more and more invalid.

Small-scale generation units connected at the distribution level are commonly referred to as distributed generation. Technically, most power grids have had some form of distributed generation (DG) for a long time - commonly in the form of peakers or stand-by generators. However, modern day application of newer DG technologies presents situations of a different nature; in today's energy market, DG is owned and operated privately and not for the intent of supporting overall grid operation. 
Furthermore, the rising quantity of DG present on the grid, as well as the various types of generation used, presents new issues of concern. The amount of DG units connecting to distribution grids is expected to continue increasing as new technologies and new applications develop; the power grids of the future may operate very differently than traditional grids $[2,3,4]$. Yet for the implementation of DG to be successful on existent grids, previously unaddressed scenarios must be investigated. The high voltage network of a power grid has always accommodated many generation plants and was thusly built to do exactly that. The same cannot be said of most distribution networks. Typical distribution lines are fed radially from substations under the assumption that power will flow strictly from the substation to the various loads downstream on that line. Distribution grids were simply not built to accommodate generation, as will be discussed at length throughout this paper. True as this may be, most distribution areas can handle some amount of DG with little concern, some can handle very large amounts with only minor upgrades needed, and some stand to benefit greatly from the installation of DG units.

In any case, many issues will need to be addressed if safe, reliable service of electric grids is to be maintained with increasing levels of DG interconnections. These issues may include reforms in tariffs, insurance, regulation, and operating standards along with the many technical issues. The purpose of this paper is to identify the technical issues encountered in DG interconnection scenarios - both problematic issues that must be overcome, as well as potential benefits that must be optimized. The ultimate objective is to identify the scenarios where DG poses challenges and where DG benefits are highest and most applicable so that the proliferation of DG can be directed in the most cost-effective and universally advantageous ways. Standards for DG interconnection are currently being written and revised by electric standard organizations 
and committees around the world. The issues presented in this paper are those that demand investigation in order for such standards to be effective.

Section I of this paper addresses the definition of DG, which is foggy at best, and also present the motivations, uses, and types of DG that have begun to alter the paradigm of the electric grid. Section II provides background on distribution system designs, which must be understood when investigating the effects of DG. Sections III through VIII address the primary challenges encountered in DG interconnection. Each of these sections easily warrants a full thesis on the individual issue addressed. However, the intent here is to provide a high level view of each topic and identify the specific circumstances that the design of DG interconnection must be engineered to meet. Upon full identification of the issues at hand, Section IX presents a case study on a large distribution system that is existent and in service on the campus of California Polytechnic State University in San Luis Obispo (Cal Poly). This campus purchases large quantities of electrical energy from the local utility Pacific Gas and Electric. Under current energy market situations, it is widely agreed that the university stands to find great financial benefit from the proper implementation of DG on their distribution system. The objective of the case study is find optimal methods of DG interconnection that can provide an alternative to the import of energy to the campus, while designing to meet all challenges presented in the other sections. It is the author's intent to find a system design that provides the university a source of energy independence while causing no strain to the upstream grid of the utility, but rather offering beneficial support to the grid. 


\section{DISTRIBUTED GENERATION: IDENTIFICATION AND EVALUATION}

The term distributed generation (DG) is generally ill-defined. At its loosest definition, it refers simply to generation of a small scale (when compared to large power plants). The International Conference on Electricity Distribution (CIRED) posed the question to all member countries in 1997 as to how they defined distributed generation. There was no consensus. Today, the definition is still muddled. The criteria most commonly used to determine what generation should fall under the classification of DG are size, location, voltage level, type, and use/application.

Size

Those who qualify DG by size - in part, or in whole - typically set a cut-off of about $50 \mathrm{MW}-100 \mathrm{MW}$ as the maximum size of generation that could qualify as DG.

Location

The location of generation is used as a criterion because DG is often considered to be that generation that is used directly by end-users without transmission being necessary. Therefore, the proximity of the generation to the loads it supplies is sometimes used to classify DG.

\section{Voltage Level}

Voltage level is also used to define DG, where generation at or below the maximum distribution level voltage is typically the maximum voltage level of DG. This is a particularly poor classifier since there is often overlap between transmission voltage levels and distribution voltage levels. Furthermore, various countries use significantly different levels of voltage for distribution purposes. 


\section{Type of Generator}

The type of generation, or the fuel source, is sometimes used to define DG, but this is usually done in a case where DG is meant to refer more specifically to renewable/alternative sources of generation.

\section{Use / Application}

The intended use or application is used to identify DG because it is often implemented directly at the load for direct consumption. This differs from the location criterion because the question can be raised as to whether or not a generator located directly adjacent to a load qualifies as DG when it is owned and operated by the utility for grid support. It should be mentioned that in some cases, energy storage units are considered DG. This could include capacitors and batteries, which are not actually generators.

Due to the lack of an established catholic definition, most studies, regulations, or organizations concerned with DG will formulate their own working definition at onset. For example, the Institute of Electrical and Electronics Engineers (IEEE) define DG as "the generation of electricity by facilities that are sufficiently smaller than central generating plants so as to allow interconnection at nearly any point in a power system" [1]. For the purpose of evaluation, the definition of DG in [4] is given as "a small source of electric power generation or storage (typically ranging from less than a $\mathrm{kW}$ to tens of MW) that is not part of a large central power source and is located close to the load." A plethora of definitions can be found worldwide, but they tend to all be relatively similar, only differing in the specifics of the details. In the interest of broad application, the 
definition of DG taken in this paper is intentionally loose. To the extent of the purposes of this paper, DG will be taken to refer to "any type of generation that is connected to a distribution power system which does not exceed 50MW of peak power production capabilities".

Defining what constitutes a DG unit and identifying its impact on the grid, however, falls short of quantifying the overall effects from DG. Penetration levels also must be considered when investigating the effects a grid will be subject to. The penetration level of DG refers to the total quantity of DG found within a given region of the grid. One may refer to the total DG penetration level seen on the entire grid, the level seen on one distribution system, or the level of penetration of one particular type of DG. For example, if a residential homeowner on a typical distribution grid decided to install a $10 \mathrm{~kW}$ photovoltaic system on the roof of his/her home, that alone would not likely have any significant effect on grid operation. However, if every homeowner in that neighbor were to install similar systems, there would be a very high penetration level of DG on the distribution system of that neighborhood, and effects on grid operation could be drastic.

\section{Motivations for Distributed Generation}

Over the last few decades, implementations of DG on grids around the world have been steadily increasing. The most commonly cited reason for this - or at least the most fundamental - is the deregulation and liberalization of energy markets. There is much disagreement as to the implications of a decentralized electricity infrastructure, but the fact remains that there is movement in this direction. Under the old, highly regulated situation, public utilities held full control and responsibility for their power grid system from the generation to transmission, distribution, and delivery of energy. This provided 
an economy of scale for which large centralized power plants provided the best option. Initially following the deregulation of energy markets, new energy suppliers and newly privatized utilities still found large power plants to be most cost effective for their means. Nothing changed from the perspective of power engineering, only from the perspective of ownership and cash flow. Yet since then, there have been emerging technologies and opportunities that challenge the traditional paradigm of the power grid.

The rise of DG is shifting the grid paradigm away from the traditional centralized systems that have long been the basis for grid operation. Motivations that have contributed to this case include economic opportunities of liberalized energy markets, increased demands for highly reliable energy supply, environmental concerns of generation methods, and increasing cost-effectiveness of emerging technologies. The volatile nature of energy costs, coupled with the opportunities for private energy production in a liberalized market, has driven the search for new methods of power generation by a greatly increased number of interested parties. The various applications of DG that have drawn new players into the field of electricity generation are covered in greater detail in the following section on DG uses. Suffice to say that the developments in DG technologies have provided alternatives to traditional means of obtaining and supplying energy, which many have found to be beneficial and cost-effective. Fuel sources for the production of electricity have expanded beyond coal, natural gas, nuclear, and hydro to now include wind, hydrogen, solar irradiation, algaes, and even waste matter. Efficient use of new fuel sources can be very attractive in markets where the price of traditional fuel sources can be unpredictable or expensive.

Not all DG motivation is found by customers and energy producers alone; public and private utilities find benefits in DG applications as well. The maintenance of transmission and distribution (T\&D) systems is a difficult and costly task for utilities; 
upgrades are constantly necessary to keep up with energy consumption growth while, particularly in the United States, much antiquated equipment on the old grids is in dire need of replacement. DG can offer deferment of these costs in some cases. By implementing DG at the distribution level where there is significant growth, otherwise needed upgrades of the equipment upstream can be avoided while the energy losses associated with T\&D can be reduced. Of the end-user price that customers pay for electricity in the United States, it's been found that approximately $30 \%$ of those costs are attributed to T\&D costs $[1,5]$. These costs can potentially be decreased or eliminated by on-site energy production of DG. Utilities may also be able to defer other system costs by using DG for other needed services such as voltage support or reactive power production, power factor control, harmonic filtering, and load demand following when remote DG control is possible [2].

Furthermore, demands for higher reliability of electric supply are constantly increasing, especially for industry applications such as chemicals, petroleum, refining, paper, metals, telecommunications, and the like [1]. This has created an incentive for customers to invest in DG for the purpose of increasing overall reliability, as well as for utilities to do the same. The term reliability refers to the likelihood of a power outage for any reason such as equipment failure, maintenance, or other abnormal conditions. The empirical study of DG motivators presented in [6] found that privately owned utilities typically have lower reliability rates while their T\&D costs tend to be significantly higher when compared to public utilities. For this reason, DG may be more desirable on grids operated by private utilities. The study of [6] also demonstrated that customers of private utilities are more likely to own and operate DG than those of any other ownership type utility. 
Environmental concerns have led to the development of policies that encourage the implementation of DG, albeit sometimes indirectly. Many utilities now face renewable portfolio standards (RPS) which mandate that a certain percentage of the energy they supply be generated from renewable processes. Most renewable energy sources lend themselves, by nature, to DG rather than centralized plant applications. It has been found that utilities with RPS mandates are more likely to accept or support the installation of DG at customer sites when it can be credited to their renewable portfolio [6]. With customers and utilities both finding incentives for the use of DG, the difficulties faced with realizing effective and efficient implementation are more readily overcome.

\section{Hindrances to the Applications of Distributed Generation}

As mentioned, traditional power grids were not built to accommodate generation at the distribution level. While transmission systems are designed and equipped to handle large amounts of scattered generation and bidirectional power flows, distribution systems have typically been built under assumptions that they would be used solely to distribute power from the transmission system to loads downstream. Hence, the issues involved with DG are still largely uncharted territory compared to the tried-and-true methods developed for the traditional system paradigm. There is an extreme lack of standards regarding the implementation of DG - specifically with regard to interconnection methods and schemes, tariff payment schemes, power quality characteristics, and insurance policies [6]. Regulations for DG implementation are governed country-by-country in Europe and state-by-state in the US, while in some cases a complete lack of regulation leaves individual utilities to determine their own standards [2]. The lack of standards from international committees and organizations is by no means due to apathy; persistent research has been on-going throughout. The fact 
that DG presents itself in a multitude of sizes and types along with the fact that distribution systems are found in an even greater multitude of design structures, make universal standardization of interconnection nearly impossible. Nonetheless, attempts are underway to provide technical standards that will guide the methods of implementing DG on power grids.

The lack of standards can be a sincere impediment to proliferation of DG applications. This situation often forces would-be DG operators and utilities to conduct surveys and investigations of their own to determine the proper means of installing DG. The results of such studies may then need approval from the respective regulatory bodies, which can take considerable time without governing standards. Another result is that manufacturers of equipment used for interconnection must provide equipment for a variety of system requirements. This prevents the manufacturer from being able to standardize their products, which would otherwise enable them to reduce production costs, thereby reducing integration costs. The eventual ratification of standards being developed may greatly increase the cost-effectiveness of DG opportunities. [2]

While the structure of today's energy markets was cited as a motivation for DG in the previous section, it still has aspects to it that strongly deter DG developments. Distribution operators basically make their profit from the energy that flows across their lines, so the installation of customer-owned DG that would reduce the amount of energy $(\mathrm{kWh})$ flowing on those lines is contradictory to their objectives - fundamentally at least [5]. Motivations contrary to this can often outweigh this hindrance, but tariff reforms are likely to be necessary in order for distribution operators to justify full support of DG proliferation. Furthermore, the customers are typically charged by the kWh delivered to their meters with T\&D costs incorporated into the cost per kWh, which can make up 30\% of their charges as mentioned previously. DG owners, however, may normally consume 
little or no energy from the utility despite the fact that the grid is there to support and back-up their own generation. In this case, customers without DG are, in a sense, subsidizing those customers who do own DG. Market studies are also being researched to these ends, and tariff reform and market restructuring may be necessary in order for DG to be used in a manner that does not adversely affect energy markets. [2]

Despite the ease or difficulties afforded to DG development by market forces, there are many technical issues that must be addressed for successful integration. This paper is intended to identify and address each of these issues in detail. The primary issues that pose challenges in DG-grid interconnection can be summarized as: power flow reversal, protection scheme disturbance, voltage regulation, intermittency, harmonics, and islanding. The issue of islanding tends to be of particular concern to interested parties, as it may be the issue most likely to cause extreme system damages. Each of the technical issues mentioned are addressed individually in the following sections of this paper. While all of these issues must be addressed to avoid undesirable operation, some of them also are found to offer potential benefits to overall system performance.

\section{Uses \& Types of Distributed Generation}

The types of technology used to implement DG are constantly developing and increasing; this is likely due to the rising costs of conventional energy sources and the decreasing costs of newly developed generation methods. Some types of DG are well established; reciprocating engines have been used for decades as DG and are well established as the most commonly used type today. Alternatives to the reciprocating engine, such as gas turbines and microturbines, have been developed for similar (though perhaps different scale) applications, but may provide reduced emissions and 
longer lifetimes or reduced maintenance costs. These types of DG are commonly used for combined heat and power (CHP) systems, where the waste heat of electric generation is used for on-site heat applications. CHP systems have been found to provide very cost-effective applications to large industrial sites where high quantities of heat and power would otherwise need to be purchased individually. Sterling engines have more recently found viability in small scale CHP generation application including household appliances sold in Europe. The fuel sources of such generation systems can vary from natural gas to biomass to solar concentration. [7]

Environmental concerns and governmental mandates have helped to bring about a growing use of renewable sources of energy production. Hydroelectric power has, of course, been established long before these more recent renewable incentives, but smallscale hydro has subsequently become a more enticing option as it qualifies under some mandates and subsidies while providing a well understood and highly developed generation method.

Newer technologies on this front include photovoltaics (PV), solar concentrators, wind turbines, and fuel cells. Photovoltaics have recently developed to the point where manufacturing processes and efficiencies have been refined enough for the systems to be financially viable to even the modest home-owner. Solar concentration is an even newer development with fewer completed implementations to evaluate. However, these systems hold strong promises of successful application as the fuel source used is the freely available and endless energy of solar insolation, but furthermore because it offers potential for energy storage. While PV systems only produce energy while under direct solar irradiation unless the system includes batteries or other storage techniques, solar concentration systems used a more novel technique. The concentrators can be used to "super-heat" a large quantity of fluid, which can be stored in a thermal reservoir and 
subsequently used to generate a consistent output of energy from turbines. The benefit of inherent storage ability and constant energy output makes this renewable source highly advantageous and even offers potential application for large scale centralized plants.

Wind turbines have been successfully implemented in very small scale applications such as a single turbine used to power farm equipment. However, it also has been implemented on very large scales; Denmark has successfully installed very high penetrations of wind farms, producing more than $20 \%$ of the countries electric energy from wind. Some large wind farms function as high voltage power plants, but they are more commonly used as DG.

Fuel cells are another very recent development in generation technology, which use hydrogen and oxygen to produce electricity through chemical reactions. There are many types of fuels differing most significantly in the electrolyte employed and the method of hydrogen acquisition. Most fuel cell technology is not yet available commercially, but some forms are currently in use. While costs of this young technology remain very high, motivations for its development include high efficiency and reliability, fuel sources of high abundance, and the lack of combustion needed which offers low noise and near zero harmful emissions. [5, 7]

The types of generators used for DG are currently numerous, and likely to become even more numerous and diverse. However, for the perspective of power system engineering, the raw source of energy is nearly irrelevant. The concern lies almost exclusively in the characteristics of the voltage and current waveforms produced at the point of interconnection, the protection schemes implemented, and the response to system abnormalities. These characteristics are what shall shape the requirements of DG installation to grids, and the generator systems will each employ their own methods 
of accomplishing the production of viable power supply. Inverter technology has produced highly developed equipment that now provides strong control of various generation systems to make them viable for grid interconnection.

The applications of these various generation sources are as wide and diverse as the types of generation. As mentioned, CHP systems are one of the most significantly cost-effective motivations that justify DG projects. However, decreasing manufacturing costs and government subsidies have increased the application of PV systems for rooftop installations on homes and businesses. Utilities find applications for DG as a method of voltage support, power factor correction, line loss reduction, and alternatives to more costly methods of system upgrades and extensions. Customers and utilities alike have used DG to increase reliability with standby/emergency generation systems, avoid high energy costs with peak shaving DG that reduces the consumption of expensive peak demand energy, and even provide primary power supply in costeffective manners. Application for DG promises to increase and broaden as technologies in generation continue developing and challenges of interconnection are addressed and overcome. The structure of electric power grid systems is likely to take on a whole new form over the years to come. With the proper engineering, future power grids may provide higher reliability, stronger power quality characteristics, lower energy costs, and less detrimental impacts on the environment. 


\section{RADIAL DISTRIBUTION VERSUS NETWORKED DISTRIBUTION}

Most power grids are not built of repeating sections of identical systems. While there are standards set forth by organizations like IEEE, ANSI, and IEC that help maintain consistency, nearly every section of any power grid can be viewed as unique. The huge variations in distribution system designs tend to make it particularly difficult to standardize DG installations; every distribution system will have its own requirements and limitations based on its own unique design. Despite their differences, most grids are commonly identified under two primary styles: North American or European. Other geographical regions may have a mixture of the two styles, but tend to more-or-less follow the style of the nation that had more influence over their electrical developments. The differences in these styles are primarily inconsequential for the purpose of this paper. Regardless of the over-arching style of the grid network, distribution systems throughout the world are accomplished primarily in a radial fashion [8]. A radial distribution system will feed loads from a single point of source supply, which greatly simplifies the task of protecting the system. Under radial distribution, power flow is typically unidirectional so more simplistic protection devices are adequate.

Figure II. 1 shows a general radial distribution system. The system illustrated has two feeders that are each protected by a circuit breaker at the substation. Each feeder supplies multiple loads downstream and contains additional protective devices such as reclosers, fuses, and breakers. There is also an intertie switch that is normally open (N.O.), which connects the ends of the two feeders together; this switch is not always implemented for radial distribution. Under normal operation, such a switch would be open and the system would be fed radially. The switch may be closed by grid operators for short periods, during which time the system is said to be functioning in a looped fashion. This may be done in order to allow maintenance, or for other temporary 
abnormal operation. For instance, if a fault occurred at Load 3 and the fuse immediately upstream would trip and the fault would be isolated. The faulted feeder could also be subsequently isolated by the breakers immediately upstream and downstream of the Load 3 fuse. While maintenance was performed on Load 3, Load 1 could be fed through CB1, and the switch could be closed to feed Load 5 under looped operation.

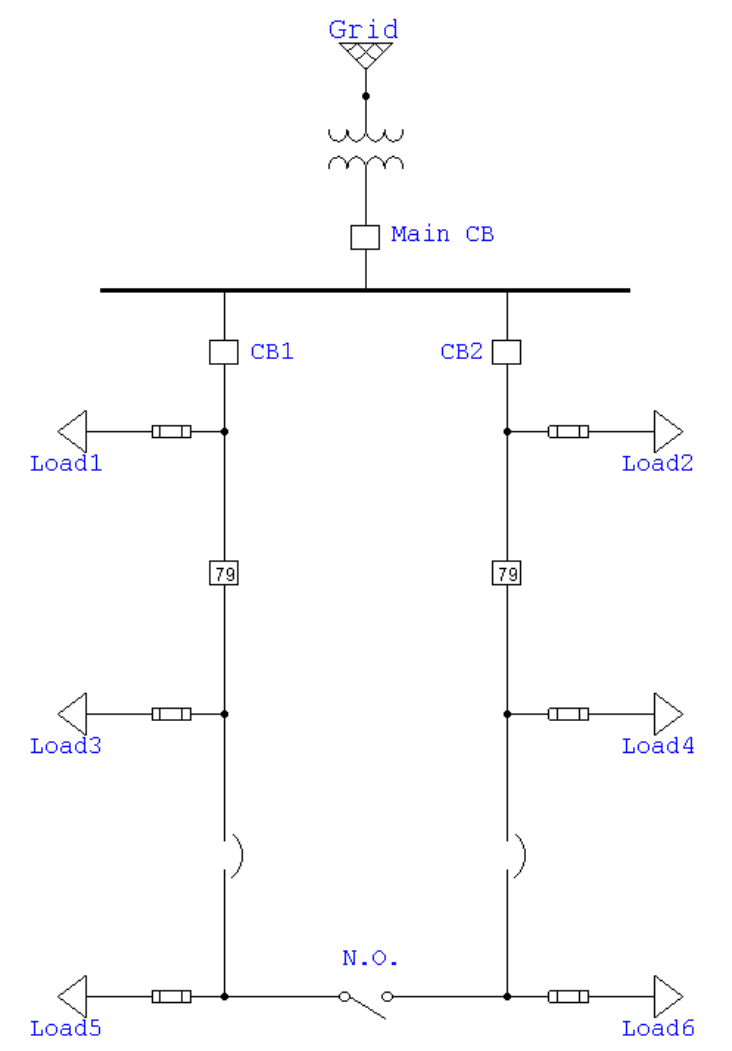

Figure II.1 General Radial Distribution System

As opposed to radial distribution, low voltage networked distribution (sometimes called meshed distribution) may be employed in areas where higher levels of service reliability are needed. Systems of this design type are common in large commercial metropolitan areas where there is a dense collection of customer loads that demand robust reliability rates. The downtown financial district of San Francisco, CA is an example of one of the most

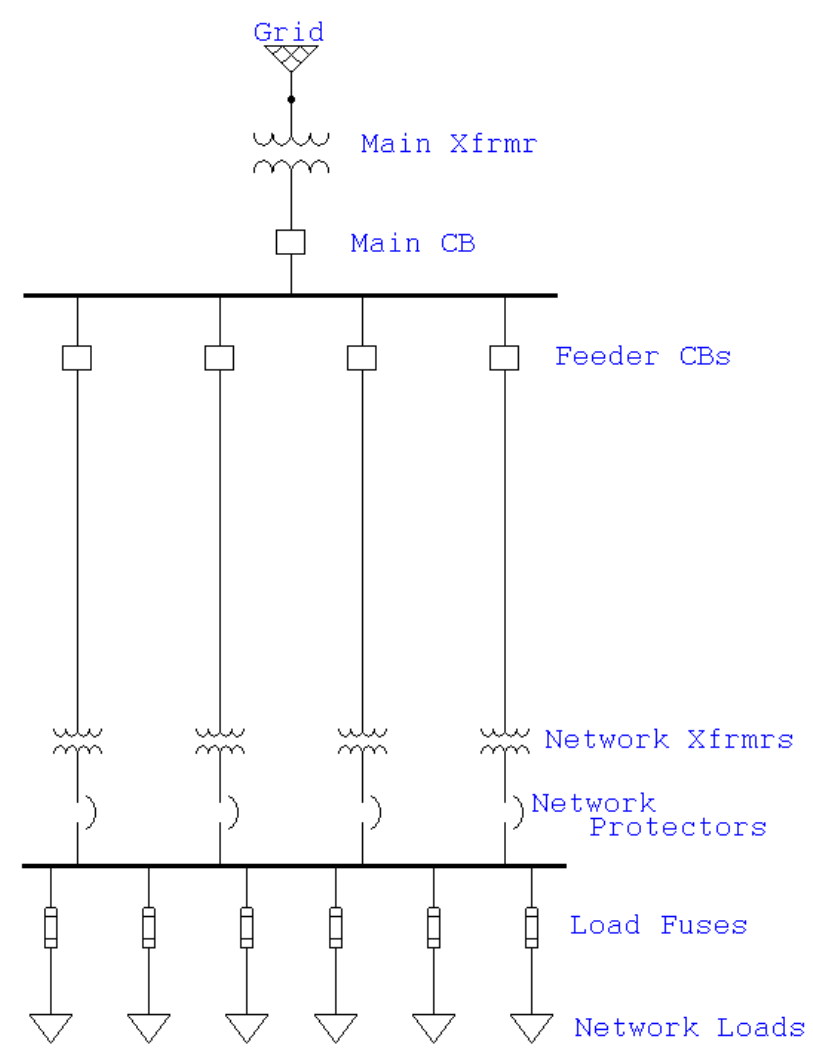

Figure II.2 General Low Voltage Network Distribution 16 
complex and expensive networked distribution systems, serviced by Pacific Gas \& Electric. Figure II.2 shows a more generic example of a low voltage network distribution system. Multiple feeders from the substation will feed a low voltage bus (typically at $208 / 120 \mathrm{~V}$ or $480 / 277 \mathrm{~V}$ ), and this bus will feed multiple network loads. The system is design so that in the occurrence of one of the feeders failing, service to the loads is undisrupted. Protection schemes on networked distribution systems are more complicated because power flow can be bi-directional. If there is a fault on one of the feeders, that fault will be fed from both the main substation bus and the low voltage bus, requiring the feeder to be disconnected at both ends. Yet since faults at the low voltage bus may also occur, the network protectors must be coordinated to trip for fault currents in both directions. Furthermore, coordination must avoid redundant or nuisance tripping, since many devices may see significant current increases for faults outside their protection zones.

The installation of significant degrees of DG capacity on networked distribution systems is rarely attempted because the costs associated with overcoming the involved complications usually eliminates any potential of financial justification. On low voltage networks, DG penetration is generally limited to $15 \%$ of the minimum network load; higher penetrations could demand extensive changes to the existing system [8]. Some networks feed customers with a very high load demand (e.g. large commercial buildings) for whom DG appeals to as a means of lower energy costs. This is not usually a problem if the generation is used on site as opposed to being exported to the network. It is net-generation sites that are most problematic for low voltage networks because the network bus would then be back-fed by the DG, but these networks are typically found in densely populated metropolitan areas where space for generation would be very limited. 
This paper focuses on radial distribution systems because they are much more prevalent in general, and because they tend to be much more likely sites for significant DG penetration. While radial distribution systems are used to illustrate the issues addressed, most of these issues apply similarly to low voltage networks - though possibly in more complex ways. It is worth mentioning, however, that operating radial systems in a looped fashion may have benefits when DG is connected. For a DG unit at the end of a radial feeder, closing an intertie switch to another feeder can significantly reduce the need for complete disconnect during faults. In the following sections, it will be illustrated that requirements for interconnection of DG to radial distribution feeders could require rather frequent disconnects. Since the DG unit would be connected to two feeders during looped operation, the unit could remain connected to the grid when a fault on one feeder would otherwise require a complete disconnect. For this reason, it has been suggested in [9] that distribution systems with high DG penetration could benefit from operating normally in the looped fashion. 


\section{POWER FLOW}

The most readily apparent limitation when integrating new DG to a distribution system is likely to be one of overflow (current capacity limits). For the most part, installing DG to a system should reduce power flow within transmission and distribution lines as it supplies power to local loads and reduces the amount of power required from a distant power plant, and thereby reduces line losses [10]. However, it is also possible that a DG could increase the power flow of a particular line. For this case, current capacity limitations must be addressed [11]. If existent grid equipment is already seeing power flow nearing its duty ratings, a nearby DG unit might cause an overload.

Similarly, the DG will increase many fault currents which may exceed levels acceptable for existent relays, and nuisance tripping may occur even under normal operating conditions; these issues will be discussed at length in the section on protection scheme disturbances.

To illustrate the issue of overflow, consider the system of Figure III. 1 in which a substation feeds a distribution system composed of four radial feeders; the possibly various loads on each feeder are modeled here a one lumped at the end of the feeder (with a $90 \%$ power factor each). Without the presence of DG anywhere on the system, Line 3 will have 14A/phase flowing through it to service Load 3. Therefore, the line may be rated at $25 \mathrm{~A} /$ phase so the line can service the load up to $150 \%$ loading without damage.

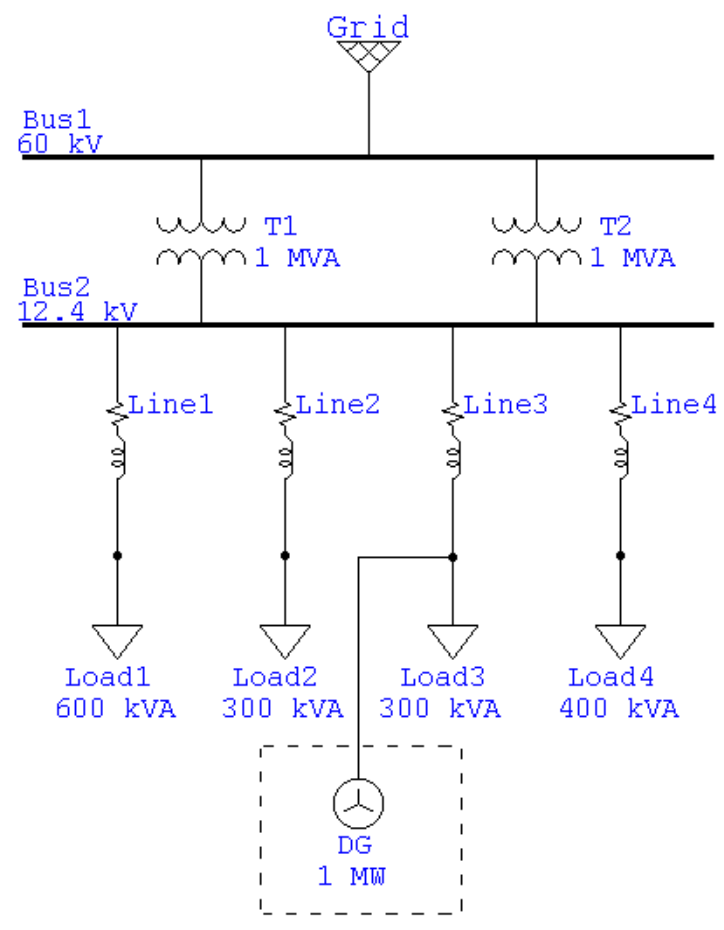

Figure III.1 Example Distribution System 
However, if a DG unit were to be connected to the system, such as the one shown on Line 3, power flows would be altered. The DG shown here produces $1 \mathrm{MW}$ at a $90 \%$ power factor, which could be a single generator or could be the model for a combined capacity of multiple units connected along Line 3 at different points. This DG unit would provide $70 \%$ of real power demand for the distribution system, alleviating demand from the grid. However, the power fed to the loads on the other lines would amount to more than $31 \mathrm{~A}$ flowing through Line 3 to Bus 2 , causing an overload of the line. The system could not handle this DG installation as illustrated unless Line 3 were upgraded or another line were added between the DG and Bus 2.

Also to be noted from the system illustrated, is that power flow is found flowing directly from the substation bus to the loads without DG presence. Yet with DG installed, the additional power that could cause an overflow would be flowing in the opposite direction - from the DG unit to the substation bus. Even if a smaller sized DG unit were installed so that no overflow occurred, there could still be power flow in the direction from the load to the substation bus.

Typical distribution systems primarily involve only unidirectional power flow at the distribution level $[1,10,12]$ and control techniques are employed accordingly. Power is generally assumed to flow from upstream (power plants; HV lines) to downstream (consumers; LV lines). When DG is added to a distribution line, it can cause power flow reversal, meaning that power may then begin to flow upstream within a section of the system that has been engineered specifically for downstream flow. Therefore, a power flow study along with loading and generation profiles may be necessary, prior to the installation of new DG, to ensure that there is no reversal of power flow or, at least, that any potential reversal will not disturb grid operation. Even if nominal operation does not cause problematic power flow reversal, extreme cases must be accounted for. The 
system may need to be able to handle a case when the DG has maximum output and local loads are at their minimum. The degree of concern with this issue, of course, is very dependent on the specific DG design being employed. Solar generation is often minimal at night when loads are also minimal, which inherent reduces the possibility of generation exceeding load demand during light loading condsitions. Some DG operators may opt to employee dynamic control system to monitor the system and adjust output levels accordingly. The issue of power flow reversal will be unique in each DG case; the issue must be addressed with regard to the specific generation unit being implemented as well as to the specifics of the distribution system it will interconnect with.

A practical design technique for evaluating a potential DG site then, is to begin first by identifying all duty ratings and current capacity limits of the grid equipment that will be affected. These limitations will either reveal the limitation on maximum power output of the DG unit, or reveal the equipment that needs to be upgraded to accommodate the DG, or both. Difficulty may lie in deciding just how far upstream and downstream one must investigate; a basic load flow analysis should give insight into which areas are pertinent, but contingency cases and other abnormal operating conditions may cause the DG presence to affect areas further than anticipated. With common radially fed distribution systems, the feeder lines often have a single point of source supply coming from a substation transformer or bus. System design may become complicated if there is the possibility of a power flow reversal that would cause an upstream flow to this source. Therefore, a practical design (technically and economically) would require that the DG output power be limited to a quantity that does not cause an upstream flow (at least on the average) - that is, the DG unit supply should not exceed the local demand load. Feeding power upstream from a radial distribution line to its supply source can cause issues not easily mitigated [13]. 


\section{PROTECTION SYSTEM DISTURBANCES}

For the purpose of protecting expensive equipment and providing reliable power to customers, every power grid is outfitted with extensive protection systems. System faults are common and unavoidable; the creative methods of protection are designed carefully to minimize the harm done by these faults. The primary components of a protection system include fuses, circuit breakers, relays, reclosers, and sectionalizers. These devices are coordinated to ensure quick removal of faults with minimal service disconnection to customers. In the case of distribution systems, most of this coordination is dependent on the assumed paradigm of downstream power flow from source to load. Once again, the transformation of distribution lines from load feeders to load/source lines when DG is connected forces traditional design principles to be rethought and altered. Protecting lines with bidirectional power flow is, by no means, a new engineering feat; high voltage transmission lines handle power flow in both directions connecting vast networks of generation sources. However, it can be very expensive and complicated to upgrade a distribution system in order to accomplish the same task. For starters, fuses are used extensively on distribution lines because they are effective and cheap; these are not ideal devices for bidirectional protection. Furthermore, the protective devices on distribution lines are usually coordinated in a fashion that is strictly dependent on unidirectional flow. For example, reclosers are often employed upstream of fuses to clear temporary faults before the fuse is permanently damaged, but may not be able to do so if there is generation downstream (this situation is addressed in detail later). These temporary faults comprise more than $70 \%$ of distribution system faults, and the methods used to remove these faults allow utility companies to maintain reliability while managing maintenance costs [14]. 
When selecting a site for DG installation, the ideal case would be that existent protection schemes would still function as designed or only need minor changes such as adjustments of relay settings. However, more extensive changes are likely to be needed for significantly large DG units or even for higher penetration levels of smaller units. These changes can often be expensive enough to overshadow the benefit of DG installation. Many distribution systems operate near maximum capacities during nominal power flow which means that the increase in fault currents due to DG would require the installation of new equipment even if coordination were not lost. There are, therefore, areas of distribution grids on which DG is simply not economically feasible. However, other areas may have significantly lower costs to protection system alteration where available capacities are greater. Finding a site for DG that demands manageable levels of alteration to protection schemes can be critical in making the project economically feasible. Careful study and simulation of the system in question should be performed beforehand; it has been found that most new DG sites will suffer unanticipated operational problems from failed protective coordination, which can prove a heavy burden for those charged with operation and maintenance duties. [8]

While some distribution lines in service show no practical hopes of handling significant levels of DG, there certainly are ways to provide system improvement with DG in other areas. As mentioned, some existent distribution systems are currently capable of accepting significant DG and are being used to do so. Furthermore, as new distribution grids are built, foresight can be used during design to provide margins of capacity increase that allow for future development of DG with minimal alterations needed. It should also be noted that areas of distribution where equipment is running near maximum capacities are likely to be the areas that are soon to be due for standard maintenance upgrades. These inevitable costs should be considered before 
determining that the cost of upgrades required for DG are too great; it may be that they mitigate one another such that DG installation is more economically sensible.

The following three sections outline some fundamental problems that may be encountered when adding DG to existing distribution systems with particular protective devices. The problems discussed here are not necessarily comprehensive, but illustrate the fundamental functionings that can be disturbed by DG. All systems are unique and must be studied individually when significant changes are made. The following issues provide somewhat of a starting point checklist for investigating how protective devices will be affected by the introduction of DG to a particular system.

\section{Fuses}

Fuses are commonly used in distribution systems partly because they less costly that other protective devices (i.e. circuit breakers) and because they have more simplistic functioning. Fuses are characterized by two main features: minimum melting (MM) time and total clearing (TC) time. Both of these characteristics are with respect to the current passing through the fuse. For a given current, the MM time is the duration of time the fuse can handle such current before it is damaged and has partially tripped. The TC time is the time it takes for the fuse to fully trip and clear a fault for a given current. Fuses with different TC and MM characteristics are used throughout a distribution system in order to coordinate tripping. See Figure IV.1 for an example of a radial distribution system that is protected by fuses. Under normal operation (ignoring DG for now), each load is consuming about 23 A. Fuses 1,3 , and 4 will see this current, while Fuse 2 will see twice that. It would be reasonable, then, for the fuses used here to be selected such that they will trip for currents above 50A and 100A (fault currents on this system are on the order of $k A$ ). 


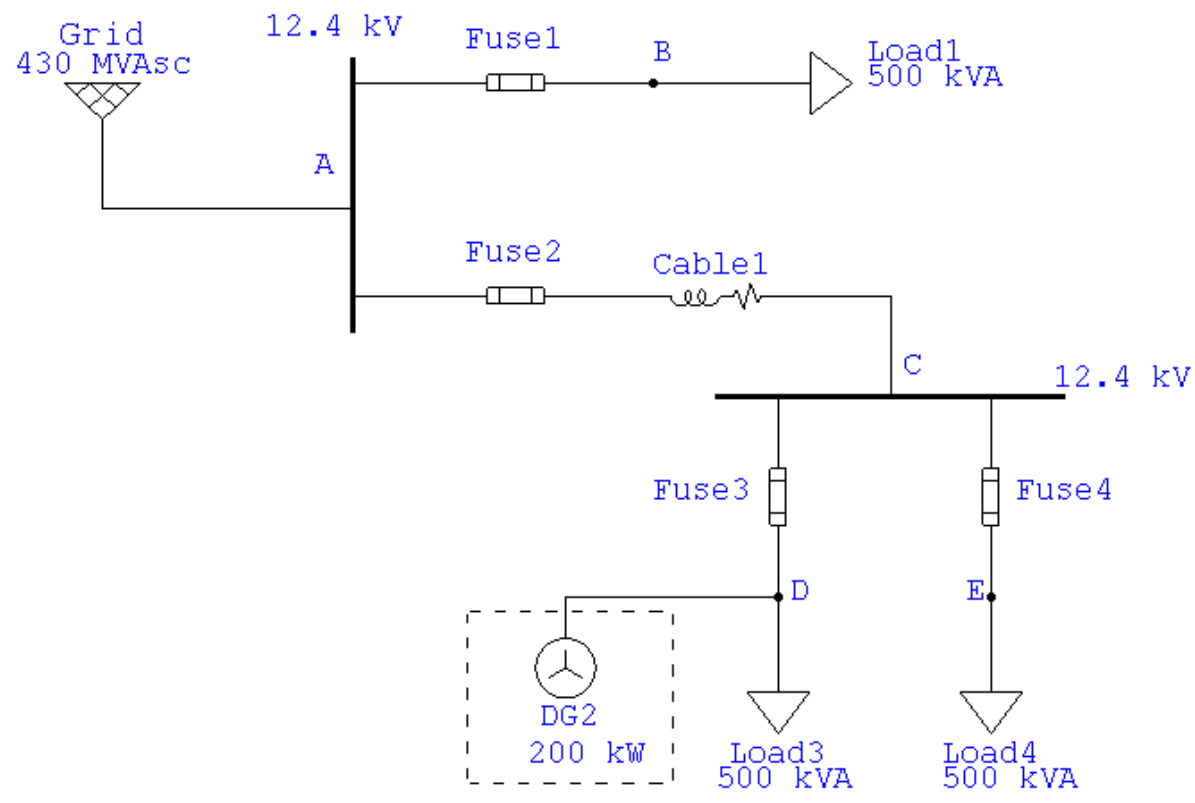

Figure IV.1 Radial Distribution System with Fuse Protection

Without DG, proper coordination would have Fuse 3 trip for a fault at D. A trip of Fuse 2 would also remove the fault, but would unnecessarily disconnect loads at E. To ensure that only Fuse 3 trips for a fault at D, the TC time of Fuse 3 must be less the MM time of Fuse 2 for the maximum fault current at D. Figure IV. 2 shows the characteristics for two fuses that may be used to accomplish this. Note that for any given fault current at $D$, Fuse 3 will clear the fault before Fuse 2 is damaged if the current through Fuses 2 and 3 are approximately equal. Prefault currents are negligible compared to fault currents, so it is generally valid to

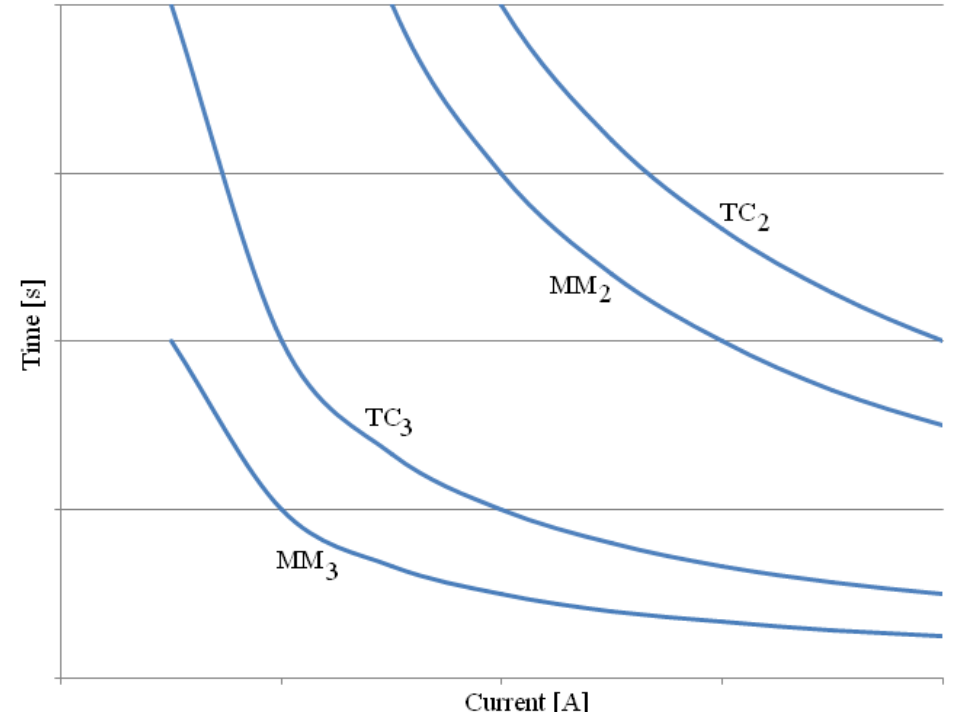

Figure IV.2 Fuse 2 and 3 Characteristic Curves 
assume equal fault currents through Fuses 2 and 3 [15]. Similar fuse selection for Fuse 4 also allows faults at $E$ to be cleared without disconnecting loads at $D$.

Adding DG to this system can disturb the protection scheme in various ways since the fault currents will all be altered by the added generation. Considering the addition of a $200 \mathrm{~kW}$ DG unit at D in Figure IV.1, multiple coordination issues arise. With the DG unit outputting $150 \mathrm{~kW}$, it will produce about $150 \mathrm{~A}$ of additional fault current for faults on the system shown.

Case 1a) If a fault occurred at $B$, the $150 A$ from the $D G$ at $D$ would flow through Fuses $2 \& 3$ and they would trip. Fuse 1 would trip as well because it would see this current plus the full fault current from the grid. This means that faults at B would cause all loads to be disconnected. Loads $3 \& 4$ could have remained in service by tripping only Fuse 1 to clear the fault.

Case 1b) If a fault occurred at C, the 150A from the DG would flow through Fuse 3, causing it to trip. Fuse 2 would also trip due to the full fault current from the grid. The result is a disconnect of Loads $3 \& 4$, which is desired. However, Fuse 3 would have to be replaced after this fault since it would have tripped unnecessarily.

In fact, a DG unit at D will cause Fuse 3 to trip for all faults upstream, as well as any other fuse between the DG and the fault. It can be seen readily, that the same problem is encountered for DG at B or $\mathrm{E}$. The main issue here is actually a manifestation of the power flow reversal issue mentioned in the previous section.

Case 1c) Considering a slightly altered system shown in Figure IV.3, a different, though similar, problem is encountered. Note that Load 3 in this system is only $200 \mathrm{kVA}$, but the 
DG attached at D produces $750 \mathrm{~kW}$. The DG is capable of providing all power needed for Loads $3 \& 4$, which would reduce capacity demands for the grid upstream of $A$ and reduce (or eliminate) losses over the line connecting $A$ and $C$. However, under the assumption that Fuse 3 was sized for Load 3, it would be tripped under normal operation with DG at D. Load 4 is more than twice that of Load 3, and Fuse 3 would see the full current of Load 4.

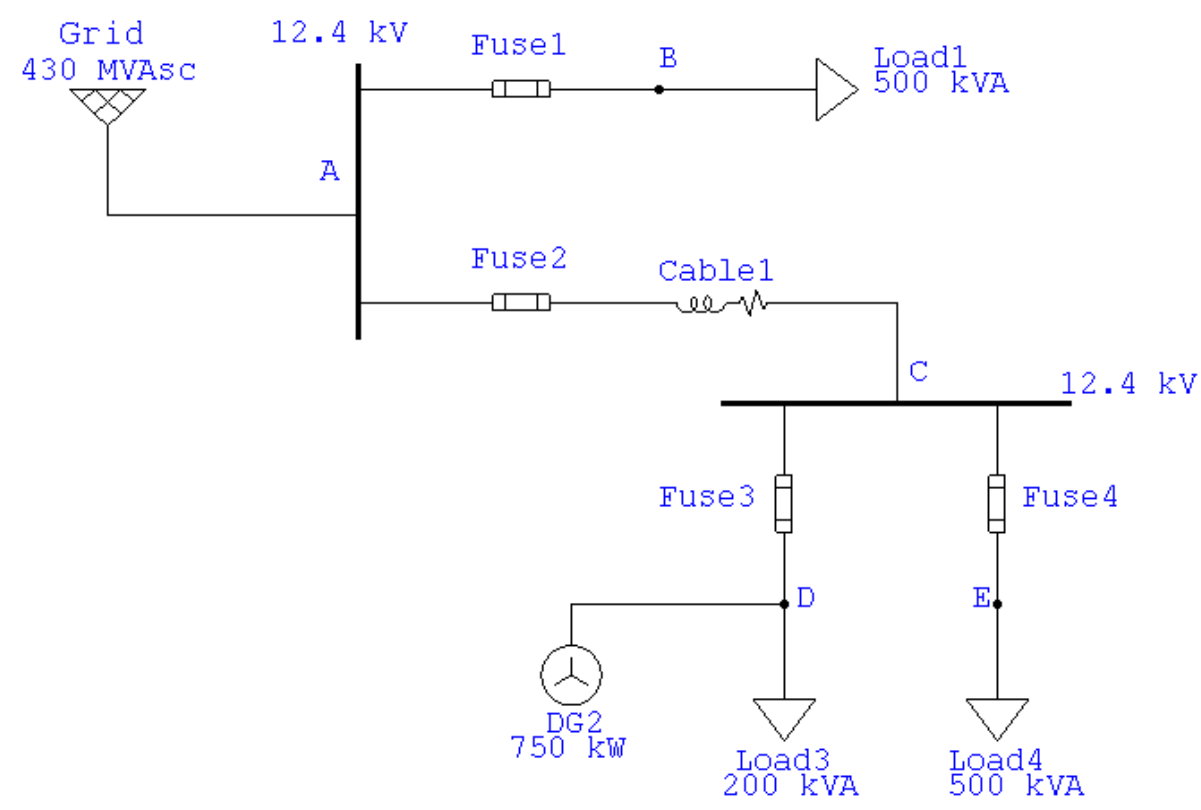

Figure IV.3 Altered System with Fuse Protection

These cases may seem to present problems that are easily solved. For example, Case 1c merely requires that Fuse 3 be resized, or to install DG at E instead of D. However, the systems presented are intentionally simplistic in order to illustrate the potential problems clearly. On larger, more realistic systems, these problems can be far more difficult to solve or even to identify. An actually distribution system may have hundreds of coordinated protection devices that would be affected by DG. 


\section{Circuit Breakers \& Relays}

Circuit breakers are also commonly used to disconnect faults from the system. The breakers are usually tripped by means of relays that detect faults with current transformers (CTs) and voltage transformers (VTs). As mentioned, the installation of DG will change fault currents throughout the system, which will then affect the ability of relays to properly detect faults. The radial distribution feeder shown in Figure IV.4 can be used to illustrate the problems encountered by relays when DG is present (assume standard overcurrent relays are used).

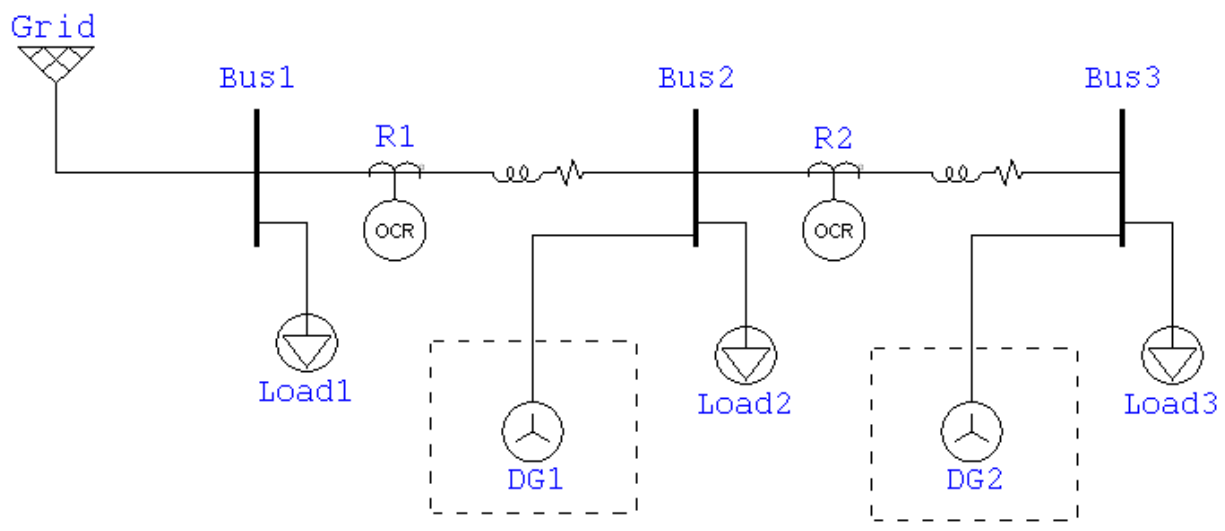

Figure IV.4 Radial Distribution System with Relay Protection

When no DG is connected, the relay R2 should trip for faults at Bus 3 but relay R1 should not. For faults at Bus 2, R1 would trip. Both relays would see the same fault current for a fault at Bus 3, therefore the relays must be coordinated so that R2 will trip faster. Relay coordination is accomplished using the current tap settings (CTS) and time dial settings (TDS) of the relays. In this case, the TDS of R1 would be set to a higher value than R2 so that R2 would trip faster for faults at Bus 3. R1 provides backup to R2 in this case; if R2 fails to operate quickly, R1 will still operate after a certain delay, 
referred to as the coordination time interval (CTI). Figure IV.5 shows a typical graph of how these settings would appear for coordination in this case.

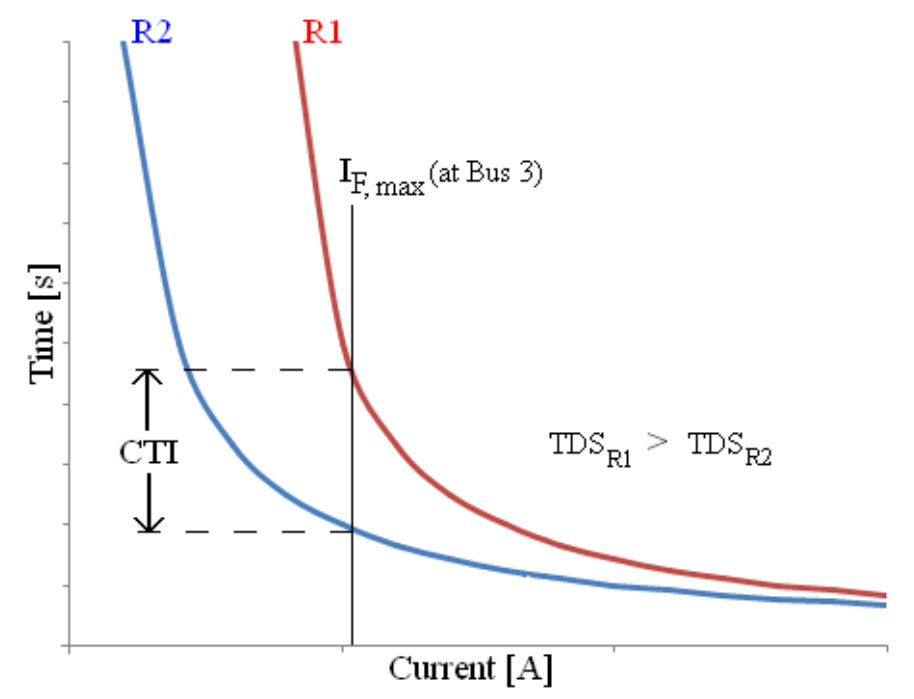

Figure IV.5 Relay Coordination for System of Fig. IV.4

Case 2a) If DG is connected to the system, it will reduce the current seen by both relays for faults at Bus 3. This can cause an underreach of the relays, which means that the fault current through the CTs is no longer large enough to trip the relays under the intial settings [16]. This does not pose a large problem, though, because it can likely be resolved by simply changing the CTS of each relay accordingly [14]. The TDS of the initial case, or similar settings, should be sufficient to maintain coordination in this case for a basic radial feeder like that of Figure IV.4. Underreaching can usually be resolved with simple setting changes, but these changes may affect a protection scheme's ability to handle other cases, so careful analysis and reevaluation is still needed.

Case 2b) If DG2 is connected to the system, then both relays will still see the same fault current for faults at Bus 3. With no DG, coordination is accomplished, as mentioned, by setting the TDS of R1 to a higher value so that it will be delayed; R2 would trip and 
remove the fault before $\mathrm{R} 1$ trips. Yet this solution presents a new problem when DG2 is connected. DG2 would feed fault current to a fault at Bus 1, so it would be desired that $\mathrm{R} 1$ trip. Yet R2 would trip first if the TDS of R1 is at a larger value than R2. Under this system configuration, R1 and R2 see the same current for faults at both Bus 1 \& Bus 3; therefore, the standard TDS and CTS of these relays cannot be configured such that R1 trips first for Bus 1 faults and R2 trip first for Bus 3 faults. This is an illustration of how existent coordination methods fail due to unexpected upstream power flows.

Case 2c) When DG1 and DG2 are both connected to the system, the variations in fault currents must be looked at carefully. For a fault at Bus 3, R2 will see a larger current than R1 (additional DG1 contribution). For a fault at Bus 1, R1 will see a larger current (upstream flow from 2 DGs). R1 will also see a larger current (utility contribution) for faults at Bus 2, but both relays should trip for this case. However, R2 should trip first for faults at Bus 3, and R1 should trip first for faults at Bus 1. Since the relays see different fault currents for these cases, coordination is possible if the differences in current levels are significant. Figure IV.6a shows coordination of the relays for a fault on Bus 3. Under the same relay settings, Figure IV.6b illustrates the margin by which the fault currents must differ (minimal current difference shown) in order for coordination to be maintained for faults at Bus 1. In order to decrease the margin necessary for coordination for Bus 1 faults (and further upstream faults), the CTI for Bus 3 faults must be decreased.

Obviously, there is a limitation on how small the margin can be made (CTIs must be long enough to ensure proper functioning), and there must be significant difference in faults currents for this coordination to hold. Furthermore, each graph shows only one fault current value for each relay, but the $\mathrm{CTI}$ and margin criterion show here must hold for all fault types. 


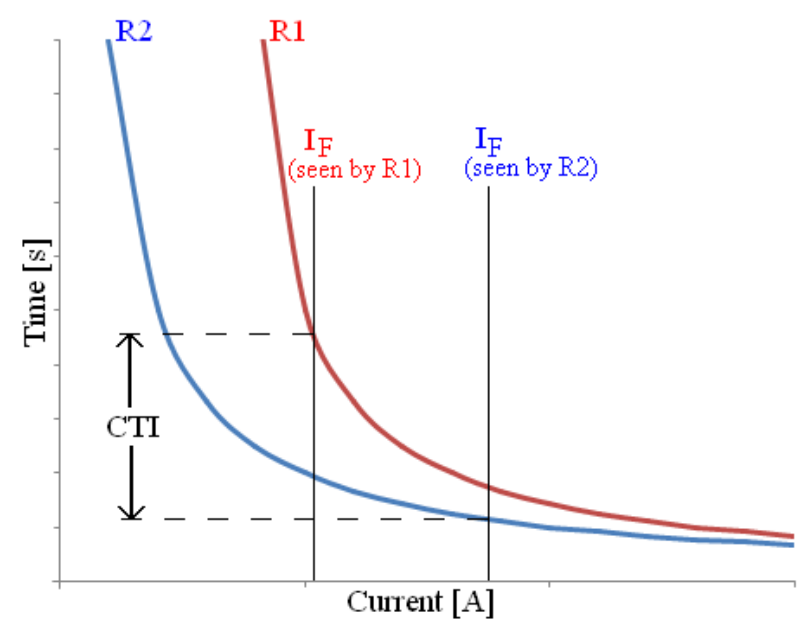

Figure IV.6a Coordination for Bus 3 Fault

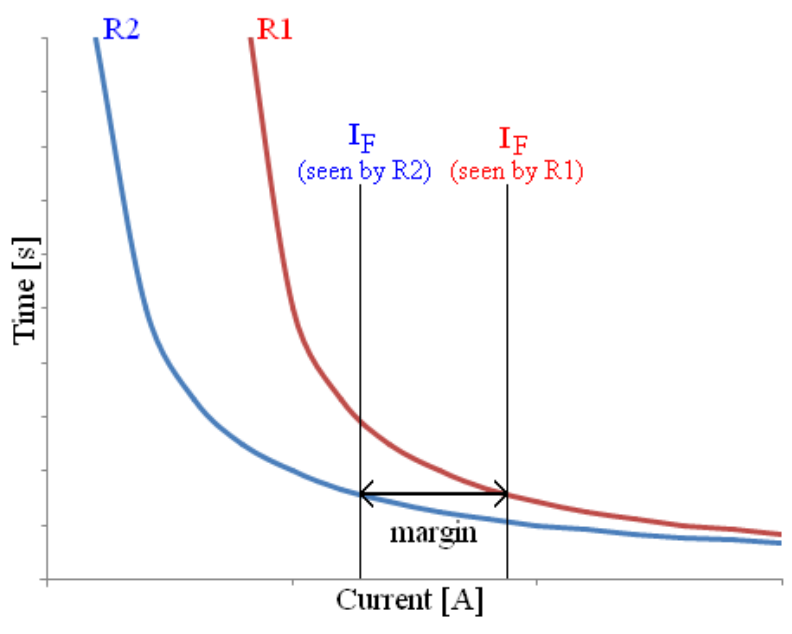

Figure IV.b Coordination for Bus 1 Fault

These three cases illustrate some of the various ways that relay coordination can be affected by the introduction of DG. However, the system investigated here was a relatively simplistic model. Every system is unique and, thusly, every protection scheme is unique. To maintain or establish sound protection on a system where DG is introduced, the principles outlined here must be extrapolated to understand how to protect the system in question. It must be kept in mind that redesigning protection schemes can add heavily to the initial costs of a DG project; even changing the settings on existent relays will have associated costs. The generation unit itself will require its own protection, but disturbances to existent relay coordination can pose an additional economic hurdle.

\section{Reclosers \& Sectionalizers}

The importance of reclosers was mentioned briefly at the beginning of this section; reclosers provide a method for quickly handling the temporary faults that make up more than two-thirds of all system faults. If a fuse or a circuit breaker is tripped to remove a fault, maintenance personnel are usually needed to come to the site in order to 
reestablish service. Furthermore, fuses must be replaced after they have tripped, and circuit breaker also can trip only a limited number of times before they degrade, making fault management an expensive endeavor. Reclosers act automatically and quickly to remove temporary faults that would otherwise destroy protective devices far too rapidly. These frequent temporary faults occur when an electric arc forms, creating a short circuit. The basic idea behind the recloser is that a disconnect from the source feeding the short will de-ionize (extinguish) the arc quickly and the system can be brought back online. Therefore, a recloser trips once a fault is detected to disconnect service then recloses a very short time later (a few seconds or less) to restore service once the arc has de-ionized. If the fault has not cleared upon reclosure (the fault is not temporary), either the recloser will trip again - this time permanently - or other protective devices will trip to isolate the fault. Reclosers often trip temporarily more than once before permanent disconnection in order to remove temporary faults of a longer duration. [16] Sectionalizers are often used in conjunction with reclosers. Sectionalizers are switches that can open to disconnect and isolate part of a system much like the other protective devices do. However, sectionalizers are meant to be opened only while the circuit is already de-energized. When a fault is in fact permanent, a recloser may deenergize the circuit by tripping for a prolonged duration, at which point sectionalizers can be opened to isolate the faulted section. If $D G$ is operating downstream from the recloser, the circuit will not be de-energized and sectionalizers cannot open. Other protective devices downstream of the reclosers may suffer similar operational difficulties. These system disconnects are very important to the safety of maintenance personnel; DG can feed circuits from downstream that would otherwise be de-energized and warrant extra precaution [16]. 
Case 3a) Figure IV.7 shows a distribution system that employs a recloser with multiple feeders downstream, each protected by fuses. If DG is connected downstream of the recloser, the protection scheme will be compromised. When a temporary fault occurs on one of the feeders, the recloser should open quickly, allowing the arc to extinguish, then close again to restore service to the loads. Under this scheme, fuses would be selected such that the MM time is less than the time it takes for the recloser to trip; this allows the fault to be cleared without damage to the fuses. With DG connected, fault current would continue to flow from this unit while the main source is disconnected by the recloser. This will have two adverse effects. First, the DG's fault contribution may be enough to maintain the arc while the recloser is open. The temporary fault may then become a [semi-]permanent fault. Second, the DG's fault contribution will be passing through the fuse protecting the faulted line. This may cause the fuse to trip for a fault that may otherwise have been quickly cleared by the recloser.

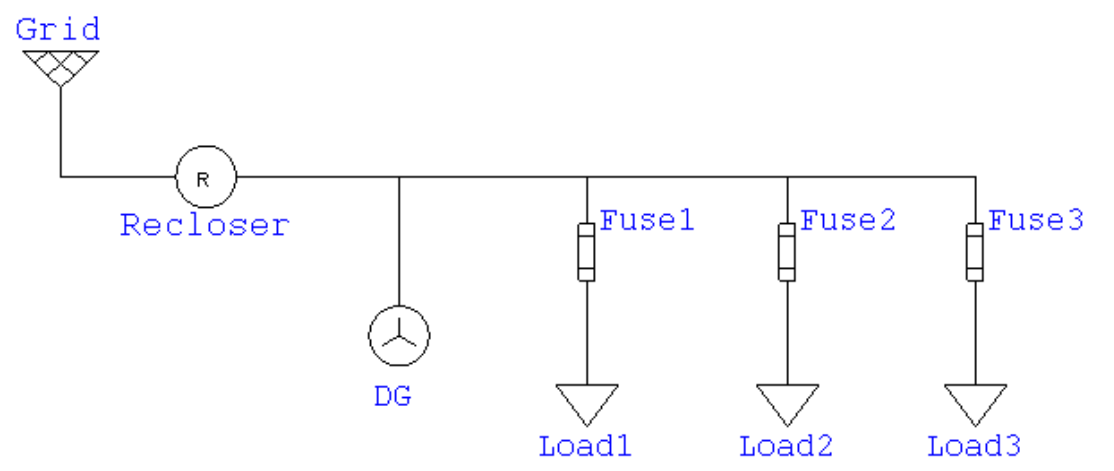

Figure IV.7 Radial Distribution System with Recloser/Fuse Protection

Case3b) The circuit in Figure IV.7 is also susceptible to another concern with DG on lines protected by reclosers. If the DG unit connected downstream of the recloser continues operating during disconnect, the grid portion downstream of the recloser may form a temporary island (see section on islanding). Reclosure would then be connecting 
two energized systems. If reclosure occurs between the larger upstream system and a small network with generation on it (an island), a connection may occur between the systems while they are out-of-phase. This can cause serious damage to the DG unit as well as upstream grid equipment. [14]

Both of the above cases imply the same necessity for DG operation downstream of reclosers: the DG unit must disconnect before reclosure occurs. The IEEE Standard 1547-2003 actually requires specifically that all DG must disconnect before reclosure for all faults. If the DG unit is disconnected, the recloser can clear temporary faults and reconnect the system without risking out-of-phase connections, and the DG fault currents will not trip other devices. This can be a difficult solution for the DG operator since the unit may be disconnected frequently. Another drawback to this solution is that additional time may be required to allow for the DG to disconnect before the reclosure can occur; this additional time will need to be coordinated in any other protective devices and will cause temporary faults to be sustained for longer durations, decreasing power quality. [16]

\section{Nuisance Tripping}

There is also one issue that can affect all protective devices when DG is present: nuisance (or sympathetic) tripping. Since DG adds an additional power supply to a system that theoretically has assumed this not to be the case, the added current present on the lines may cause devices to operate when there is no actual fault. This event disconnects customers from service unnecessarily and deteriorates system reliability. This appears to be a relatively simple problem to resolve; since fault currents usually also increase with the presence of DG, devices should merely need to be set to trip for higher currents so that normal operation will not cause nuisance tripping. Yet while 
relays have adjustable settings, fuses would have to be replaced in order to set a new tripping current. This issue may appear simplistic, but it is actually quite common and costly. Abnormal operation or spikes in generation capacity and drops in load demand will result in nuisance tripping of devices thought to have been coordinated with DG accounted for. The majority of DG sites will experience operating difficulties like this during the first year in service and may require unanticipated system modifications that can delay consistent energy production until solutions are found. [8] 


\section{VOLTAGE REGULATION}

For the purpose of ensuring high quality of power, the voltage levels along distribution lines must be regulated to remain within an acceptable range - typically within $5-10 \%$ of nominal operating voltage (ANSI standard is $\pm 5 \%$ ). [17] In the case of a radial distribution line with downstream flow, the voltage at any point on the line will drop (decrease) proportionally to the distance that point lies from the source. Furthermore, as the total loading on the line varies - say from peak consumption during the day to minimum consumption during the night - the voltage drops along the line will change accordingly. These variations in voltage level do not pose a large threat to loads such as residential lightings systems, but they can actually be catastrophic for loads such as highly sensitive manufacturing equipment. Grid operators are usually expected to provide a certain degree of power quality, and they therefore employ different methods of voltage regulation.

Transformers that feed distribution lines are often equipped with load tap changers (LTCs) to regulate voltage levels downstream. ${ }^{1}$ The LTC provides incremental changes (up or down) to the effective turns ratio of the transformer, thereby affecting changes in the line voltages. These LTCs can be controlled automatically by a sensing device such as a line drop compensator (LDC) to mitigate load voltage fluctuations. Figure V.1[17: Fig. 4] shows a schematic of a distribution system that uses LDC. By matching $X_{L}$ ' and $R_{L}$ ' with $X_{L}$ and $R_{L}$, the voltage regulating relay (VRR) will adjust the tapping of the LTC to hold constant the voltage at the reference point $\left(V_{R P}\right)$. It should be noted that this can only be accomplished to within a certain margin since the taps are incremental, not continuous, and there are minimum and maximum tap limits.

\footnotetext{
${ }^{1}$ Similar devices include step voltage regulators (SVR), load ratio control transformers (LRT), and others. The fundamental function of these devices is the same. References to LTCs in this section can be taken to refer to all such devices.
} 


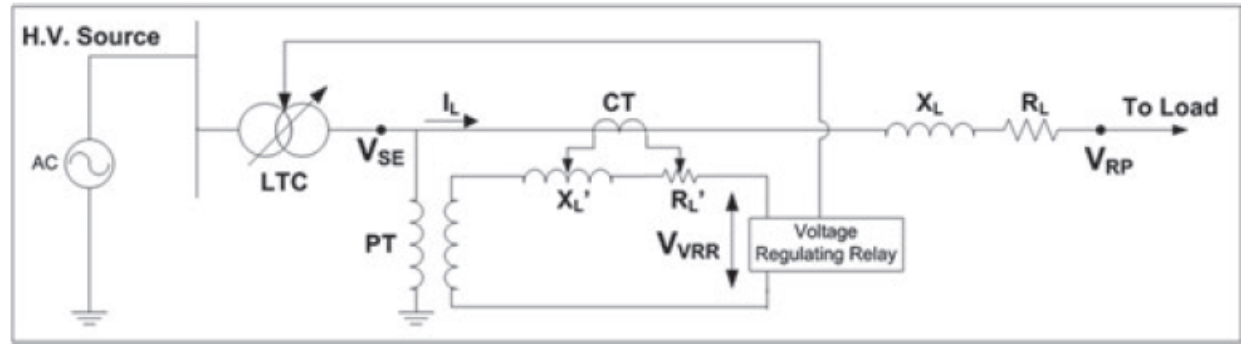

Figure V.1 Distribution Line with LTC and LDC Voltage Regulation [17]

Voltage regulation can also be accomplished through the control of reactive power flow on lines using switched capacitor banks, static var compensators (SVC), or even generators. By injecting or consuming extra reactive power (vars) to/from a system, the voltage can be regulated. The change in reactive power causes a change in current flow without necessitating extra real power; the change in current causes a change in the voltage drop across the lines it flows through. Distribution system voltage can be thusly regulated by connecting or disconnecting capacitor banks at a substation or on distribution lines based on the loading conditions present. SVCs can also be used to regulate voltage, but these devices - like most Flexible AC Transmission System (FACTS) devices - are used primarily on high voltage transmission systems [18]. Since some generators consume and/or supply reactive power, DG itself could be viewed as a type of voltage regulator. However, this view would not be typically accurate. While grid operators may use dispatchable generators to regulate voltage, most privately run DG operates in voltage-controlled mode, making it dependent on the constant voltage of the grid to be regulated by some other means. This allows the DG operators to control power and power factor while avoiding accidental islanding; besides, most small DG units do not have the capacity to effectively regulate voltage levels [8]. Therefore, the 
effects of DG presence on the existent methods of voltage regulation must be investigated.

\section{LTC Regulated Radial Distribution Line}

As discussed in the section on protection scheme issues, DG units may need to be disconnected for faults more frequently than typical high voltage power plants.

Whenever a significant source of DG is connected or disconnected from a distribution system, the line voltages will be altered. If the change in voltage due to the DG going from online to offline - or vice versa - is significant, then voltage regulation techniques may fail. Figure V.2 shows a radial distribution line with loads at various nodes along the line; the line is fed from a transformer with an LTC. The model used here assumes equal loading at each node and equal spacing of the nodes. The transformer is rated at 5MVA, 33/12.4kV with tap increments of $1.5 \%(0.186 \mathrm{kV})$. The loads each consume $250 \mathrm{kVA}$ at an $85 \%$ power factor and have $(1.067+\mathrm{j} 0.241) \Omega$ of impedance between them.

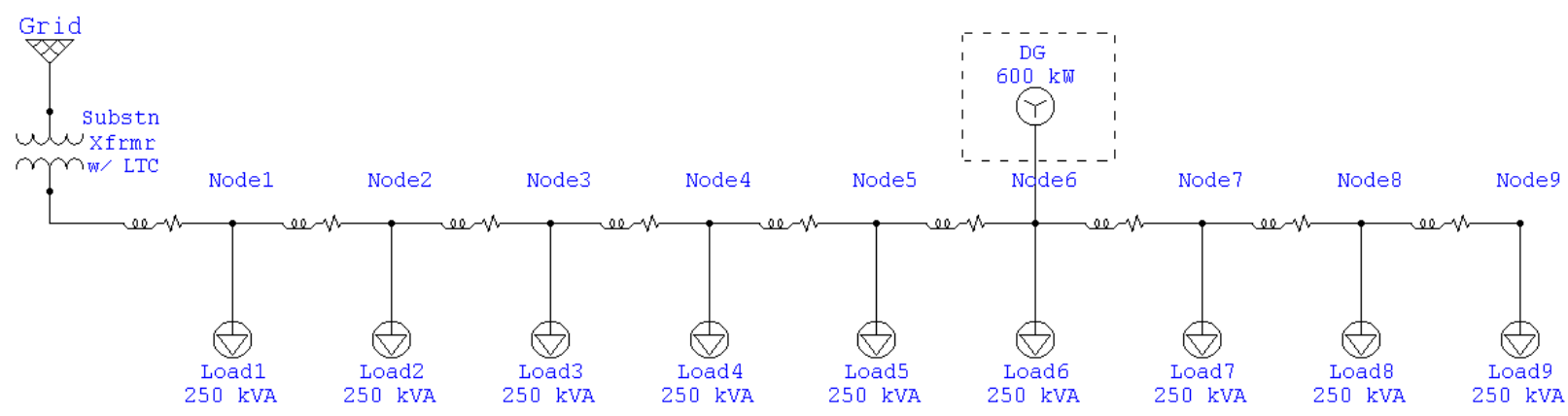

Figure V.2 Radial Distribution Line for Investigation of Voltage Level Effects from DG

The system shown in Figure V.2 was first simulated without the DG connected, and then again with the DG, under various conditions. The voltage profile for this line at full load without DG connected is shown in Figure V.3a; a 5\% voltage variation margin is shown in red. The profile is shifted upward (increased voltages) with the raising of the 
LTC tap setting; the variance of node voltages from the nominal 1.0 per unit is minimized at a tap of $6 \%$ or $7.5 \%$. Without an LTC employed (tap $=0)$, the voltage at node 5 drops to 0.9 p.u. - far below the acceptable $5 \%$ margin. For this reason, using a simple 33kV:12.4kV transformer would be unacceptable. Instead, an LTC should be used to regulate the voltage and, by observation of the profiles, an LDC that uses node 4 as the reference point of regulation would minimize voltage deviations. For decreased loading, the voltage profile will improve; with less power flowing, the voltage drops along the line will be decreased. Node 4 will be an acceptable reference point for lighter loads as well, and voltage variations will be slighter. This can be observed in Figures V.4a\&b, which show the profiles for $30 \%$ loading.

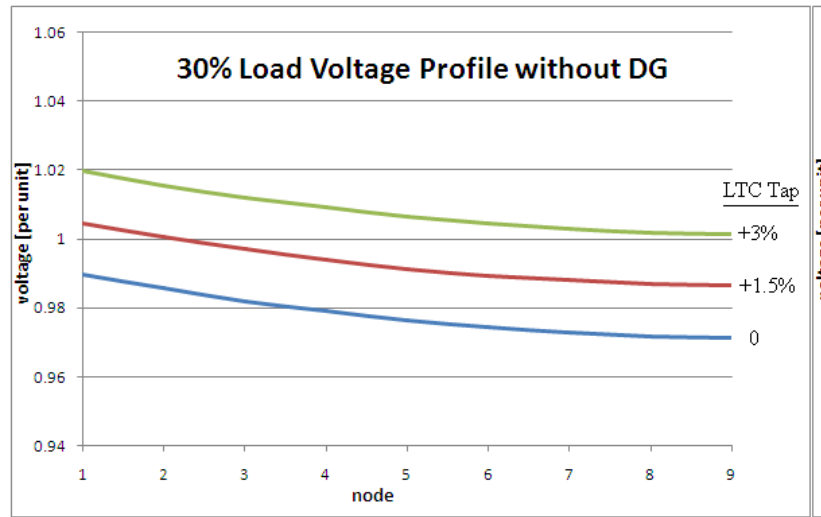

Figure V.3a Full Load Voltage Profile w/o DG

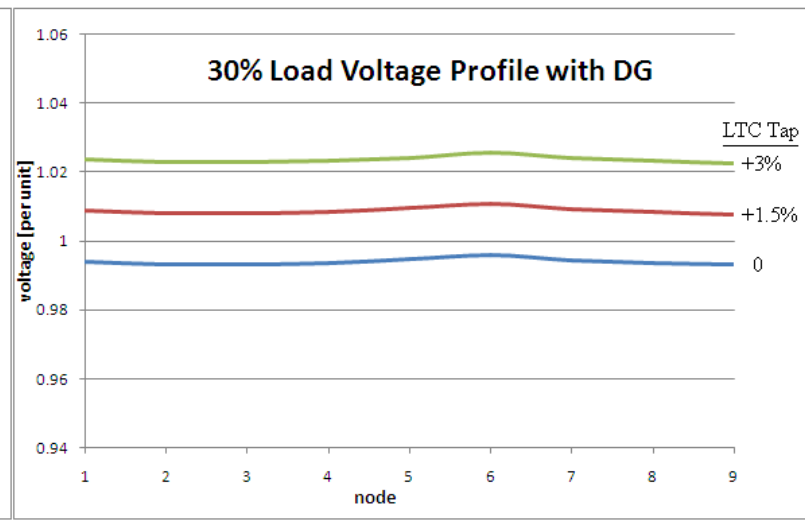

Figure V.3b Full Load Voltage Profile w/ DG
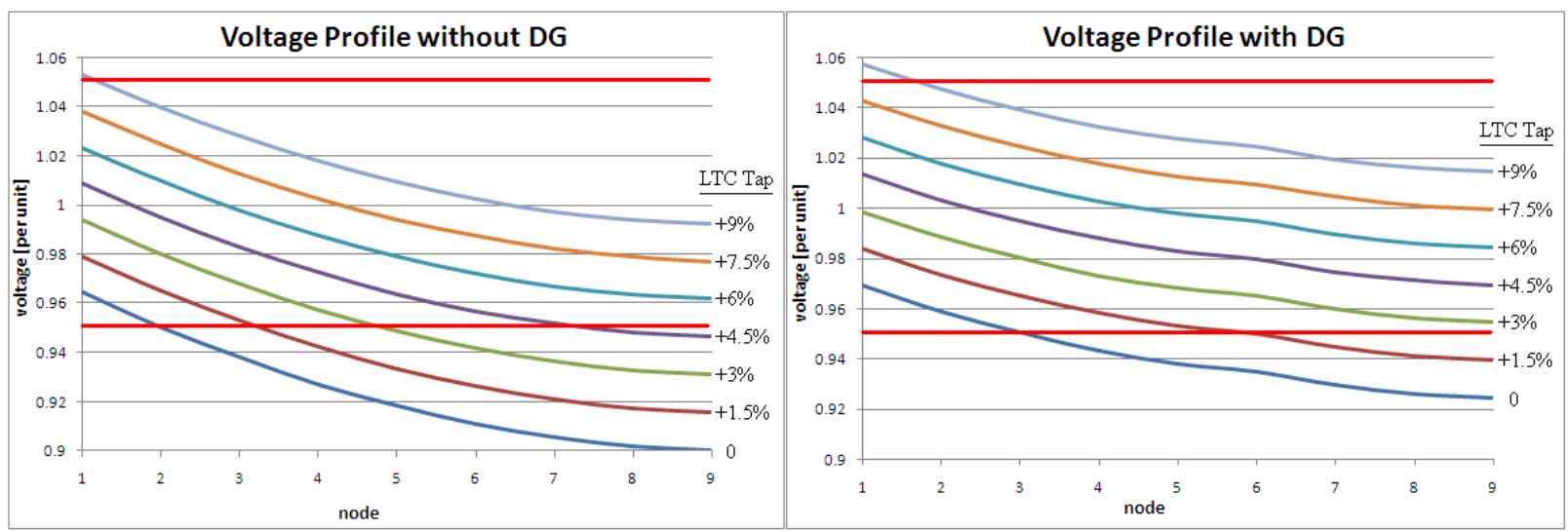

Figure V.4a 30\% Load Voltage Profile w/o DG
Figure V.4b 30\% Load Voltage Profile w/ DG 
Figure V.3b shows the voltage profile of the line when the DG unit is connected to node 6 . This shows a drastic improvement to the profile due to the addition of DG. Since this unit provides power locally to the loads, less current is supplied through the transformer and there is less voltage drop from line losses. A tap of $6 \%$ is still ideal for minimizing voltage deviations, and a reference point at node 4 is still acceptable. While the DG is connected, the voltage regulation of this line is improved significantly. However, the system must be able to handle the DG coming on- and off-line. It is often possible to bring a generator online gradually, but disconnects may happen often and instantaneously. From Figure V.3b, when the DG is connected and the system is at $100 \%$ load with the LTC at a $6 \%$ tap, the voltage at node 9 is 0.9845 p.u. (12.21kV). If the DG were to suddenly disconnect for a temporary fault, the system would jump to the profile of Figure V.3a upon reclosure and the voltage at node 9 would be $0.9618 p . u$. $(11.93 \mathrm{kV})$. This means that loads at node 9 would see a sudden dip of $280 \mathrm{~V}$ when the DG disconnects; other nodes on this system would see similar dips. This may not pose a dire threat since voltages would remain within $5 \%$ of nominal, but as the amount of DG on the system increases, the results become more serious. If identical DG units were added to nodes $7 \& 9$ as well as node 6 and a temporary fault at node 4 caused them all to disconnect, node 9 would see a spike of $998 \mathrm{~V}$. Node 9 would be at $6.9 \%$ below nominal voltage and a change in the tap of the LTC would immediately be necessitated. This situation could cause severe undervoltages that the LTC is not likely to be able to handle quickly enough.

For this system, node 6 was chosen arbitrarily as the point of connection for DG. However, if the point of connection could be chosen by grid operators, then the benefits of DG to voltage regulation could be maximized. Figure V.5 shows graphs of the voltage profile for the DG unit connected at each node. Loading was at $100 \%$, and the LTC was 
held constant at a tap of $6 \%$. It can be observed from the graphs that voltage regulation is improved more for DG connection further from the source, at the end of the line where voltage drop is normally greatest. The graph below indicates how the effects of DG on voltage regulation can best be mitigated when a choice in the point of interconnection is available.

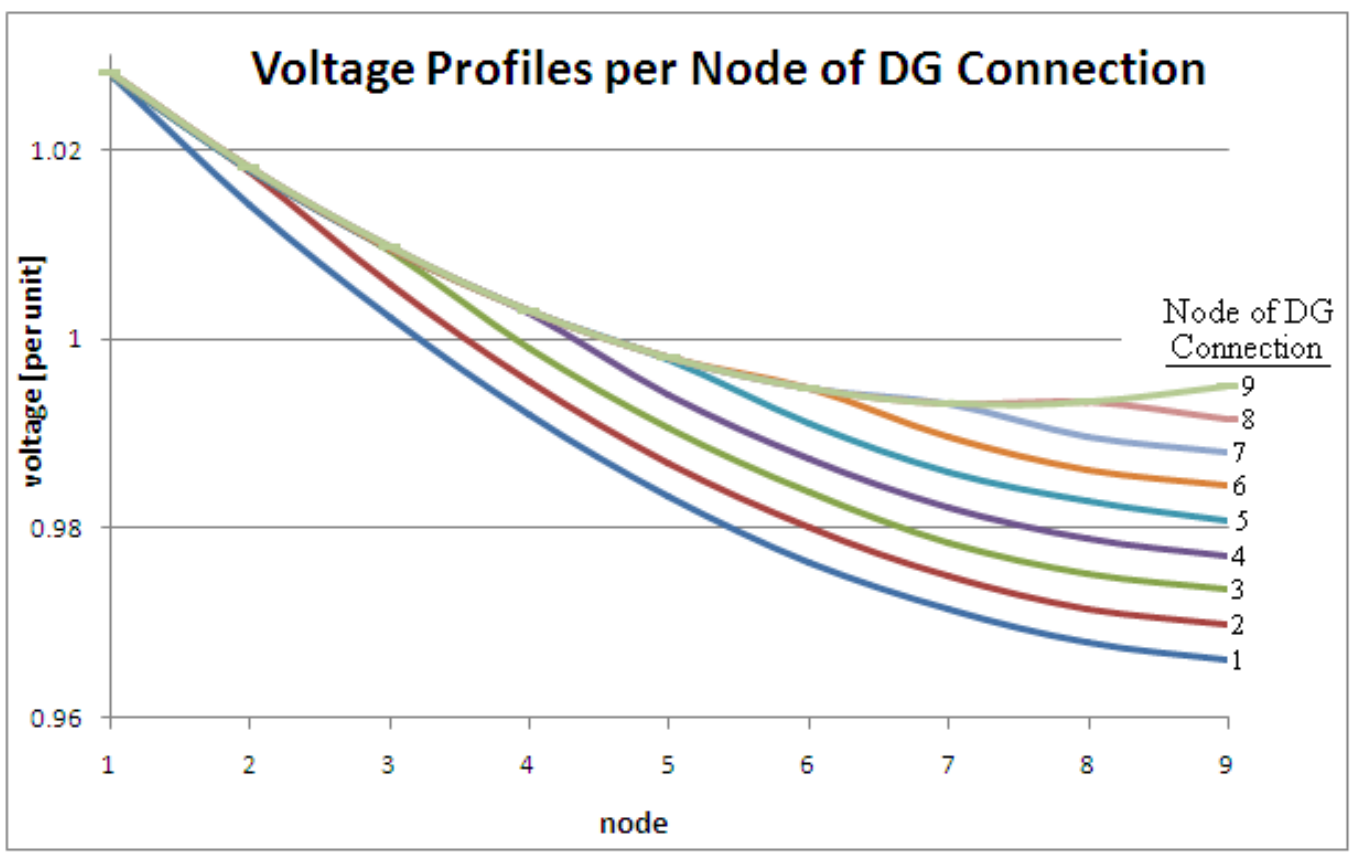

Figure V.5 Voltage Profiles at Various Points of DG Connection 


\section{INTERMITTENCY / FLUCTUATING SOURCES}

Some forms of DG, such as photovoltaics (PVs) and wind generators, provide power at unpredictably intermittent intervals. There is no way to control this behavior, short of controlling the weather itself. In order to use such generators to provide constant power output, storage devices and inverters can be used to regulate output. However, these solutions will decrease efficiencies and increase costs. Large wind farms sometimes employ static var compensators or other active voltage control techniques, but these large systems combine many (sometimes several hundred) individual turbines and feed the combined power to high voltage transmission systems [8]. This is not likely to be a feasible option for a small scale DG site that may employ only a few wind turbines, or even just one. Designing a stable grid system with an unknown amount of generation can be an arduous task. When the maximum possible power produced from DG is small in relation to nearby power flows (low DG penetration), it may be possible to design the system with minimal concerns to the behavior of the generation. However, if the total power from DG units in a given region is significant in relation to power flows within that region (high DG penetration), then the DG behavior must be accounted for.

Large power plants that produce hundreds or thousands of MW are equipped with some form of "throttling" that allows operators to regulate the output quite precisely. It is because of this control that extensive interconnectivity of power systems is possible. Controlling the output to maintain a very small margin of voltage levels and frequency enables many large networks to be interconnected at the high voltage level. Controlling the power angle of these interconnected networks allows for power flow to be directed so that one network can import power from another. This is the typical fashion in which energy is dispersed to customers: they set demands, and system operators find an 
available supply that can be directed to the demand. This works under the assumption that generation capabilities are known and controllable. Of course, a 100kW DG unit is going to have virtually no effect on the ability to manipulate the GWs of power flow on high voltage transmission lines. However, thousands of $100 \mathrm{~kW}$ systems might, and just one small system could affect the power flow of the local distribution system it is connected to.

Previous sections mentioned briefly that DG systems will, by nature, have lower reliability than typical large power plants. They may be out of service much more frequently due to disconnection necessities for faults, which can take significant time before bringing them back online. Yet, DG units that have unpredictable outputs even when they are online will have much less benefit to offer. Today, some utilities still use extremely inefficient diesel generators as peakers. When demand levels rise extremely high, these inefficient generators can be an economically sensible solution. One of the reasons these generators provide a suitable solution is that they can be dispatched very quickly - that is, they can be brought online quickly at anytime with a known output capacity. A DG unit with greater efficiencies would be capable of providing similar beneficial applications, but it would have to be dependable. If demand levels rose drastically on a cloudy day with low winds, solar units and wind turbines may be able to offer very little help. However, this does not eliminate these DG systems as viable solutions. Some areas - such as the Los Angeles Metro region in southern California see their greatest demands during hot summer months at midday when solar units would have their greatest output capacities.

In any case, when generators are dependent on variables beyond human control, the systems they connect to must be able to handle all possible cases. This means that the intermittency of some DG will force design considerations in the areas of power flow 
directions, protection schemes, voltage regulation, and more. The unpredictable variables that govern these systems (i.e. wind and sun) are not completely unpredictable; they are predictable to some degree. A solar-powered unit would never experience an instantaneous transition from full sunlight conditions to pitch darkness, for example. However, a wind turbine could experience rather quick changes of input power during strong gusts. Figures $\mathrm{VI} .1 \mathrm{a}^{2} \& \mathrm{~b}^{3}$ show examples of daily output for a photovoltaic system and a wind turbine, respectively. The PV system of Figure VI.1a is located at Vantage Point High School in Northglenn, CO, while the wind turbine of Figure VI.1b is located at Dolan Labs in Groveport, $\mathrm{OH}$. Each Figure shows data for the day of 1Jan, 2010. Both sites provide open access to real-time data of these systems yearround on the internet.

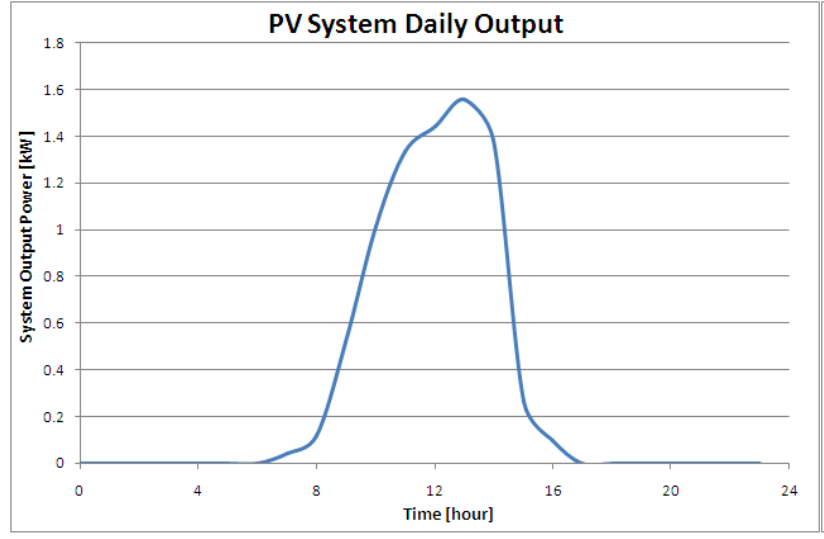

Figure VI.1a² PV System Daily Output

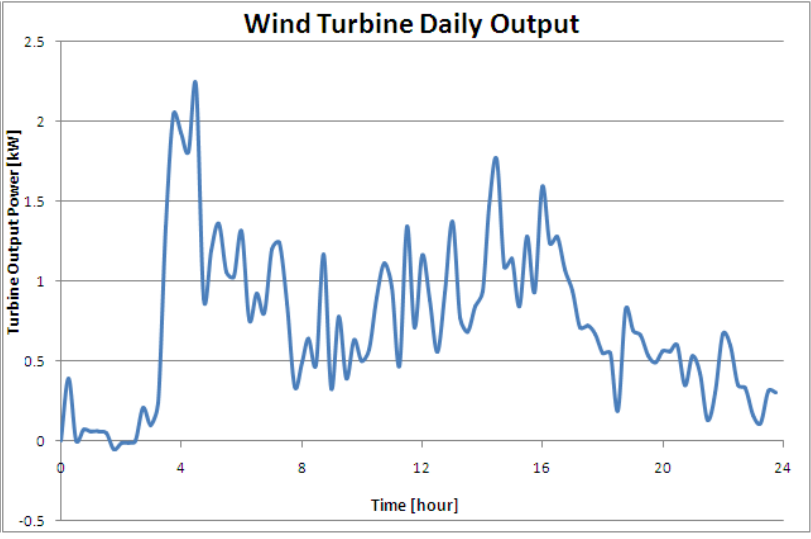

Figure VI.1 $b^{3}$ Wind Turbine Daily Output

Both of the graphs shown above illustrate examples of systems that can transition from maximum output to zero output in the course of a day. This equates to the variation between the condition of no DG installed on a system to the condition of an online DG system in the cases discussed in the previous sections. However, a PV system typically makes this transition more gradually than a wind turbine. A solar-

\footnotetext{
${ }^{2}$ Source: http://cosolarschools.org/schools/vantagepoint-fs.html

${ }^{3}$ Source: http://www.aep.com/environmental/education/wind/groveport.aspx
} 
powered system also tends to follow load demand since both are high during the day and minimal at night.

The intermittency of such DG units further warrants the necessity of the distribution system of connection to be capable of handling maximum output as well as minimal, or zero, output. Power flows may be reversed, or at least changed, between conditions of maximum and minimum DG output. Fault current contributions of DG will also change with the level of output at the time of fault and the protection devices, therefore, will need to function properly for all possible values of output power. This could make coordination particularly tricky. To investigate one particular way this difficulty could manifest itself, reconsider the system of the relay protection section. This system is shown again below in Figure VI.2.

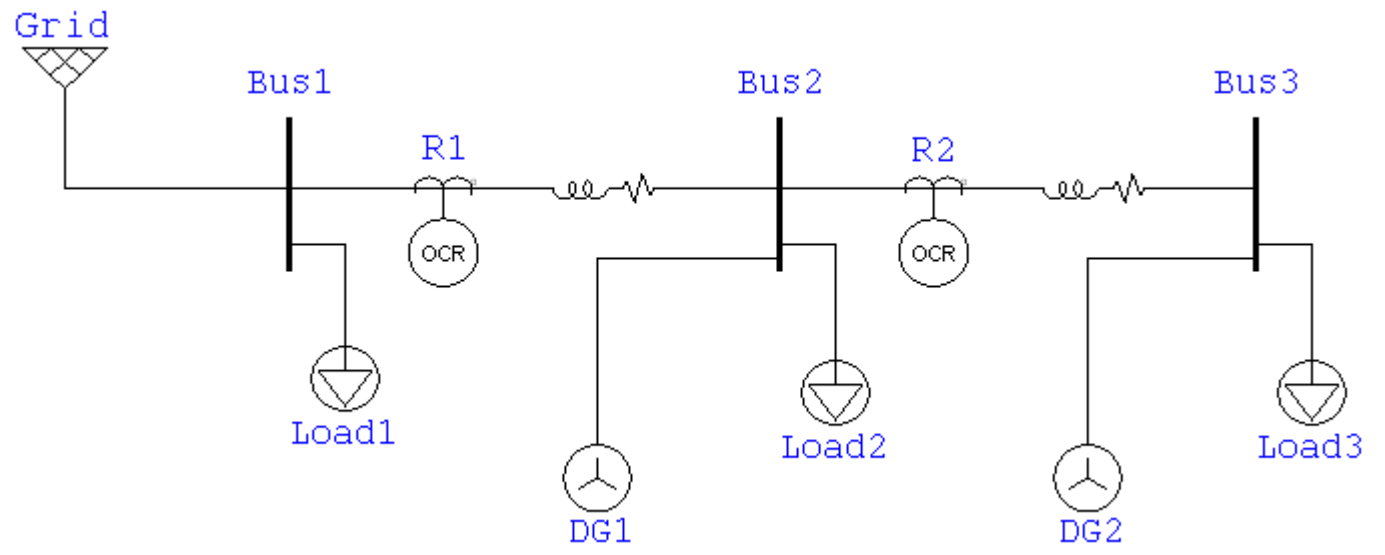

Figure VI.2 Radial Distribution System with DG, Protected by Relays

With DG connected and running on the system shown above, it would be desired that relay R1 provide protection for faults at Bus 1 for the upstream flow of the DG units. Of the two connected DG units, R1 would see more fault current than R2 and could, therefore, be coordinated to trip first in this instance. However, consider the case that DG1 is a wind turbine generator and that a fault occurs on Bus 1 at a time when no wind is blowing. In this case, R1 and R2 would see the same fault current from DG2, which 
means that R2 might trip if the coordination was relying on R1 having larger fault current. Then if the wind picks up before the fault was cleared, DG1 would begin generating and R1 would trip as well (or else the fault would be fed once again). On a larger system with many more buses and multiple DG connections, this type of situation could cause numerous breakers to trip for a fault that actually only required one device to trip. When coordinating protection systems, any intermittent DG systems will require that the protection be capable of handling faults during all possible output level combinations of the DG units.

Intermittency will also affect voltage regulation in manners similar to the online/offline variations discussed previously. Generators with rapid fluctuations will cause greater disturbance. Referring back to Figures VI.1b, it is observed that the output of a wind turbine may change by more than $50 \%$ in a matter of minutes; extreme conditions could be even worse. This has stronger implications on voltage regulation capabilities than a generator with smoother, more gradual changes like the PV system of Figure VI.1a. The reason for this lies primarily in the switching time of regulators such as a load tap changer (LTC). As discussed in the section on voltage regulation, DG will usually cause a voltage boost at the point of connection. This boost in voltage might then require the LTC to operate at a lower tap since less voltage droops are seen along the distribution line. If the DG were to disconnect (or drastically lower its output power), the tap setting of the LTC would need to be raised. The control system for an LTC is often able to change at rates that follow changes in voltage levels caused by the rising and lowering output power seen from a PV system. However, most LTC controls are not likely to be capable of tracking the rapid changes that would result from a wind turbine connection, and in some cases PV systems would become problematic as well [8]. 


\section{HARMONIC DISTORTION}

Ideally, the voltages and currents on lines of a power grid network would be purely sinusoidal at precisely the fundamental frequency desired $(60 \mathrm{~Hz}$ in the U.S.). However, there is always some degree of distortion that cannot be avoided. Generators, loads, and equipment on grids can all contribute to distortions in voltage and, more commonly, in current. These distortions can be mathematically quantified by harmonic content through Fourier analysis. However distorted a waveform is, it can be represented as a series of harmonic sinusoids. An ideal waveform would have only one frequency component at the fundamental frequency, but a distorted waveform would contain components at frequencies of integer multiples of the fundamental frequency. Figure VII.1 shows an example of a current waveform with harmonic distortion; the line current is obviously non-sinusoidal, but it can be expressed as the sum of three sine waves. The figure shows the three harmonic components that comprise the current waveform. A common method used by power engineers to quantify the amount of distortion present in a waveform is known as total harmonic distortion (THD). The THD of a waveform is the ratio of the rms value of its non-fundamental frequency components to the rms value of the fundamental component [19]. The THD of the current in Figure VII. 1 is computed as follows:

$$
\begin{aligned}
& \text { Line Cwrrent }=l_{\text {the }}(t)=0.7 \sin (377 t)+0.2 \sin (1131 t)+0.1 \sin \left(1885 t^{2}\right.
\end{aligned}
$$

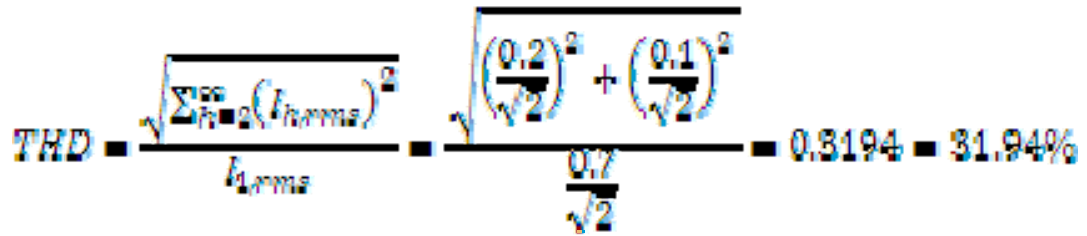




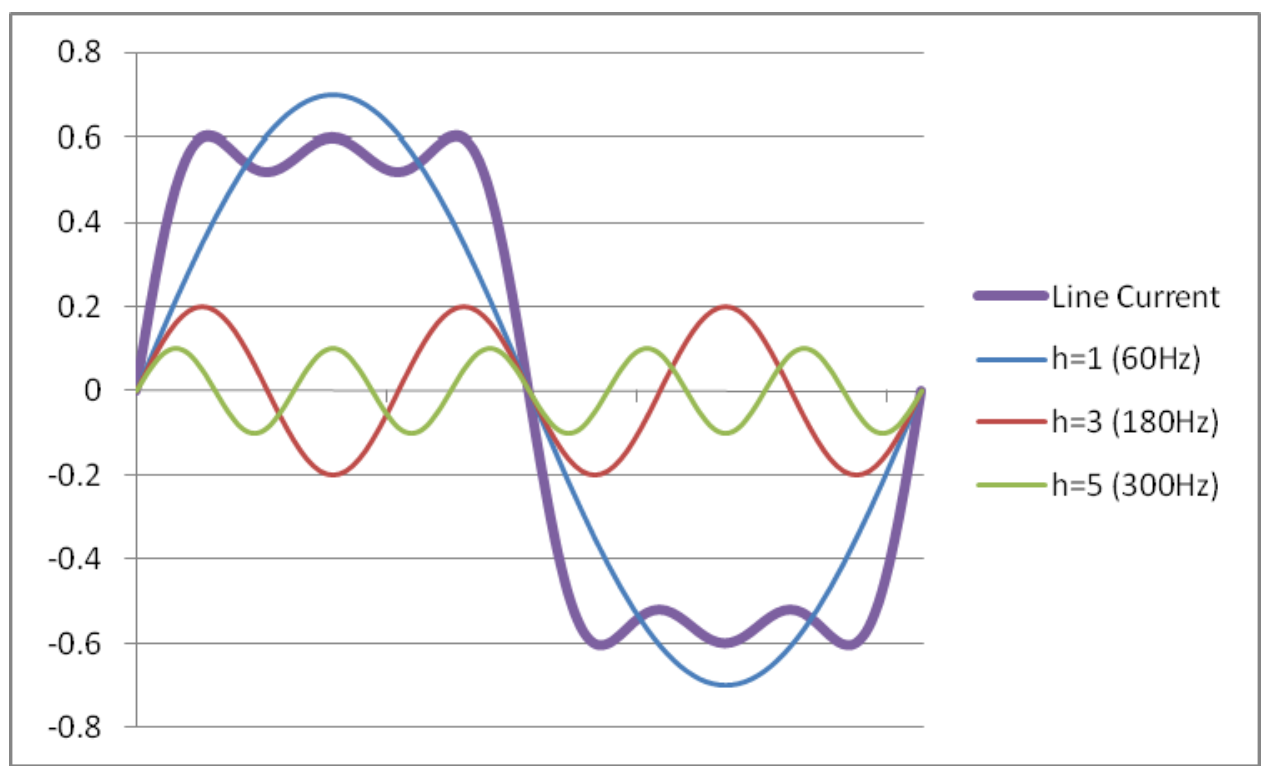

Figure VII.1 Distorted Current Waveform \& Harmonic Components

THD is a figure commonly used to express the level of distortion a waveform contains, but by itself it does not fully describe harmonic content. A current with a THD of $5 \%$ may have all $5 \%$ of its distortion at the $3^{\text {rd }}$ harmonic, or it may have its distortion spread over components ranging from the $11^{\text {th }}$ harmonic to the $33^{\text {rd }}$ harmonic. The $3^{\text {rd }}$ harmonic is particularly dangerous to a power system, while very high frequency distortion may be more readily filtered. However, high frequency harmonics produce greater voltage drops along lines because of increased skin effect. Triplen Harmonics $\left(3^{\text {rd }}, 9^{\text {th }}, 15^{\text {th }}\right.$, etc. $)$ are highly problematic for power systems with grounding because they produce zero sequence currents, meaning that they produce current in the neutral wire. Since the value of THD does not fully characterize the distortion of a waveform, IEEE standard 519 limits not only the acceptable THD levels, but also the acceptable levels for individual harmonic components. The limits from this standard are shown in Table VII.A. 


\begin{tabular}{|c|c|c|c|c|c|c|}
\hline \multicolumn{7}{|c|}{ Maximum Harmonic Current Distortion in \% of Load Current } \\
\hline \multicolumn{7}{|c|}{ Individual Harmonic Order (Odd Harmonics) } \\
\hline$I_{S} / I_{L}$ & $h<11$ & $11 \leq h<17$ & $17 \leq h<23$ & $23 \leq h<35$ & $35 \leq h$ & THD \\
\hline$<20$ & 4.0 & 2.0 & 1.5 & 0.6 & 0.3 & 5.0 \\
\hline $20-50$ & 7.0 & 3.5 & 2.5 & 1.0 & 0.5 & 8.0 \\
\hline $50-100$ & 10.0 & 4.5 & 4.0 & 1.5 & 0.7 & 12.0 \\
\hline $100-1000$ & 12.0 & 5.5 & 5.0 & 2.0 & 1.0 & 15.0 \\
\hline$>1000$ & 15.0 & 7.0 & 6.0 & 2.5 & 1.4 & 20.0 \\
\hline \multicolumn{7}{|c|}{ Even harmonics are limited to $25 \%$ of odd harmonic limits } \\
\hline \multicolumn{7}{|c|}{$I_{S C}=$ maximum short circuit current at $\mathrm{PCC}$} \\
\hline \multicolumn{7}{|c|}{$I_{L}=$ maximum demand load current (fundamental frequency) at PCC } \\
\hline
\end{tabular}

\begin{tabular}{|c|c|c|}
\hline Bus Voltage at PCC & Individual Harmonic & THD (\%) \\
\hline $69 \mathrm{kV}$ and below & 3.0 & 5.0 \\
\hline $69.001-161 \mathrm{kV}$ & 1.5 & 2.5 \\
\hline $161 \mathrm{kV}$ and above & 1.0 & 1.5 \\
\hline
\end{tabular}

Table VII.A IEEE 519 Current \& Voltage Distortion Limits

\section{Negative Effects of Harmonics}

The presence of harmonics in a power system is dangerous for various reasons.

If a line is carrying rated current at the fundamental frequency but has additional harmonic currents, then the total effective current is above the rated value. This additional current will contribute to the voltage drops across lines and other equipment causes voltage regulation problems. As mentioned, high frequency currents cause greater voltage drops (compared to low frequency currents of equal rms value) because the resistance of conductors increases with increasing frequency [19]. Aside from just increasing voltage drops, these harmonic currents will also increase the heating within conductors. For this reason, conductors may actually overheat while carrying rated rms current. Neutral conductors in a grounded three-phase four-wire system are particularly susceptible to these currents, since triplen harmonics will create zero sequence currents 
(current in the neutral wire). Ground conductors are generally not rated for high current and are often not protected by circuit breakers like the phase conductors are. However, the neutral conductor is often monitored by relays to indentify ground faults. In this case, harmonic currents may cause the breakers on the phase conductors to trip when no fault is present [20].

Harmonics will also have adverse effects on other grid equipment such as transformers and capacitors. Much like the effects within conductors, harmonic currents add losses in transformers both electrically and magnetically; the additional current contributes to the losses in the conductor windings as well as core losses seen by the magnetic flux. Harmonics, therefore, derate transformers through the increased losses in impendence, eddy currents, and hysteresis. To derate a transformer is to determine the actual current it is capable of carrying (less than rated value) due to internal losses generated by harmonics. Capacitors do not generate any harmonics on a system, but they can possibly create resonance if there are certain harmonics present. Line capacitance can actually be rather dynamic since banks are switched off and on lines to control power factors. If a system's resonant frequency at any time, which changes with changing capacitance, occurs near a harmonic frequency that is present, the resonance will amplify that harmonic and exacerbate the problem. [19]

\section{Harmonic Contribution of DG}

Some forms of DG employ newer forms of generation that can only produce DC current, such as photovoltaics and fuel cells. In order for these generators to be connected to the grid, a DC-AC inverter must be used. Some AC generators, like wind turbines and microturbines, also use converters to produce acceptable outputs for grid connection [21]. Inverters/converters all use high-speed switching in order to produce 
sinusoidal outputs. These outputs are never purely sinusoidal since they are produced by discrete switching and, therefore, they also produce harmonics. It is not possible to obtain a pure and continuous sine wave from discrete switching, but modern inverter technologies allow for outputs to come extremely close.

It is worth noting that most of the concern over harmonic contributions of inverters has been due to the fact that older inverters that used line-commutation produced high levels of harmonic currents [22]. Most inverters used for gridinterconnections today employ self-commutation with pulse width modulation (PWM) that generates much cleaner (more sinusoidal) outputs. Because modern inverter technology is able to reduce harmonic injections so well, the harmonic distortion concerns of DG units is rather negligible when compared to harmonic contributions of the non-linear loads commonly connected to grids. [20] Non-linear loads that contribute harmonics include arc furnaces, personal computers, adjustable speed drives, and even motors. These loads are used extensively by various electricity customers, so they are basically unavoidable. Therefore, grid operators must find methods of suppressing harmonics.

Though inverter technology developments have greater reduced concerns with DG grid-interconnects, the issues of harmonic distortion should still be considered along with DG installation projects. Any DG unit that is to be connected to the grid will need to produce output which has harmonic content within the limits outlined in Table VII.A, but engineering beyond these minimal requirements will add to the benefits DG has to offer grid operation. In areas of distribution that services high levels of non-linear loads, even small amounts of additional harmonics due to DG can be problematic. The local harmonic distortion in existence should be considered when siting new DG installations. The inverter control methods, such as power filtering, can be used to mitigate the 
harmonic injection of generation units as well as non-linear loads. If a new DG site will be employing harmonic suppression techniques, it should be done with consideration of other harmonic sources present. In this manner, costs can be mitigated, concerns can be minimized, and benefits can be maximized.

\section{Power Filtering}

One common method of harmonic suppression is by use of active power filters (APF) or passive power filters (PPF). Both filters function in roughly the same manner; they are, in essence, LRC tanks - a circuit composed of inductance, capacitance, and resistance. A PPF would be made of static impedances based on assumed loading. They are widely used because of their reliability and their simplicity, which makes them cheaper and easier to maintain. However, PPFs tend degrade faster and are highly susceptible to frequency changes of the grid; in some cases, the PPF can become resonant with the system and cause operational problems for the system and the filter. APFs, on the other hand, provide dynamic compensation by injecting current that matches harmonic current present but is 180 degrees out of phase with it. The effect is the negation of those harmonic currents so that the current seen by the system is more ideal. APFs provide the benefit of compensating inconsistent dynamics on the system, but need further development before they become widely applicable; limitations needing improvement are cost, losses, and reliability. [23] 
Figure VII.2 shows the benefits offered by power filtering. Figures (a) \& (b) show an example of the load voltage and current drawn by a commercial
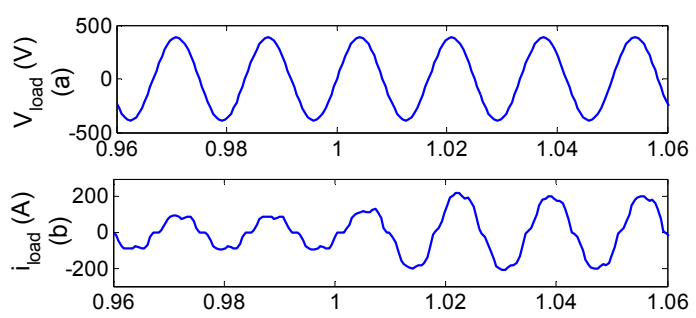
building during start-up of its air conditioner. Figure (c) shows the current injected by a local APF, and Figure (d) shows the resulting line current. Without the APF, the line current would match the
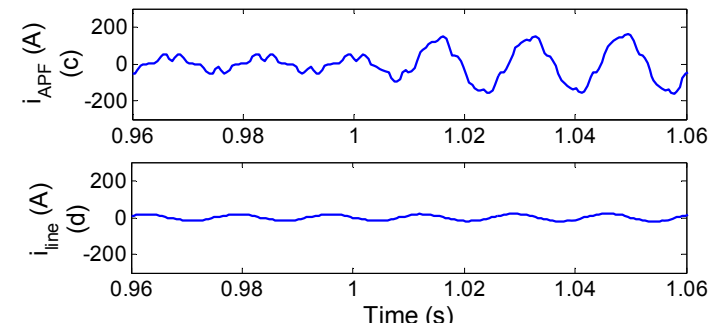

Figure VII.2 Harmonic Reduction with APF load current (containing many harmonics), but the injected APF current results in significantly smoothed line current with highly reduced harmonics.

\section{Concern for Harmonics from DG}

Compared to the other issues of DG discussed in this paper, harmonic contribution is not of high concern; the harmonics caused by non-linear loads and transients tend to be far more significant than those caused by inverter-based DG [20, 22]. DG operators must ensure that they do not exceed the harmonic limits of IEEE Standard 519 , but this usually requires only that a modestly sophisticated inverter be used when one is needed. If the inverter system desired, or other supportive equipment, produces abnormally high levels of harmonics, a power filter can be used to remove these distortions. 


\section{ISLANDING}

The concept of islanding on a grid system is unique insofar as it is regarded as a dangerous problem to be avoided in some cases, but regarded as a benefit to system performance in other cases. An island refers to a section of the distribution grid that has been disconnected from the rest of the grid network but is still energized by local generation - this is sometimes referred to as a microgrid whenthe islanded section is intentional design to be capable of supporting itself as an independent grid. When a breaker, fuse, or other type of switch trips upstream from one or more generators, but those generators continue to supply local loads that are also downstream of the disconnect, those generators, loads, and other connected equipment then comprise an island. The issue of islanding was addressed briefly in the previous section on protection through auto-reclosers, but this section looks at the issue more in depth. Figure VIII.1 shows an example of a system where an island could form. If a fault occurred at Bus 2 and Fuse 2 tripped from the contribution of the DG connected at Bus 4, then the DG unit and all the loads on Bus 4 would comprise an island.

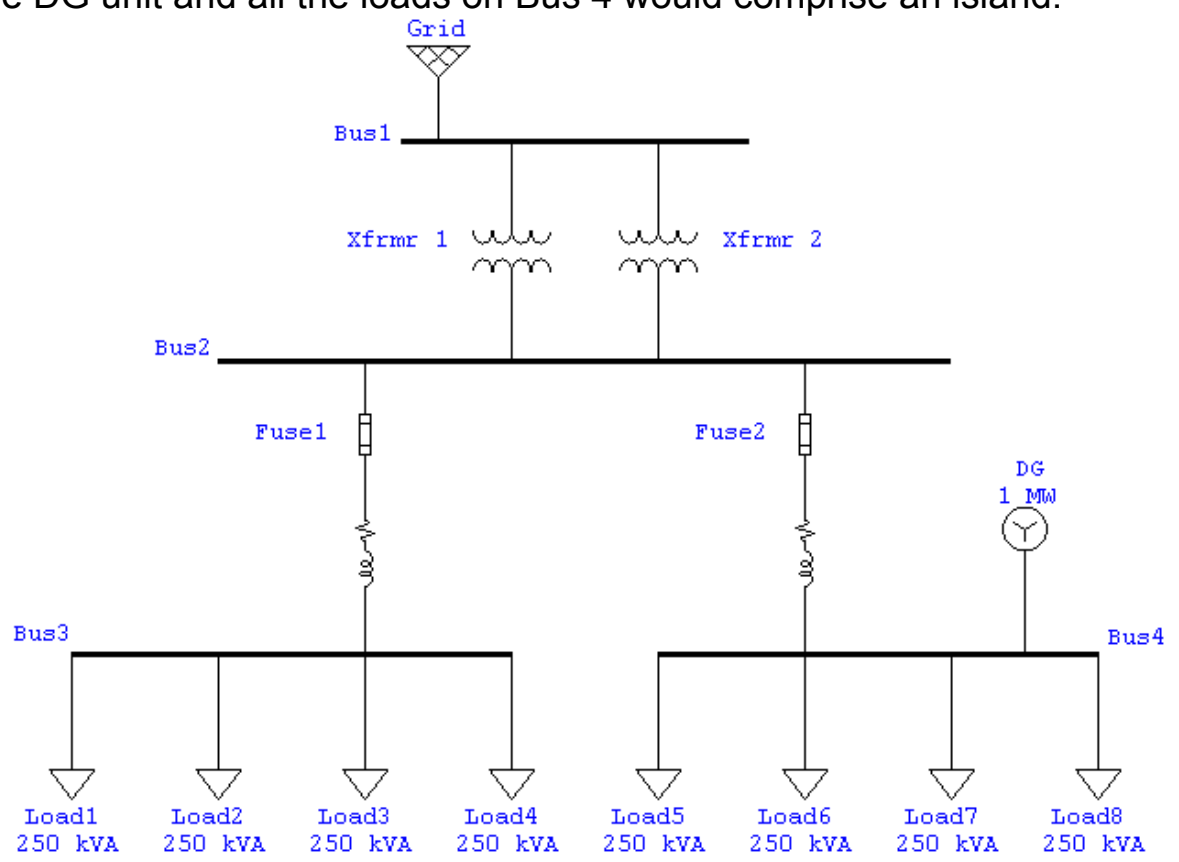

Figure VIII.1 Distribution System that is Susceptible to Islanding 
The system shown above could form an island because the amount of power generated by the DG unit approximately matches the power demand of the attached loads; this is the primary condition that must hold for an island to sustain. For this reason, DG units with built-in power control (such as synchronous generators and selfcommutated inverters) are more likely to form islands than those with external sources of excitation [13]. In most cases, long-term islands formed (or potentially formed) by DG would function poorly at best because DG is rarely equipped with the capability to regulate voltage or match power demand. The power demand of most load feeders changes fairly regularly, and the output of some DG units changes regularly as well (see Intermittency). However, if a disconnect occurs upstream of a system like that of Figure VIII.1 when the right conditions are met, an island will form even if only temporarily. Temporary islanding is far more common than the currently rare cases of long-term islanding, but it still poses a severe threat to the power system and the DG unit itself [16]. As DG penetrations are increasing and advancing technologies are increasing the efficiency of DG control methods, the probability of islanding occurrences also increases [24].

The issue of islanding (and protection from it) is currently the greatest obstacle in realizing the benefits of DG, and this issue is therefore under much research and development $[13,16,24,25]$. Nearly all utility standards dictate that anti-islanding protection be implemented for DG installations, with few exceptions only for very small synchronous generators and self-commutated inverters $[9,13]$. One such standard is IEEE 1547, which also proposes that small-scale photovoltaic installations within a region be limited to one-third of peak load demand to avoid islanding from high penetration of small units. This standard, however, is currently being expanded to establish criteria by which islanding can be permitted so that the full benefits DG can 
offer might be realized [25]. Until the complications of islanding are overcome, utilities require that all significant DG units disconnect within 10 cycles $(0.17 \mathrm{~s})$ or less when loss of utility service is detected [22]. The difficulty in detecting such loss, however, is partly what makes the issue of islanding so complicated.

\section{Problems Encountered from Unintentional Islanding}

Although standards generally provide that all systems have protection to prevent it, islanding does still occur on occasion. When an island is formed, it presents a danger to both grid equipment and maintenance personnel. Disconnects usually occur to remove a fault on the system, and maintenance personnel may subsequently be sent out to clear the fault. The disconnect would likely be meant to de-energize all downstream lines, but the DG supported island may actually be keeping some lines energized and thereby pose electrocution threats to maintenance crews. For this and other reasons, maintenance personnel must take special precautions in areas with DG to ensure that lines are de-energized before attempting to work on the system or reconnect it. The extension of precaution that is necessary may actually reduce service reliability since faults may take longer to clear.

DG units are typically not designed to support sections of the grid alone; they generally rely on the virtually ideal voltage support provided by the grid. In an unintended island scenario, the DG will have no sufficient means to regulate voltage or frequency on the connected lines. This can quickly result in extremely poor power quality for all connected equipment and cause permanent damage to loads, utility equipment, or DG units themselves.

The greatest problem is that even if the voltage and frequency of the island are able to be maintained within acceptable limits, the island will still drift quickly out-of- 
phase with the grid once disconnect occurs [22]. If an island and grid are reconnected while out-of-phase, again severe damage to equipment is the result. The dangers of out-of-phase connection contributes to the delay in restoring service when an island has formed; generally, the DG on the island must be taken offline so the utility can reconnect to de-energized lines, then the DG can be brought back online. As mentioned previously, the most commonly encountered danger of islanding is that out-of-phase reconnection inhibits the ability to implement auto-reclosing. This phenomenon is far more common because the island need only be formed momentarily for reclosure to be inhibited. Most DG is found on grid sections where the local load demand is significantly different from DG supply capacity; an island would not sustain in these cases. However, loading even in these areas may vary enough that, at some given time instance, the DG output very closely matches the load demand. If a fault occurred at this moment and a recloser was tripped, the reclosure would then reconnect two out-of-phase systems. This "perfect storm" scenario is usually very unlikely, but the danger is very real and common islanding detection methods cannot protect against this situation. Most antiislanding protection functions on the basis that DG capabilities will be insufficient to properly sustain proper voltage and frequency on the islanded system.

\section{Detection \& Protection Methods}

Current utility standards require that all DG disconnect rapidly whenever utility service is lost so that the harmful effects of islanding can be avoided. Protection during loss of utility power to a section of the grid to which the DG is connected is typically referred to as loss of grid protection (LOG protection). An LOG occurrence is produced from switching on the system that can result from fault clearance, equipment failure, load shedding, or maintenance outages. The goal of LOG protection is to detect the 
occurrence quickly (regardless of cause) and to disconnect the DG within the timeframe established by utility standards. Commonly used methods are usually of either the passive method or active method variety. Passive methods detect LOG by simply taking measurements at the DG unit's point of connection to the grid. Active methods, on the other hand, inject slight disturbances to the system at the point of connection and observe the response. Newer forms of LOG detection use telecommunication signals, which can also have applications for implementing intentional islanding and synchronous reclosing. In many cases, DG is protected from islanding by a combination of multiple methods of LOG detection.

\section{Passive Methods}

In most cases of LOG, the power produced by DG will not match the power consumed by attached loads, and passive methods can detect the situation easily by voltage and/or frequency monitoring. The most typical case today is found with small penetration of DG that is insufficient to power local loads alone. The LOG will overload the DG unit(s) and the voltage and frequency will quickly collapse. In the rarer case where DG supplies more power than local loading demands, LOG will cause overvoltage. Passive methods are simple, cheap solutions that can be used to remove DG very quickly when there is a significant power mismatch during LOG.

The most prevalent form of traditional LOG detection is under/over voltage and under/over frequency relaying [24]. This method is usually effective for small DG units because the units typically are greatly insufficient for supporting system voltage or frequency without grid service, so LOG causes immediate drops in both that is quickly detected. Yet they can fail if the DG system is able to maintain voltage and frequency or fail to operate quickly enough if the DG can maintain the system even for a second or 
two. Therefore, under/over relays may be insufficient for large DG units, or in areas of high penetration. This method inherently has a nondetection zone (NDZ), which refers to the range of power mismatch between DG and loads for which LOG will not be detected. If the LOG occurrence cause the voltage and/or frequency to change only slightly - within the tripping limits of the

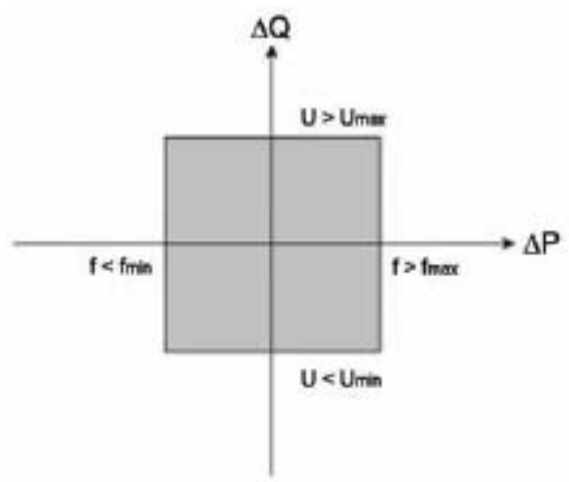

Figure VIII.2 Non-Detection Zone [24] relay - the relays will not trip. Figure VIII.2 from [24] shows a general example of the NDZ of these relays. Under/over voltage and frequency techniques are quite effective and useful for most DG, but their shortcomings must be recognized for instances where power mismatch may be low.

Newer methods of passive detection have been developed to provided smaller NDZs and more reliable protection. One such method is referred to as rate of change of frequency (ROCOF), which still is accomplished by observing changes in frequency at the point of DG connection. The relay will disconnect the DG when the ROCOF exceeds a preset value over a set interval of time (the operating time). A typical optimized setting for ROCOF relays used on small or medium sized DG units is $0.3 \mathrm{~Hz} / \mathrm{s}$ with an operating time of $0.3-0.7 \mathrm{~s}$, but extreme frequency changes may provide for an operating time as low as 4 cycles $(0.07 \mathrm{~s})$. This method still has an inherent NDZ due to the fact that oversensitivity of the relay settings will cause a disconnect for commonplace system disturbances as well as LOG, but the NDZ is usually quite narrow in comparison to typically expected responses to LOG. Phase displacement monitoring and rate of change of generator power output are other passive techniques closely related to the 
ROCOF method. These methods all have the inherent advantage that in the case of a failure to operate in the first instance of system disturbance, they would still operate for the subsequent instance immediately following. [9]

Another passive method that has been developed to increase sensitivity of LOG detection is that of vector shift (VS), also called vector surge. VS detection is accomplished through continuous measurements of the cycle duration of waveforms at the point of DG connection, comparing each measurement with the previous one. The difference in cycle duration times will increase when there is a power mismatch. Essentially, this method is still measuring frequency changes like ROCOF. However, the difference with this method is that measurements are compared with previous measurements instead of with a preset value. This gives VS detection the advantage of extremely quick detection of islanding (one cycle), and they are therefore often implemented without time delays. Typical VS relay settings are to operate when there is a change in cycle duration of around $8^{\circ}$ to $12^{\circ}$.

Other, less common, methods of passive detection are also studied and used, but most are a variation on the principles employed by those discussed above. Every method is unable to escape one fundamental downfall: they must not be so sensitive that they trip for commonplace disturbances, so they cannot detect islanding if the power match is close enough that the disturbances caused are slight and within that typical range.

\section{Active Methods}

Active methods of LOG detection do not merely make measurements of system characteristics like passive methods do; they involve the intentional injection of disturbances to the system and then measure the response. This form of detection 
commonly comes under criticisms due to the fact they reduce power quality and are usually only applicable for inverter-based DG [16]. Inverter-based DG is more suited for the use of active detection methods because the inverter itself is well suited for implementing the small disturbances to be observed. While these disturbances are usually slight, the use of active detection is not permitted on some networks due to concerns of power quality degradation [24].

One form of active detection, known as reactive power export error detection, is accomplished by control of reactive power generation. Most modern inverters allow for control of the power factor of generation, or by extension, for control on the quantity of reactive power produced. This ability can be used to set the level of reactive power exported from the DG to such a level that may only be sustained if there is connection to the utility source. For an LOG occurrence, the actual reactive power generated will deviate from its set value and the relay will disconnect the DG. There are, of course, fluctuations in the output from the DG under normal operation. The operating time of this detection method must be greater than the duration of typical fluctuations. This results in relatively slow operation with typical operating times of $2 \mathrm{~s}$ to $5 \mathrm{~s}$. However, this method is capable of detecting island formation even when the LOG causes no change in DG loading. Because it operates slowly but detects islanding situations that other methods cannot, this method is generally applied for back-up to the faster methods discussed.

As illustrated in previous sections, the fault current contribution from the utility source is far greater than even significantly large DG units' contributions. This fact is used to implement system fault level monitoring as a LOG detection method. By firing thyristors to connect a shunt inductor at the point of DG supply, at short circuit is produced. The thyristors would be fired for a very short duration, just prior to zero 
current occurrence. This short would cause a brief surge of current through the inductor and a spike in voltage, allowing for a measurement of the fault level. The fault level will be drastically higher when there is connection to the utility grid than when the DG is islanded, which makes the tripping decision of the relay very accurate. This accuracy allows for extremely fast operating times as low as half of a cycle [9]. The primary shortcoming of this method is the adverse effects to power quality from injecting waveform spikes and introducing additional harmonics.

While active methods are currently used effectively to avoid islanding events, the methods are fundamentally based on the creation of disturbances. They may have some suitable applications, but their reliance on disturbing a system that is already disturbed by DG's presence makes it ill-suited as a widespread solution to islanding concerns.

\section{Communication-Based Methods}

In addition to passive and active detection methods, communication-based methods (sometimes called intertripping) can be implemented. This method is far less common in implementation, but is the source of much speculation and research. This method is superior insofar as it has no NDZ and does not interfere with normal system operation in any way. This method is based on the fact that the virtually exclusive cause of islanding is a result of the tripping of grid switching equipment. Therefore, using communication channels to relay the occurrence of a switch trip to any DG downstream presents a reliable source of LOG detection. The level of reliability in detection is dependent solely on the reliability of the communication channel. Likewise, the operating time depends strictly on the speed of propagation of the communication signal; 
no forced time delay is needed since the DG should ideally disconnect immediately when a disconnect from the grid occurs.

Communication based methods theoretically offer the possibility of very robust protection, but its primary hindrances are the level of complexity and cost that will match its level of robustness. The communication medium would have to be fast and reliable in order to be effective. Some systems suggested by [24] include SCADA, permanent IP connection, wireless GPRS, and radio links. All of these systems present viable application as a means of LOG detection, but each also has its limitations. There are not currently utility standards for the use of telecommunication for DG operation, but they may be developed as DG penetrations increase. One method to protect the grid from the failure of telecommunication detection methods is to use "allowance signaling" or "enable signaling". That is, a signal would be generated from a substation that "allowed" the operation of DG downstream, but the signal would cease upon a switching that disconnected the DG from the grid. This provides that DG would disconnect upon communication failure to protect against the case of an LOG occurrence while communication was down. Furthermore, by using a generic signal of allowance, multiple DG units downstream can be protected using the one signal. This provides particular benefit in the case of residential areas where PV penetration is significantly high. If many inverters connected in one area of distribution all used active methods of islanding protection, power quality level could drop too low. Using a single communication signal to allow or disallow the connection of all inverters could be highly preferable. However, a single signal will not always be sufficient. In some cases, switching will island some DG units but not others. It may also be the case that some DG is connected to the grid by multiple switches, making a LOG occurrence dependent on the state of all relevant 
switches, not just one. These complexities will affect the cost and reliability of the protection scheme.

One clever method of using communication signals for protection is to use the distribution lines themselves, as suggested in [24]. A high frequency signal can be generated on the bus at the substation, which would propagate along on the downstream distribution lines (assuming downstream flow). This can serve as the "allowance signal" for all connected DG sites, and the need for a separate communication channel can be eliminated. Furthermore, it provides a novel means of creating a simple, but highly reliable, method of LOG detection. Regardless of how many switches may or may not connect any given DG unit to the grid, this signal created at the substation will only reach those units whose grid connection is intact.

To provide electric services in modern infrastructures, most grids are currently under much communication developments. New "smart grids" will have established methods of reliable communication for the status of nodes throughout the grid. As these developments take root, they may provide a convenient means for communicationbased islanding protection.

\section{Intentional Islanding}

Regulations on utility grids rarely allow for DG to continue operation in an islanded situation; this is primarily due to concern for out-of-synchronism reclosure. If the issue of loss of synchronism were tackled, the use of DG to create viable islands would likely gain swift support [9]. Intentional allowance of island formation would increase system reliability and provide back-up power supply to loads when grid supply is lost. Intentional islanding can only be applied in cases where the available DG is capable of supporting the island. This means that the DG must be of a capacity greater 
than the load demand of all possible connected loads and it must have sufficient capabilities for maintaining voltage and frequency on the island without grid support. In order to avoid momentary interruptions on loads during a disconnect that forms the island, a static device must be employed for switching. The DG unit must also be capable of handling any inrush it may experience when it is initially switched into island mode, and it must be able to detect any faults within the island and disconnect accordingly. All of these requirements can be met with relatively modest technologies and engineering assuming that the costs and benefits justify it - the technical hurdle here lies in synchronism.

Any island will run out of synchronism with the grid unless it is somehow forced into synchronicity. Proposed methods of keeping an island in sync with the disconnected grid are closely reminiscent of methods of communication-based LOG detection mentioned above. The general idea is that the island and the grid must communicate (independently of power connections) in order to match up in phase before the two can be reconnected. Ideally, control systems would keep the island operating in synchronism with the grid at all times so that reconnection could occur at any time. This type of control may be much simpler today as new circuit breaker technology offers the possibility of exchanging information between the systems on either side of a switch [26]. Another method is to transmit a reference waveform signal for a secure nearby point of the grid (likely from the immediately upstream substation) to downstream DG. This signal can be used by the DG to govern the frequency and phase of the island such that it matches that of the grid.

Time delay and phase angle variation must be carefully considered and calculated for communications to be successful in obtaining synchronism. Hard-line connections for transmitting the signal, such as fiber-optics, or telephone lines, could 
introduce time delays on the order of $100 \mathrm{~ms}$ to $300 \mathrm{~ms}$. Short-range FM radio transmission could be used to obtain more negligible delays, but this technique would be less suited for broader application of networks with multiple DG units and multiple island configuration possibilities. Time stamped global positioning system (GPS)

measurements can provide accuracy to within $1 \mu$ s with a phase error of 0.018 [9]. The time stamping will allow for phase alignment at the DG despite transmission delays. The measurements are likely to be made at a point other than the point of connection/disconnection between grid and island - i.e. at the substation instead of at the tripped switch. For this reason, there will be some degree of phase angle variation between the reference signal and the waveform at the point of reconnection. Likewise, there may be a variation between the waveform produced by the DG and the point of reconnection. These variations would have to be quantified beforehand, through knowledge of system characteristics such as load flow and impedances so that the precise phase of the waveforms at the intertie could be determined.

Synchronizing an island during grid disconnection is currently the biggest impediment in using DG islanding to improve system reliability, but other difficulties would also need to be overcome were methods of synchronism to be successful. Detection of the state of the DG (islanded vs. grid-connected) would be necessary for implementing control system. However, reconnection could be hard to detect when the two systems are tightly synchronized because there would be minimal transient effects. It has been suggested by [9] that the steady-state phase difference between the two systems is likely to be an effective means of detection since it should vary more greatly during islanded operation than when connection is restored. Furthermore, coordinating protection schemes for networks where islanding may occur could be particularly difficult. Power flow may change directions between normal and islanded operation 
modes, and fault current levels may be drastically lower during islanding. For this reason, and for the simplification of other issues mentioned here, intentional islanding tends to be more feasible for areas where DG is found at the end of a radial feeder than when it is found on low voltage networks. 


\section{CASE STUDY - CAL POLY DISTRIBUTION SYSTEM}

The design case study presented here is implemented on the distribution system of California Polytechnic State University in San Luis Obispo, CA (Cal Poly). The singleline diagram of the existing distribution system is shown in Figure IX.1. The objective of this case study is to design an upgraded system that would make Cal Poly's system a near net-zero consumer - that is a facility that has nearly $100 \%$ of its energy demand provided locally and imports zero energy on an average. The generation methods used to achieve this goal should use only renewable fuel sources to reduce or eliminate fuel costs, to support research and development in the field of renewable energies, and to foster environmental responsibility within the campus and community. The underlying purpose of this case study is to illustrate how the issues discussed in this paper should be addressed during design so that the system functionality is optimized and problematic scenarios are avoided.

Multiple justifications for implementing such a design at Cal Poly exist. Firstly, a large institution such as Cal Poly has energy bills so large that investments in generation capabilities can be economically justified rather easily. Furthermore, the primary objective of Cal Poly is education; design and implementation of emerging technologies, such as those of renewable energies, provides resources for application-based education in various fields. The power delivery system of Cal Poly maintains the facilities necessary to run the institution, but it can also serve as a real-world scenario for students to research and develop. The city of San Luis Obispo has high solar insolation levels, consistent wind stream areas, and a close proximity to coastal regions. Cal Poly has access to large portions of open land in these local areas, making the school an ideal candidate for implementing renewable energy methods. With a design focused on renewable energy that addresses all areas of concern discussed in this paper, the local 
utility Pacific Gas \& Electric (PG\&E) also stands to benefit a great deal from such a project since it would credit their renewable portfolio requirements. With all parties involved in a position to benefit, implementation should be easily accomplished if a design is achieved that ensures safe and reliable service.

The existent system shown in Figure IX.1 was modeled using ETAP software. The system loading was derived from metering data gathered by Cal Poly's facilities department; yearly loading data is shown in Appendix A. The loading data presented is incomplete and contains some incongruencies due to abnormal operation. However, the loading data was used to gain only approximate typical loading; the simulations were performed to account for light and heavy loads that entailed the full range of possible loading. In this high-level model, the various loads on each feeder are modeled as a single lumped load; further detail of one feeder is also shown for brevity. Main protection for the system feeders is shown in the figure; the Upper Substation feeders are protected differentially, while the Middle and Lower Substation feeders are protected by overcurrent relays. The protection devices downstream of those shown are primarily fuses; some feeders may have hundreds of fuses with various trip settings downstream of the main breakers. The ratings and impedance values of the equipment shown in Figure IX.1 are tabulated in Appendix B. Load flows for the system are presented in Table IX.A for various loading and various output levels of the existent DG on the system. The values given are the $\mathrm{kW}$ of load flow in the downstream direction for each branch of the system listed (negative values indicate upstream flow). 


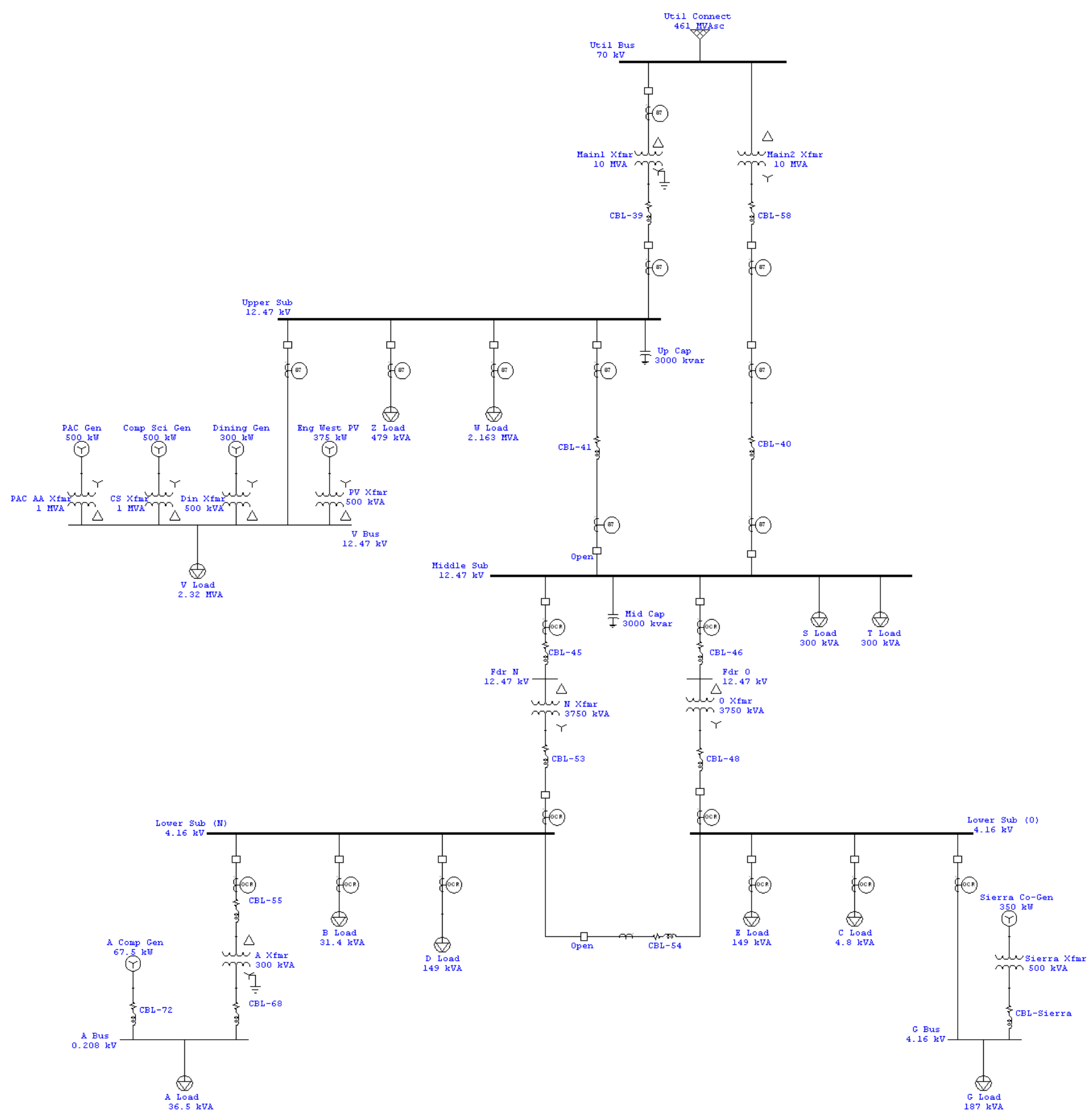

Figure IX.1 Nominal High-Level System of Cal Poly Distribution Network 


\begin{tabular}{|c|c|c|c|c|c|c|c|c|c|}
\hline & \multicolumn{3}{|c|}{$0 \%$ Existent DG Output } & \multicolumn{3}{|c|}{$50 \%$ Existent DG Output } & \multicolumn{3}{|c|}{$100 \%$ Existent DG Output } \\
\hline & $50 \%$ Load & $100 \%$ Load & $150 \%$ Load & $50 \%$ Load & $100 \%$ Load & $150 \%$ Load & $50 \%$ Load & $100 \%$ Load & $150 \%$ Load \\
\hline Total Import & 3003 & 5240 & 8107 & 1789 & 4197 & 6950 & 869 & 3176 & 5970 \\
\hline Main Xfmr1 & 2644 & 4136 & 6368 & 1611 & 3297 & 5441 & 1004 & 2463 & 4641 \\
\hline Main Xfmr2 & 578 & 1158 & 1743 & 390 & 950 & 1520 & 274 & 784 & 1344 \\
\hline Feeder Z & 241 & 479 & 715 & 240 & 479 & 716 & 240 & 2162 & 716 \\
\hline Feeder W & 1087 & 2163 & 3225 & 1085 & 2162 & 3231 & 1085 & 479 & 3230 \\
\hline Feeder V & 1166 & 2319 & 3458 & 1271 & 1770 & 2538 & -1553 & 1556 & 2050 \\
\hline Feeder $\mathrm{T}$ & 150 & 300 & 449 & 150 & 300 & 449 & 150 & 300 & 449 \\
\hline Feeder S & 150 & 300 & 449 & 150 & 300 & 449 & 150 & 300 & 449 \\
\hline OXfmr & 170 & 339 & 511 & -66 & 175 & 334 & -212 & -133 & 210 \\
\hline $\mathrm{NXfmr}$ & 108 & 215 & 324 & 76 & 178 & 283 & 55 & 152 & 254 \\
\hline Feeder G & 93 & 186 & 280 & -98 & 53 & 107 & -273 & -195 & -130 \\
\hline Feeder E & 74 & 148 & 223 & 74 & 148 & 223 & 74 & 148 & 223 \\
\hline Feeder C & 2 & 5 & 7 & 2 & 5 & 7 & 2 & 5 & 7 \\
\hline Feeder D & 74 & 148 & 223 & 74 & 148 & 223 & 74 & 148 & 223 \\
\hline Feeder B & 16 & 31 & 47 & 16 & 31 & 47 & 16 & 31 & 47 \\
\hline Feeder A & 18 & 36 & 55 & -16 & 9 & 28 & -52 & 33 & -15 \\
\hline
\end{tabular}

Table IX.A System Branch Load Flows (in kW) at Various Loading \& Generation Levels

The system shown in Figure IX.1 is a strictly radially fed system, and normal operation of the system is as shown. However, most of the feeders have a possible intertie (not shown) with at least one other feeder through a switch that is normally open. These interties can be used to maintain service to a feeder that is otherwise out of service, but the interties also allow for the system to be operated in a looped fashion. For example, feeders $D$ and $G$ can be intertied to establish the "dorm loop" (the loads on these feeders are dormitories), which would also create a tie between the two buses of the Lower Substation. This

\begin{tabular}{|c|c|c||}
\hline \multicolumn{2}{|c|}{ Feeders } & Intertie Device \\
\hline$Z$ & $W$ & $S 201$ \\
\hline$Z$ & $V$ & $S 061$ \\
\hline \multirow{2}{*}{$W$} & $V$ & $S 124$ \\
\cline { 3 - 3 } & & $S 019$ \\
\hline$T$ & $S$ & $S 171$ \\
\hline$G$ & $D$ & $S 106$ \\
\hline$E$ & $B$ & $T 170$ \\
\hline
\end{tabular}

Table IX.B Feeder Interties also allows the Sierra Co-Generation Plant to feed directly to both feeders. The possible interies between feeders are not shown in the figure, but they are presented in Table IX.B for reference. 
Prior to completing an analysis of the system for investigating DG potential, the following observations of the nominal system were made:

- Approximately $80 \%$ of the real power loading is on feeders $\mathrm{V}, \mathrm{W}$, and $\mathrm{Z}$ off the Upper Substation. This portion of the system is operating near capacity, while the Middle and Lower Substations have plenty of room for further growth.

- Feeders $\mathrm{W}$ and $\mathrm{V}$ run through the densest portions of the campus and are, therefore, poorly suited for interconnection with greenfield developments. Feeders $Z$ and $C$ run through remote areas of the campus where there is much potential for greenfield projects.

- The Middle Substation currently has four spare feeders, making this bus the most likely candidate for future developments. Two of the spare feeders have been designated for future load growth accommodation, while one has been designated for future co-generation development.

- Under normal operating conditions, the Main1 Transformer feeding the Upper Substation bus is significantly more heavily loaded than the Main2 Transformer feeding the Middle Substation bus. While the load on Main1 is still well within its ratings, closing the tie between the Upper and Middle Substations would balance the transformer loadings and may improve voltage regulation.

- Feeder V currently has four generators intertied with it - not enough to supply the full $\vee$ feeder load, but additional generation on this feeder may pose coordination difficulties.

- Existent generation capabilities on Feeders A and G exceed the load demand on those feeders; therefore, if these generators run at full capacity they also supply power to adjacent feeders and the power flow is reversed. 


\section{Design Analysis}

Simulations were performed on the system using ETAP software to investigate the parameters that would influence the various issues previously discussed in this paper. Unless otherwise stated, these simulations were performed with the loads at the nominal values shown in Figure IX.1 and all existent generation running at $90 \%$ capacity.

\section{Power Flow}

Any additional DG added to this system must not exceed the rated capacities or reverse power flows between substations, or the costs and difficulties of such a project may become too great. A load flow analysis was performed for the system at nominal loading, light loading (50\% of nominal), and heavy loading ( $150 \%$ of nominal). The data in Table IX.C shows the generation capacity (in kW) that could potentially be added to each bus without reversing the power flow to an upstream bus. If the power flow is not reversed, this will also guarantee that current ratings are not exceeded.

Reversal of power flow, however, would not necessarily be detrimental in each case. For example, with the existent Sierra Co-Gen plant running at full capacity, the power flow on Feeder $\mathrm{G}$ is already reversed and

\begin{tabular}{||c|c|c|c||}
\hline \multirow{2}{*}{ Bus } & \multicolumn{3}{|c|}{ Generation Potential [kW] } \\
& $\mathbf{5 0 \%}$ Load & Full Load & $\mathbf{1 5 0 \% \text { Load }}$ \\
\hline Upper & 571 & 2624 & 4662 \\
\hline Middle & 176 & 724 & 1271 \\
\hline Lower (N) & 42 & 145 & 248 \\
\hline Lower (0) & 0 & 9 & 170 \\
\hline Z & 201 & 401 & 599 \\
\hline W & 903 & 1799 & 2688 \\
\hline V & 0 & 424 & 1376 \\
\hline T & 142 & 285 & 427 \\
\hline S & 142 & 285 & 427 \\
\hline G & 0 & 0 & 0 \\
\hline E & 72 & 144 & 215 \\
\hline D & 72 & 144 & 215 \\
\hline C & 2 & 4 & 6 \\
\hline B & 14 & 27 & 41 \\
\hline A & 0 & 0 & 0 \\
\hline \hline
\end{tabular}

Table IX.C Possible Bus Generation Capacities without Power Flow Reversal this power can supply Feeders E and C, or it can supply Feeder D if the intertie switch 
between $D$ and $G$ is closed. In most cases, power flow reversal from a feeder to the substation bus should not be a problem - the power can then supply adjacent feeders on that same bus. This will, however, require that protection scheme settings be reappraised to ensure that there will be no nuisance tripping.

\section{Protection Schemes}

The substation bus and feeder protections for the system are shown in Figure IX.1, but there are many more protective devices downstream on the feeder buses. These devices are almost entirely fused switches. The main feeder circuit breakers are not likely to be problematic for modest generation growth on the feeders because they can accommodate generation levels up to at least the load demand of the feeder, though settings may need to be altered. The downstream fuses, however, would place much higher restrictions on the amount of generation that could be added without upgrading the protection if the generation was implemented downstream of one or more of these fuses.

Figure IX.2 shows the feeder bus for Feeder $Z$ with the protective devices for the various load branches, and the tripping current of each fuse is given. Generation capabilities that could service a large portion of the total Feeder Z load or more would not be practical to implement downstream of one of the individual load branch transformers. These transformers and the protection schemes have been sized to accommodate just that particular load branch. However, generation tied directly to the $Z$ Bus could service the entire feeder loads without disrupting the fuse protection scheme. If this generation exceeded the demand of Feeder Z, though, power would flow upstream to the Upper Substation bus. Yet the Upper Substation is protected 
differentially, so this should not pose a problem to the protections shown in Figure IX.1. The other feeders on the system present very similar situations to Feeder $Z$.

Small DG systems can be implemented downstream of the distribution fuses, but these systems should be sized only to service the immediately local loads. The photovoltaic system on the roof of the Engineering West building is an example of an existent implementation of such generation. These systems can be beneficial, but it would take many such systems to significantly reduce the total consumption of imported energy to the campus.

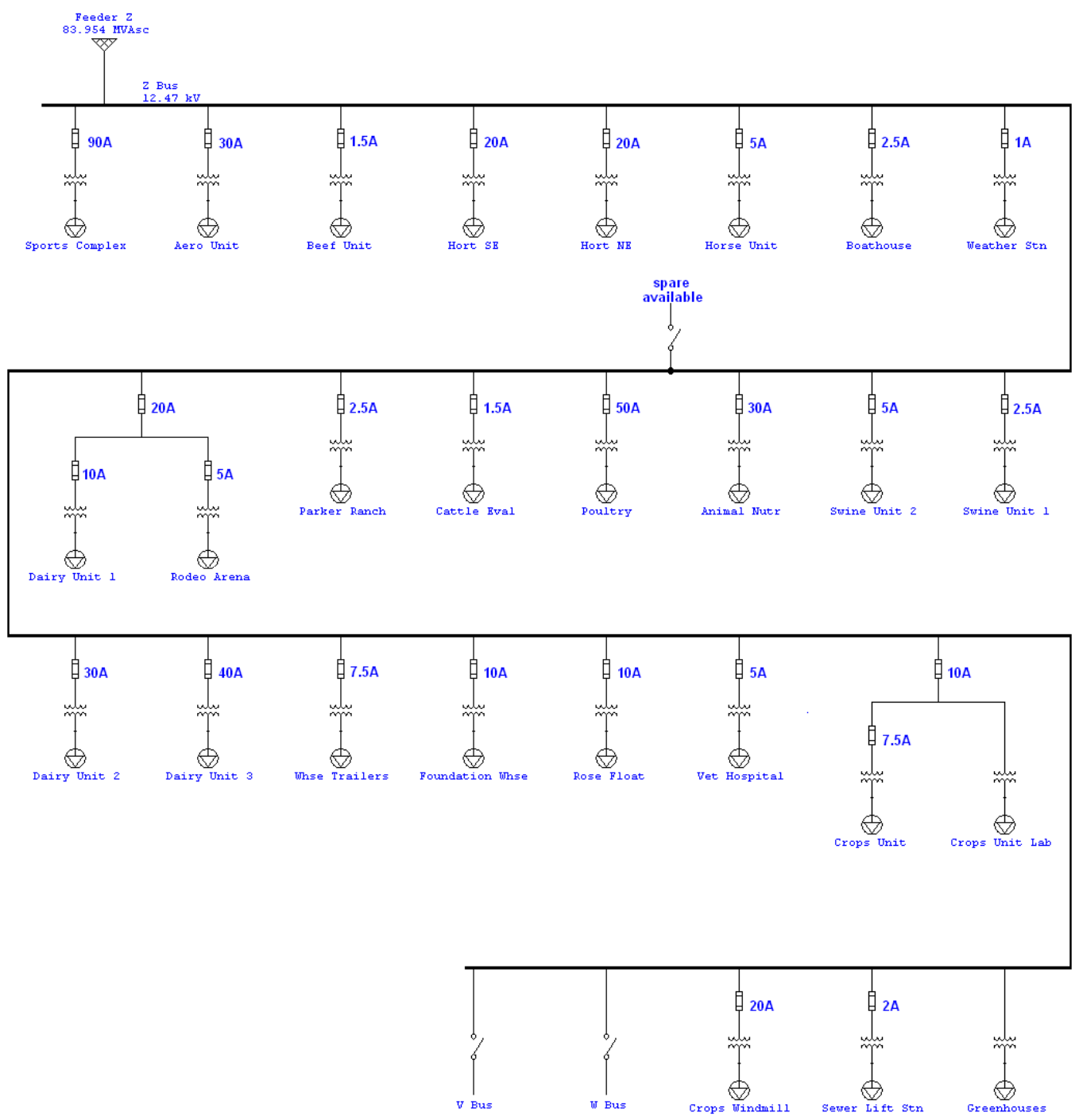

Figure IX.2 Feeder Z Distribution and Fuse Protection Ratings 
In order to quantify the effects of additional DG on the fault levels of the system, a short circuit analysis was performed on the system using ETAP. Table IX.D presents the changes in maximum fault currents seen for faults at each bus of the system in Figure IX.1 due to added generation capacities. The Upper and Middle Substation buses - and the feeder buses connected to them - can handle up to $300 \mathrm{~kW}$ of additional generation with less than a $2 \%$ change in fault levels. The Upper Substation bus and its feeder buses can handle $1 \mathrm{MW}$ of additional generation with less than a $5 \%$ change. $\mathrm{A}$ small change in fault levels implies a more simplistic implementation of DG because existent coordination schemes may still handle the new system characteristics, but changes in the protection scheme may be necessary even for small fault level changes. Yet existent relays are likely to be capable of handling small fault level increases by adjustment of settings. Conversely, an addition of $300 \mathrm{~kW}$ at the Feeder $\mathrm{A}$ bus would cause a $30 \%$ increase in fault levels, and significant upgrades to the protection scheme would likely be needed.

\begin{tabular}{|c|c|c|c|c|c|c|c|c|c|c|c|c|c|c|c|}
\hline \multirow{2}{*}{\begin{tabular}{c|} 
Gen Added: \\
Effects:
\end{tabular}} & \multirow{2}{*}{\begin{tabular}{|l|} 
Nominal \\
$\mathrm{I}_{\mathrm{F}} \max$ \\
\end{tabular}} & \multicolumn{2}{|r|}{$50 \mathrm{~kW}$} & \multicolumn{2}{|c|}{$100 \mathrm{~kW}$} & \multicolumn{2}{|r|}{$150 \mathrm{~kW}$} & \multicolumn{2}{|c|}{$200 \mathrm{~kW}$} & \multicolumn{2}{|c|}{$300 \mathrm{~kW}$} & \multicolumn{2}{|c|}{$500 \mathrm{~kW}$} & \multicolumn{2}{|c|}{$1000 \mathrm{~kW}$} \\
\hline & & $I_{F} \max$ & $\%$ increase & $\mathrm{I}_{\mathrm{F}} \max$ & $\%$ increase & $I_{F} \max$ & $\%$ increase & $\mathrm{I}_{\mathrm{F}} \max$ & $\%$ increase & $\mathrm{I}_{\mathrm{F}} \max$ & $\%$ increase & $I_{F} \max$ & $\%$ increase & $I_{F} \max$ & $\%$ increase \\
\hline Upper Sub & 5.83 & 5.85 & $0.34 \%$ & 5.86 & $0.51 \%$ & 5.87 & $0.69 \%$ & 5.89 & $1.03 \%$ & 5.92 & $1.54 \%$ & 5.97 & $2.40 \%$ & 6.12 & $4.97 \%$ \\
\hline Middle Sub & 4.63 & 4.64 & $0.22 \%$ & 4.66 & $0.65 \%$ & 4.67 & $0.86 \%$ & 4.69 & $1.30 \%$ & 4.72 & $1.94 \%$ & 4.77 & $3.02 \%$ & 4.92 & $6.26 \%$ \\
\hline Lower Sub (O) & 6 & 6.04 & $0.67 \%$ & 6.09 & $1.50 \%$ & 6.13 & $2.17 \%$ & 6.17 & $2.83 \%$ & 6.26 & $4.33 \%$ & 6.43 & $7.17 \%$ & 6.86 & $14.33 \%$ \\
\hline Lower Sub (N) & 5.63 & 5.67 & $0.71 \%$ & 5.71 & $1.42 \%$ & 5.75 & $2.13 \%$ & 5.8 & $3.02 \%$ & 5.88 & $4.44 \%$ & 6.06 & $7.64 \%$ & 6.48 & $15.10 \%$ \\
\hline Z Bus & 5.83 & 5.85 & $0.34 \%$ & 5.86 & $0.51 \%$ & 5.87 & $0.69 \%$ & 5.89 & $1.03 \%$ & 5.92 & $1.54 \%$ & 5.97 & $2.40 \%$ & 6.12 & $4.97 \%$ \\
\hline W Bus & 5.83 & 5.85 & $0.34 \%$ & 5.86 & $0.51 \%$ & 5.87 & $0.69 \%$ & 5.89 & $1.03 \%$ & 5.92 & $1.54 \%$ & 5.97 & $2.40 \%$ & 6.12 & $4.97 \%$ \\
\hline V Bus & 5.83 & 5.85 & $0.34 \%$ & 5.86 & $0.51 \%$ & 5.87 & $0.69 \%$ & 5.89 & $1.03 \%$ & 5.92 & $1.54 \%$ & 5.97 & $2.40 \%$ & 6.12 & $4.97 \%$ \\
\hline T Bus & 4.63 & 4.64 & $0.22 \%$ & 4.66 & $0.65 \%$ & 4.67 & $0.86 \%$ & 4.69 & $1.30 \%$ & 4.72 & $1.94 \%$ & 4.77 & $3.02 \%$ & 4.92 & $6.26 \%$ \\
\hline S Bus & 4.63 & 4.64 & $0.22 \%$ & 4.66 & $0.65 \%$ & 4.67 & $0.86 \%$ & 4.69 & $1.30 \%$ & 4.72 & $1.94 \%$ & 4.77 & $3.02 \%$ & 4.92 & $6.26 \%$ \\
\hline G Bus & 6 & 6.04 & $0.67 \%$ & 6.09 & $1.50 \%$ & 6.13 & $2.17 \%$ & 6.17 & $2.83 \%$ & 6.26 & $4.33 \%$ & 6.43 & $7.17 \%$ & 6.86 & $14.33 \%$ \\
\hline E Bus & 6 & 6.04 & $0.67 \%$ & 6.09 & $1.50 \%$ & 6.13 & $2.17 \%$ & 6.17 & $2.83 \%$ & 6.26 & $4.33 \%$ & 6.43 & $7.17 \%$ & 6.86 & $14.33 \%$ \\
\hline D Bus & 5.63 & 5.67 & $0.71 \%$ & 5.71 & $1.42 \%$ & 5.75 & $2.13 \%$ & 5.8 & $3.02 \%$ & 5.88 & $4.44 \%$ & 6.06 & $7.64 \%$ & 6.48 & $15.10 \%$ \\
\hline C Bus & 6 & 6.04 & $0.67 \%$ & 6.09 & $1.50 \%$ & 6.13 & $2.17 \%$ & 6.17 & $2.83 \%$ & 6.26 & $4.33 \%$ & 6.43 & $7.17 \%$ & 6.86 & $14.33 \%$ \\
\hline B Bus & 5.63 & 5.67 & $0.71 \%$ & 5.71 & $1.42 \%$ & 5.75 & $2.13 \%$ & 5.8 & $3.02 \%$ & 5.88 & $4.44 \%$ & 6.06 & $7.64 \%$ & 6.48 & $15.10 \%$ \\
\hline A Bus & 17.16 & 18.01 & $4.95 \%$ & 18.86 & $9.91 \%$ & 19.71 & $14.86 \%$ & 20.56 & $19.81 \%$ & 22.26 & $29.72 \%$ & 25.68 & $49.65 \%$ & 34.23 & $99.48 \%$ \\
\hline
\end{tabular}

Table IX.D Maximum Fault Currents due to Amount of Added Generation 
In the interest of designing the system alterations to minimize the need for protection upgrades and changes, two specific parameters are aimed for. Firstly, any additional DG implemented on the system should be upstream of the fuse protections on the feeder distribution branches. As mentioned, small DG systems could be implemented downstream of these fuses, but the goal of this design is to significantly reduce the amount of imported energy and such small-scale systems provide limited benefit to this end. Secondly, changes in fault current levels should be within a $2 \%$ margin when possible to avoid expensive protection scheme alterations. However, this second parameter must be balanced with other expenses. If this $2 \%$ margin were to warrant the implementation of many small DG installations over few large installations, the cost of implementing and maintaining the many DG units could outweigh the cost of the protection scheme changes needed for the few large units.

\section{Voltage Regulation}

Voltage regulation of this system appears to present little challenge. On the buses shown in Figure IX.1, there is less than $1 \%$ drop of voltage on any bus. The capacitor banks on the Upper and Middle Substation buses are dispatchable for voltage support during load demand changes. The voltage drop along the feeder lines must also be considered since these are modeled simply as a lumped load on the feeder bus in the system of Figure IX.1. However, it was found that under nominal operating conditions, each of the feeders currently exhibit less than $0.1 \%$ voltage drops at any point along their lines. Voltage drops of the feeder lines do not present need for concern.

To ensure acceptable power quality, the design shall limit the changes of all operating voltages between the existent system and the system with added DG to within 
$2 \%$. This constraint will allow for the disconnection and reconnection of DG units without causing drastic dips or spikes in voltage levels.

Intermittency \& Harmonics

This design shall avoid intermittency of the main portion of generation, but take advantage of it in a small portion. The load demands on this system are, as usual, maximum during the day, but minimal at night. A photovoltaic system can provide increased generation levels during higher demand without operator intervention. Yet this benefit cannot be consistently reliable in predictable quantity. Therefore, a storage system would be required for such a generator. Any wind turbines or other intermittent sources would also require storage capabilities that could provide regulated output. Therefore, primary generation on this system shall be from a predictable source (nonintermittent). This will eliminate the need for an extensive storage system and provide regulation for the intermittencies present.

The high level design presented here involves minimal concern for harmonic contributions created. Any inverter-based DG added to this system will be assumed to have inverting capabilities that keep harmonic levels within the limits presented in Table VII.A (IEEE 519 Std.). As discussed in Section VII, available inverter technology makes this a relatively simple task to achieve if there is significant non-inverter-based generation present on the system as well.

\section{Islanding}

A system design for intentional islanding capabilities on the Cal Poly campus would be difficult to justify, though an exciting notion. If enough generation were implemented to sustain service to the campus, the school would basically function as a 
microgrid. A microgrid is an electric power system with local loads and generation that is capable of operating autonomously from local utility service. Microgrids are a relatively new concept of interest, and DG proliferation has increased the relevance of their study. For this reason, a microgrid electric system on the Cal Poly campus - capable of intentional islanding - would provide a unique opportunity for power engineering research at the university. However, the justification just about ends there.

Islanding capability could provide extremely high reliability of service at Cal Poly, but such high levels are not warranted for the school. Demands for extremely high reliability rates (sometimes as high as $99.9999 \%$ ) are generally seen from military, industrial, and commercial customers with large loads of expensive and sensitive equipment. Power outages can have devastating effects for such customers. A college university, on the other hand, has little need for reliability above what utilities already provide. Small back-up generators are usually a more economical solution to protecting the few sensitive loads a campus might have than to obtain very high reliability for the entire campus. An electric system capable of intentional islanding would simply be an unnecessary luxury on a college campus in most cases.

One way that such an extensive electric system might be justifiable would be if the school campus was to become a net producer of energy, and the university could profit from exported energy sales. However, this would entail a plethora of additional difficulties that would only warrant address by a company looking to enter the energy market on a large scale. Such an endeavor on an existent college campus's system would be foolish at best; transition from a university to an energy production company is not likely to be simplistic.

Aside from this caveat on the lack of direct benefit from an electric system capable of islanding, it is the author's contention that the notion still deserves 
contemplation. As discussed throughout this paper, developing a system that provides the campus with greater energy independence through local generation would clearly stand to benefit the university, its students, and possibly the local utility. If done sustainably, it stands to benefit the nation and the world through reduced environmental impact and resource depletion. If such a system were to be developed, the additional requirements necessary for islanding capabilities may not cause drastic increase in project costs, were they to be done in conjunction with other system upgrades.

The system proposed below could be implemented either with anti-islanding protection or with intentional islanding capabilities. There would be differences in the upgrades needed, and the manner of nominal operation for the system based on whether or not islanding is to be avoided. Therefore, the system is presented first under the assumption that islanding shall be avoided, and then the requirements for enabling the system to handle intentional islanding operation are addressed.

\section{Proposed Developments}

This system shall provide energy independence and reliable electrical service to the Cal Poly campus through the installation of three new generators. The three proposed generation units are listed below, and subsequent system alterations or studies needed are presented as well. The total added generation capacity was initially based on an assumption of $100 \%$ system loading and $50 \%$ supply of existent generation capacity. Some of the existent generators may serve as more of a back-up system rather than consistent generation, so full output should not be relied upon. These generators serve as only a small portion of loading in most cases, so their effect is usually minimal. The loading will vary significantly on a daily, as well as monthly, basis. Yet an assumed $100 \%$ loading should provide for the capacity needed on average. 
Referring back to Table IX.A, this implies a needed generation capacity of more than $4 \mathrm{MW}$ to meet the demands.

- A photovoltaic panel system with $250 \mathrm{~kW}$ of maximum output power shall be installed with interconnection to Feeder C.

- Wind turbines with a combined total output of $1 \mathrm{MW}$ shall be installed with connection to Feeder Z.

- A solar thermal plant with 4MW maximum output power shall be installed with interconnection directly to the Middle Substation bus through Feeder P (currently spare). The solar thermal plant uses a solar collector to create a super-heated liquid, which can be stored and used to run a traditional steam turbine powered synchronous generator.

A single generation source could possibly be used to provide all of the necessary power, but three separate units are suggested here for multiple reasons. A large solar thermal unit can provide consistent and predictable output due to its energy storage capability, and heat storage is more efficient and sustainable than electrical energy storage. Therefore, the $4 \mathrm{MW}$ solar thermal unit will provide the base generation for the campus. The photovoltaic and wind generation is more unpredictable and intermittent; they can be thought of as auxiliary sources. Their presence will reduce transmission losses and provide voltage support. The photovoltaic system will only produce energy during the day so it adds the benefit of naturally increased campus generation during higher load demand times. Furthermore, the diversity of generation methods provides more opportunities for research and education at the university.

The Feeder $\mathrm{C}$ line runs northeast from the main campus into Poly Canyon, where there are isolated, undeveloped areas well-suited for a sizable photovoltaic system. There is very little load demand on Feeder C (usually less than 5kVA), so significant 
generation capacity - like that suggested - would back-feed to the Lower Substation. If this photovoltaic system outputs near maximum power with the Sierra Co-Generator on Feeder $\mathrm{G}$ also running, Transformer $\mathrm{O}$ would be back-fed (power flowing upstream from the Lower Sub to the Middle Sub). This would be non-ideal system operation; Bus O of the Lower Sub would be feeding the Middle Sub, while the Middle Sub would be feeding Bus $\mathrm{N}$ of the Lower Sub. Instead, the intertie between Feeders $\mathrm{G}$ and $\mathrm{D}$ could be closed, forming the "dorm loop". The looped operation would provide more efficient use of the Sierra plant since it would be servicing loads on the dorm feeders more directly, and the power flow through the two transformers/feeders connecting the Middle and Lower Substations would be better balanced.

Feeder $Z$ provides power to isolated loads throughout the northwest portion of the campus as far as Cheda Ranch and Stenner Creek Ranch. There is an available interconnect to this feeder (switch number S154) at the most northwestern area near Stenner Creek Road. A wind farm could be installed on the hillside north of this switch and/or on the hill to the west of this switch near Highway 1. This area provides a convenient location for wind energy development with viable access and interconnection in the immediate vicinity. A $1 \mathrm{MW}$ wind farm would produce more than the loads of Feeder $Z$ demand, but even with all the existent generation on Feeder $V$ at maximum output, the Upper Substation would still need to import a significant amount of power. For this reason, the intertie between the Upper and Middle Substations should be normally closed to allow this import to come from the Middle Substation as well as from the utility connection.

The Middle Substation has a relatively light load demand, but it has direct connection to the utility as well as both other substations. It also has four spare feeders at present. This makes it an ideal interconnection point for a large quantity of 
generation. A solar thermal plant could be developed in a convenient location and new service lines could be run from that location to the Middle Substation bus. With the intertie to the Upper Substation closed, this plant could service all system loads without disrupting power flows. This will provide a stable source of generation for the bulk of the campus load demands.

The primary changes to the system that have just been outlined are shown in Figure IX.3. Further changes to the system and to system operation are still necessary in order to add the generation capacities suggested here. These changes are discussed on the following pages with respect to each issue of concern that warrants them. Nominal operation of the system proposed would entail full utilization of the new generation as well as the Engineering West Photovoltaics and the Sierra Co-Generator. The other existent generation on the system would be used mainly for back-up generation and high loading; they would otherwise be off or operating at low capacity. This will reduce fuel costs while maintaining reliable service. 


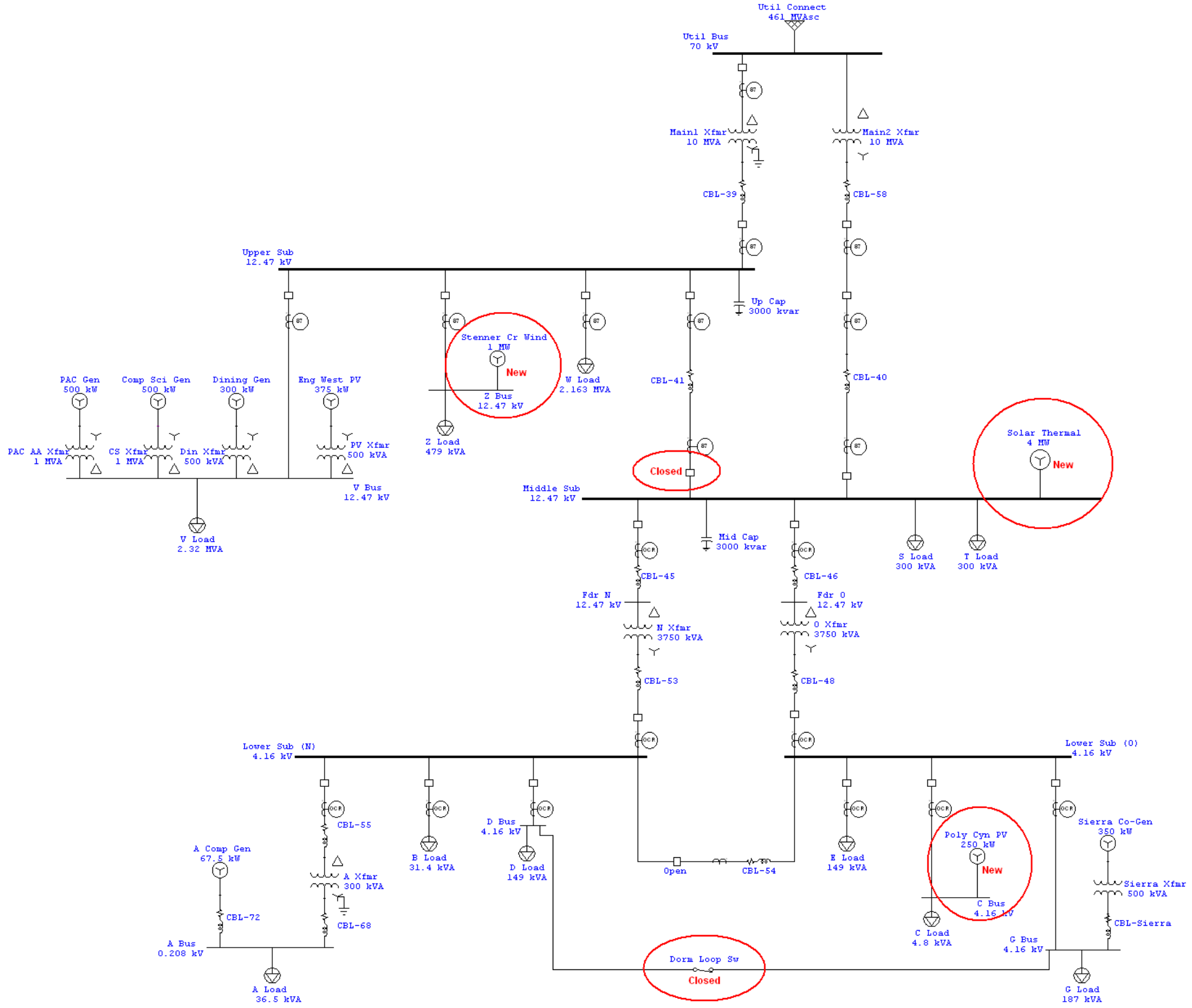

Figure IX.3 Proposed Upgrades to Cal Poly Distribution Network 


\section{Analysis of Proposed System}

Power Flow

The campus distribution system should now be viewed more as a microgrid. The system is still functioning primarily in a radial fashion with mostly downstream power flow (no flow changes are seen by the fuses or anything further downstream). The only upstream flows seen are from feeders with generation up to the substation bus they are connected to, and possibly between substations. There are no issues of overflow since all transformers see the same power flow and the new currents are well within the ratings for the lines, buses, and breakers affected. While there is no pertinently problematic power flow during nominal operation, the load flows of the new system are more complex and dynamic. All possible situations must be considered.

Abnormal operating conditions could cause dangerous power flow reversals. For example, if Feeder $\mathrm{E}$ were to disconnect during nominal operation and all generators maintained the same outputs, power would flow from the Lower Substation to the Middle Substation, from the Middle Substation to the Upper Substation, and from both the Middle and Upper Substations to the utility. Power flow upstream to the utility may be problematic since it may have adverse effects on the utility protection schemes. All affected protection schemes must account for such scenarios.

\section{Voltage Regulation}

The upgraded system shows slight improvements in voltage regulation with the lowest voltage on the system during nominal operation being above $99.5 \%$. Yet the changes in voltage levels compared to the existent system are minor - the greatest change in voltage levels occurs on the Lower Substation bus with an increase of $0.36 \%$ from the existent system to the proposed system. With the changes of voltage levels 
observed being so small, connection and disconnection of generators will not produce problematic spikes or droops in voltage.

\section{Protection Schemes}

The generation added in the proposed system was intentionally implemented to minimize the disturbances to existent protection schemes. Since the added generation is upstream of all fuse protection, the existent fuse coordination need not be altered. However, the potential changes in power flow that were mentioned must be addressed. In addition to standard internal fault protection for the generators, basic overcurrent protection should protect against external faults. Table IX.E shows the nominal operating currents for the relevant sources as well as minimum and maximum fault currents for external faults. Note that the nominal operating current for the utility

\begin{tabular}{||c|c|c|c||}
\hline Source & Nominal I & $\mathbf{I}_{F} \mathbf{m a x}$ & $\mathbf{I}_{\boldsymbol{F}} \min$ \\
\hline Utility Connection & 3.7 & 3800 & 541 \\
\hline Solar Thermal & 160 & 1150 & 777 \\
\hline Stenner Cr Wind & 54.6 & 286 & 194 \\
\hline Poly Cyn PV & 40.9 & 215 & 146 \\
\hline Sierra Co-Gen & 769.5 & 6390 & 4340 \\
\hline
\end{tabular}

Table IX.E Source Currents (in A) for New System connection is only $3.7 \mathrm{~A}$; this value would increase to nearly $30 \mathrm{~A}$ if all on-site generation were out of service. For external fault protection, time-inverse overcurrent relays on each generator should be set to operate for 2-3 times the maximum operating current. This will account for heavy loading and transient spikes seen by the generator while still providing back-up protection in case a generator were feeding an uncleared fault.

The existent overcurrent protection for the feeders on the Lower Substation bus should still be valid. Nominal currents on these feeders are on the order of $30 \mathrm{~A}$ or below, whereas minimum fault currents on these feeders are on the order of nearly 1000 A to $6000 \mathrm{~A}$. However, nuisance tripping could occur due to fault contributions of generators downstream of this protection. For example, a fault on the bus of Feeder $A$ 
will cause nearly 1000 A to flow through Feeder A, half coming from Feeder D (Sierra Co-Gen and Poly Cyn PV sources) and half coming from Feeder N (Middle Substation source). The desired response is for the breaker on Feeder A to open, but not any others. Therefore, the overcurrent relays on Feeders $D$ and $N$ should not operate for this fault current. To protect against nuisance tripping, the overcurrent protection of the feeders should be set to operate first for the minimum possible fault current seen for faults within their zone of protection, and set to operate with a greater time delay for fault currents seen for faults outside their zone (in order to provide ample back-up protection).

Table IX.F shows the nominal operating currents and fault currents for the feeders; the values in red depict upstream currents. The table also shows the relay settings that will provide feeder protection, as well as redundant protection for faults outside the immediate zone of protection. Most feeders can be protected with inversetime overcurrent relays (51), but directional overcurrent relays (67) are needed to protect the interties between substations and some feeders with DG since bi-directional current flows occur on these lines. The 51 relay protections can most likely be covered by existent protection, but relay setting adjustments may be necessary. Note that all upstream flow protection is protected using 67 relays, as well as the downstream protection on the substation interties.

The relay settings shown here account for all possible system power flows including " $n-1$ contingencies" for operation during the loss of a generator, a load, or a branch/interconnection. These settings will provide complete fault protection (plus redundant protection outside primary zones), while allowing for operational power flows of all possible generation conditions from no onsite generation to full on-site generation. Individual loads on this system are still served radially, and the existent fuse protection remains valid. The substation interconnections and feeder buses, however, now 
function with bi-directional flow as with high voltage systems. Differential protection of the buses and transformers is still the optimal protection in those cases. Directional relays will provide the additional protection needed.

\begin{tabular}{|c|c|c|c|c|c|c|c|c|}
\hline \multirow{2}{*}{ Feeder } & \multirow{2}{*}{$I_{\text {nominat }}$} & \multirow{2}{*}{\begin{tabular}{|c|} 
(within zone) \\
$I_{F} \min$ \\
\end{tabular}} & \multicolumn{2}{|c|}{ (outside of zone) } & \multicolumn{2}{|c|}{$\mathrm{I}_{\mathrm{TRIP}}(51)$} & \multicolumn{2}{|c|}{$\mathrm{I}_{\mathrm{TRIP}}(67$; upstream) } \\
\hline & & & $\mathrm{I}_{F} \min$ & $I_{F} \max$ & TD1 & TD2 & TD1 & TD2 \\
\hline$Z$ & 22.2 & 7980 & 194 & 400 & 500 & 200 & 100 & - \\
\hline $\mathrm{W}$ & 100.3 & 8180 & 0 & 518 & 500 & 200 & - & - \\
\hline $\mathrm{V}$ & 96.6 & 8120 & 0 & 965 & 500 & 200 & 100 & - \\
\hline $\begin{array}{l}\text { Up-Mid } \\
\text { Sub Tie }\end{array}$ & 134.9 & 3770 & $\frac{55}{14}$ & $\begin{array}{l}1210 \\
5070\end{array}$ & $200 *$ & $100^{*}$ & 300 & 200 \\
\hline $\mathrm{T}$ & 13.9 & 7530 & 0 & 71 & 100 & 50 & - & - \\
\hline $\mathrm{S}$ & 13.9 & 7530 & 0 & 71 & 100 & 50 & - & - \\
\hline$P$ (new) & 159.9 & 7280 & 778 & 1150 & 500 & 300 & - & - \\
\hline \multirow{2}{*}{$\mathrm{O}$} & \multirow{2}{*}{1.4} & $2160 / 6460$ & $1660 / 4990$ & $1800 / 5380$ & \multirow{2}{*}{$\begin{array}{l}100^{*} \\
\text { (HVS) }\end{array}$} & \multirow{2}{*}{$\begin{array}{c}50^{*} \\
(\mathrm{HVS})\end{array}$} & \multirow{2}{*}{$\begin{array}{c}100 \\
\text { (LVS) }\end{array}$} & \multirow{2}{*}{$\begin{array}{c}50 \\
\text { (LVS) }\end{array}$} \\
\hline & & 0 & 0 & $148 / 443$ & & & & \\
\hline \multirow{2}{*}{$\mathrm{N}$} & \multirow{2}{*}{1.4} & $1610 / 4820$ & $133 / 399$ & $1740 / 5200$ & \multirow{2}{*}{$\begin{array}{l}100^{*} \\
\text { (HVS) }\end{array}$} & \multirow{2}{*}{$\begin{array}{c}\mathbf{5 0}^{*} \\
\text { (HVS) }\end{array}$} & \multirow{2}{*}{$\begin{array}{c}100 \\
\text { (LVS) }\end{array}$} & \multirow{2}{*}{$\begin{array}{c}50 \\
\text { (LVS) }\end{array}$} \\
\hline & & 0 & 0 & $143 / 428$ & & & & \\
\hline \multirow{2}{*}{ G } & \multirow{2}{*}{24.9} & 5130 & 425 & 432 & \multirow{2}{*}{100} & \multirow{2}{*}{50} & \multirow{2}{*}{30} & \multirow{2}{*}{ - } \\
\hline & & 0 & 0 & 5750 & & & & \\
\hline E & 4.4 & 7690 & 0 & 106 & 50 & 20 & - & - \\
\hline \multirow{2}{*}{ D } & \multirow{2}{*}{5.2} & 5110 & 4880 & 5320 & \multirow{2}{*}{100} & 50 & - & \\
\hline & & 0 & 5050 & 6560 & & & 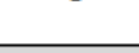 & 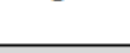 \\
\hline $\mathrm{C}$ & 37.3 & 6460 & 0 & 218 & 100 & 50 & - & - \\
\hline B & 4.4 & 6340 & 0 & 22 & 50 & 20 & - & - \\
\hline A & 5.1 & 837 & 609 & 612 & 100 & 50 & - & - \\
\hline 2 & & 0 & 0 & 67 & 100 & 0 & 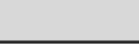 & 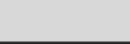 \\
\hline
\end{tabular}

Table IX.F System Currents and Necessary Relay Settings for Protection

* directional units (67) necessary for these downstream flow protections

HVS = high voltage side of transformer $:$ LVS = low voltage side of transformer

The amount of alteration needed for the proposed system appears acceptable since only the directional relays discussed constitute significant protection equipment upgrades; the existent system protection will suffice for the majority of system fault protection. However, two areas of protection have not yet been addressed here: islanding protection and the two interconnections with utility service. Islanding protection issues are discussed later. For the grid interconnection feeders, existent overcurrent 
protection will surely be adequate since fault levels (in both directions) here are on the order of 10-100 times greater than any reasonable operational current levels; unless there is an export of more than $1 \mathrm{MW}$, the current through these transformers is less than one tenth of the fault currents. Yet PG\&E's protection schemes on the utility grid may be adversely affected by the changes to the Cal Poly system - namely the possibility of a net export of power from the campus at any given time. An investigation of the upstream protection schemes should be performed prior to implementing this system. Yet since Cal Poly is connected to the grid via a $70 \mathrm{kV}$ line tap on a PG\&E line interconnecting other large substations, this line is most likely already equipped for bi-directional power flow and existent protection schemes are not likely to need significant upgrades.

If an annual average energy consumption of zero is desired, the system will have to be able to export power. Consistently matching the varying load demands exactly with the on-site generation would be an over-zealous task - hence the need to maintain grid interconnection. Therefore, a net zero consumption will be reached through an annual average by over-producing (exporting) power during light loading and underproducing (importing) power during heavy loading. Adequate protection that accounts for the exportation of power from the campus is necessary to reach this goal. However, the alternative is to merely reduce the nominal output of on-site generation and implement protection that will disconnect generators when total power imported approaches zero. The Cal Poly campus would still be a net consumer of energy, but the consumption would be drastically reduced and most benefits would still be realized, even if only to a lesser degree. 
Intermittency

The intermittency of the wind and photovoltaic generation should not pose any problems to system functionality. In fact, only minimal energy storage capacity will be needed for these generators. Since the solar thermal plant and utility service are capable of providing power for full load demand, these intermittent sources serve mainly as a means to reduce the amount of imported power (or increased the amount of exported power) when weather conditions are ample. Of course, some storage will be necessary to ensure proper operation of the inverters. Energy storage that can sustain full-load output for one or two hours with no charging should be adequate for both systems - this would be around 50-100Amp-hours of storage in both cases. Further storage may be warranted if the system is to be capable of operating in islanded mode, but these generators may otherwise only output when wind or sun are readily available. The campus will need to be capable of providing consistent and reliable power in the case of islanding, and greater storage capacity on these generation sources will make that possible. The existent on-site generators provide additional support in this case, though, so the need for storage is still limited. In the case of the PV system, output tends to be higher during heavy loading times (day time); the loss of this generation at night actually reduces the need for variation of the solar thermal output. In this way, the initial and maintenance costs of battery banks (or other storage means) are marginalized here, while the benefits of these renewable sources are still obtainable.

\section{Harmonics}

As mentioned previously, modern inverter technology has made management of harmonic injections easily realized. Since the bulk of on-site generated power comes 
from a synchronous generator (solar thermal), the harmonic content on the system should fall well within standard limits even if only modestly advanced inverters are used.

\section{Islanding}

If islanding is to be avoided, loss of grid (LOG) detection will be necessary to disconnect generators when the utility connection becomes faulted. Since on-site generation is capable of matching on-site load demands without utility connection, most detection methods could fail. Active methods could be implemented for the photovoltaic and wind generation since they have inverter interconnection, but those detection methods would fail (though perhaps only temporarily) if the solar thermal plant were able to sufficiently maintain voltage and frequency. The inherent non-detection zones of all passive methods would make LOG detection at the point of solar thermal interconnection unreliable. Intertripping methods coordinated with utility protection equipment could prove to be very complicated and expensive since the utility breakers that could cause an LOG occurrence may be numerous and quite distant from the Cal Poly campus.

Since LOG detection cannot be simply or reliably implemented at the point of DG interconnection, the most sensible option is to implement it elsewhere. Any true LOG occurrence could be quickly and easily detected at the point of grid interconnection - the high voltage sides of the two main transformers. An LOG occurrence for the Cal Poly campus is electrically equivalent to a fault immediately upstream of both main transformers (only one connection with the grid is necessary for the proposed system to operate adequately). Therefore, the most reliable method of LOG protection could be accomplished with under/over voltage and frequency relays on the $70 \mathrm{kV}$ bus that would trip all generator connection through high-speed communication links. This will provide 
quick and reliable detection for all true LOG occurrences, but further protection should be implemented as well.

Without an actual fault on the utility grid, some portion of the Cal Poly distribution system may experience an LOG occurrence. That is, fault detection tripping may isolate one or more of the generators from any grid connection while still leaving them connected to loads. For this reason, LOG detection must still be implemented at the point of each DG connection. A rate of change of frequency (ROCOF) relay and/or other passive methods can be used to protect the solar thermal plant. Over/under frequency or voltage relays could be used, but ROCOF relay have shown to be more reliable since their non-detection zones are smaller for the same sensitivity levels [9]. The sensitivity can be relaxed enough to allow for typical operational fluctuations because the primary protection will still prevent the feeding of faults under true LOG occurrences. Likewise, the other generators can also be protected passively against faults that isolate them from the grid.

Islanding protection for this system is somewhat complicated because the system is capable of providing a viable island - generation capacities are able to meet load demands. Because of this, intentional islanding during loss of utility service could be accomplished by this system. The solar thermal plant has a large capacity and well regulated output; it could therefore serve as the "swing" generator during islanding. While connected to the grid, the generators can operate in droop mode or in power control mode. These modes are dependent on the grid for maintaining constant system frequency, while output power is dictated by energy input, load demand, or operator settings. Yet upon the occurrence of islanding, the solar thermal plant would need to be immediately switched to isochronous mode to maintain a system frequency of $60 \mathrm{~Hz}$. Without grid connection, the frequency and voltage of the Cal Poly island could quickly 
collapse if the DG units were all in droop or power control mode. Yet in the isochronous mode, a generator operates at a fixed frequency (fixed speed) regardless of loading. Only one generator on an island may operate in isochronous mode or the resulting fight between generators to maintain slightly different frequencies would result in system collapse. Sensibly, the largest generator of an island should be the isochronous generator - this is the solar thermal plant here. Methods for instantaneous switching between droop mode and isochronous mode upon islanding occurrences may be difficult to realize because current regulations prohibit islanding operation in almost all cases. This may be the biggest hindrance in implementing intentional islanding operation on this system. Nonetheless, much literature speculates about this method of intentional islanding soon being realized for the sake of reducing outage costs for highly sensitive utility customers. $[9,27,28,29]$

For intentional islanding operation, the same LOG detection on the $70 \mathrm{kV}$ bus previously mentioned could still be used. Instead of a LOG detection signal being used to disconnect the generators, however, in this case it would be used to switch the solar thermal plant into isochronous mode. The LOG signal would have to instantaneously activate autonomous switching of the solar thermal plant into isochronous mode. Another change to the proposed system necessary to implement intentional islanding is that all the generators on the $\mathrm{V}$ Bus should be running during nominal operation. They need not produce significant output during nominal operation, but they must be available to do so for load support in the event of islanding when the renewable sources are not adequate to meet current demand. The switching to island mode must happen instantaneously upon LOG, so the other generators must already be running since the solar thermal plant may not be capable of supporting the system during their start-up times. 


\section{System Summary}

$>$ Solar Thermal Plant

- Solar collectors for superheating fluid; heat storage of fluid; synchronous machine powered by steam turbines for regulated output

- 4MW (191A) capacity; around 3.5MW (169A) nominal operation

- Connected to Middle Substation via spare Feeder P

- Passive LOG protection in addition to standard generator protection

- Nominally operated in droop mode; isochronous mode for intentional islanding

Poly Canyon Photovoltaics

- $250 \mathrm{~kW}(41 \mathrm{~A})$ maximum output capacity

- Connected to Feeder C in Poly Canyon

- Passive LOG detection in addition to standard generator protection

- Low harmonic content inverter

- deep cycle battery storage of $50-100 \mathrm{~A} / \mathrm{hr}$

$>$ Stenner Creek Wind Farm

- $1 \mathrm{MW}(55 \mathrm{~A})$ maximum output capacity

- Connected to Feeder Z near Cheda \& Stenner Creek Ranches

- Passive LOG detection in addition to standard generator protection

- Low harmonic content inverter

- deep cycle battery storage of $50-100 \mathrm{~A} / \mathrm{hr}$ (possibly more for islanding capability)

$>$ System Protection

- Time-Inverse Overcurrent (51) relays on all load feeders

- Directional Overcurrent (67) relays on interties and Feeders Z, V, \& G

- Feeder relay settings shown in Table IX.E

- LOG detection at DG interconnection as well as grid interconnection

$>$ Interties

- Upper Sub - Middle Sub intertie nominally closed

- Feeder G - Feeder D intertie nominally closed (dorm loop)

- System power flows are more complex (bi-directional); care must be taken to ensure safety during maintenance switching 


\section{CONCLUSIONS}

The nature of power grids is inevitably changing, evidenced by the steady increase of distributed generation installations on grids worldwide. The issues discussed in this paper are natural hindrances to the reliable operation of grids that experience high levels of DG growth, but they are not insurmountable. The benefits that DG provides to customers and utility and the increasing need for renewable energy sources have proven to outweigh the difficulties encountered in their implementation. In many cases, DG offers a means to improve grid operation through voltage support, decreased transmission losses, and increased reliability. The issues presented in this paper, though, demand consideration before the installation of any distributed generator. Electrical standards are direly needed in this field, as each DG development is currently addressed on merely a case-by-case basis. If grids - or portion of grids - are evaluated on a more complete scale, the use of DG may be more ideally optimized instead of developing in a "patchwork" fashion. It is likely that DG will provide much higher portions of total energy production on the future grids and the challenge for engineers then, is to mitigate the adverse effects so that the benefits may be fully realized.

The case study of Cal Poly's distribution system presented in this paper is an example of what may become a commonplace endeavor. As the cost of conventional electrical energy continues to rise and the cost of modern DG technologies continues to decrease, large facilities like college campuses and industrial complexes will experience greater incentives to produce energy independently. The formation of microgrids in such instances, as well as within utilities' own grid systems, is a concept piquing much interest. The paradigm of future grids may look significantly different than the traditional paradigm, but the fundamental principles needed to operate current grids are the same principles that any new paradigm will need to maintain for successful operation. 


\section{Future Studies}

Most sections of this paper could easily warrant an entire thesis on their own. This paper presents a high level overview of the various issues surrounding DG, but indepth investigations into each issue would prove beneficial as engineers strive to keep up with evolving changes in power distribution systems. The case study presented here provides a basis from which many research projects could begin. Foremost, more extensive data collection would provide the ability to refine and expand the usefulness of this study. Presented below are a few areas in which future research could help make the proposed system for Cal Poly's net zero consumption a reality. With the research of this paper primarily focused on the effects of DG on grids in general, the data collected on Cal Poly's system and resource availability was limited. Data acquisition in this area would be most immediately beneficial to the progression of such a system.

\section{Cost Analysis}

Before the changes suggested for Cal Poly's distribution system could be implemented, such changes must be proven economically justifiable. An extensive cost analysis would be needed to this end. The cost of installing the new generation, upgrading the protection systems, as well as any additional operating and maintenance costs should be identified. Current rates and costs, along with future projections, of Cal Poly expenses for imported energy must also be quantified. With this information, one should be able to project the timeframe in which the upgraded system costs would be recouped. In such a study, one may also choose to address potential cost mitigations through the implementation of student research programs that would provide preliminary engineering design or operational engineering. 


\section{Optimized Operations}

With more extensive data collection on the existent generators as well as those to be added, one may be able to better identify optimal operating conditions. More accurate loading data would also be beneficial to this end, along with meteorological data that could give insight into wind and solar generation expectations. With more accurate load projections - daily and yearly - and expected availability of renewable generation, nominal operating conditions could be more accurately identified.

\section{Environmental \& T\&D Benefits}

The benefits the proposed system would offer are certainly not limited to the curtailment of energy bills for Cal Poly. With identification of annual energy production through the renewable sources used, one could perform a study to quantify the environmental benefits gained. This system will reduce the consumption of fuel supplies that would otherwise be needed to provide campus electricity; an analysis of the resource depletion and harmful emissions/waste avoided could prove quite significant. Likewise, a reduction of imported power would inevitably reduce the power losses seen by the utility that would come from the otherwise transmitted power. Quantifications of such benefits could well supplement other studies such as the cost analysis suggested. 


\section{BIBLIOGRAPHY}

[1] Pepermans, G. , Belmans, R. , Driesen, J. , D’haeseleer, W. , \& Haeseldonckx, D. (2006). "Distributed generation: Definition, benefits, and issues". Energy Policy, 33(6), 787-798

[2] Golkar, M. (2009). "Distributed generation and competition in electric distribution market”. leee Eurocon 2009, Eurocon 2009, .

[3] Slootweg, J. , \& Kling, W. (2002). "Impacts of distributed generation on power system transient stability". Proceedings of the IEEE Power Engineering Society Transmission and Distribution Conference,2(SUMMER), 862-867.

[4] Dondi, P., Julian, D. , Bayoumi, D. , Suter, M. , \& Haederli, C. (2002). "Network integration of distributed power generation". Journal of Power Sources, 106(1-2), $1-9$.

[5] Hammons, T. (2007). "International practices in distributed generation developments worldwide". Proceedings of the Universities Power Engineering Conference, .

[6] Carley, S. (2009). "Distributed generation: An empirical analysis of primary motivators". Energy Policy,37(5), 1648-1659.

[7] E Source (2006). Distributed generation: reciprocating engines, microturbines, fuel cells, stirling engines, and photovoltaics. E Source Companies LLC.

[8] Power Quality Impacts of Distributed Generation. EPRI, Palo Alto, CA 1008507

[9] Chowdhury, S.P. , Chowdhury, S. , \& Crossley, P. (2009). "Islanding protection of active distribution networks with renewable distributed generators: A comprehensive survey". Electric Power Systems Research, 79(6), 984-992.

[10] Senjyu, T. , Miyazato, Y. , Funabashi, T. , Urasaki, N. , \& Yona, A. (2008). "Optimal distribution voltage control and coordination with distributed generation". IEEE Transactions on Power Delivery, 23(2), 1236-1242.

[11] Hayashi, Y., Hosokawa, S. , Matsuki, J. , Kobayashi, N. , \& Hanai, Y. (2009). "Computation of locational and hourly maximum output of a distributed generator connected to a distribution feeder". Electrical Engineering in Japan (English Translation of Denki Gakkai Ronbunshi), 167(2), 38-47.

[12] Bruno, S. , Lamonaca, S. , Stecchi, U. , Rotondo, G. , \& La Scala, M. (2009). "Load control through smart-metering on distribution networks". 2009 IEEE Bucharest PowerTech: Innovative Ideas Toward the Electrical Grid of the Future,

[13] Distributed Renewable Energy Generation Impacts on Microgrid Operation and Reliability. EPRI, Palo Alto, CA: 2002. 1004045

[14] Brahma, S. , \& Girgis, A. (2006). "Overview of the effect of distributed generation on protection in power distribution systems". Series on Energy and Power Systems, 2006, 276-280. 
[15] Blackburn, J. , Domin, T. (2007) Protective Relaying: Priciples and Applications, $3^{\text {rd }}$ ed. Boca Raton: CRC Press, Taylor \& Francis Group

[16] Kumpulainen, L. , \& Kauhaniemi, K. (2004). "Analysis of the impact of distributed generation on automatic reclosing". 2004 IEEE PES Power Systems Conference and Exposition, 1

[17] Lawrence, C. , Salama, M. , \& El Shatshat, R. (2009). "Studying the effects of distributed generation on voltage regulation". International Journal of Electrical Engineering Education, 46(1), 11-29.

[18] Taufik (2008). Introduction to Power Electronics, $6^{\text {th }}$ Rev. (Taufik

[19] Taufik (2009). Advanced Power Electronics, $3^{\text {rd }}$ rev. @Taufik

[20] Farret, F. , Simões, M. (2006). Integration of Alternative Sources of Energy Hoboken: John Wiley \& Sons

[21] Esposito, G. , Golovanov, N. , Zaninelli, D. , \& Lazaroiu, G. (2007). "Impact of embedded generation on the voltage quality of distribution networks". 2007 9th International Conference on Electrical Power Quality and Utilisation, EPQU

[22] Barker, P. , \& De Mello, R. (2000). "Determining the impact of distributed generation on power systems: Part 1 - radial distribution systems". Proceedings of the IEEE Power Engineering Society Transmission and Distribution Conference, 3, 1645-1656.

[23] Chen, H. , Sun, Y. , \& Chen, W. (2009). "Harmonic suppression of gridconnected distributed generation based on novel hybrid power filter". 2009 4th IEEE Conference on Industrial Electronics and Applications, ICIEA 2009

[24] Mäki, K. , Kulmala, A. , Järventausta, P. , \& Repo, S. (2007). "Problems related to islanding protection of distributed generation in distribution network". 2007 IEEE Lausanne POWERTECH, Proceedings.

[25] Ranade, S. , Surabhi, R. , Sagi, D. , Mitra, J. , \& Mulpuri, R. (2007). "Likelihood of islanding in distribution feeders with photovoltaic generation". 2007 IEEE Power Engineering Society General Meeting, PES

[26] Carpaneto, E. , Chicco, G. , \& Prunotto, A. (2006). "Reliability of reconfigurable distribution systems including distributed generation". 2006 9th International Conference on Probabilistic Methods Applied to Power Systems, PMAPS

[27] Ten, C. , \& Crossley, P. (2008). "Control of Multiple Distributed Generators for Intentional Islanding". CIRED Seminar 2008: SmartGrids for Distribution, Paper 0125

[28] Mahat, P. , Chen, Z. , Bak-Jensen, B. (2010). "Islanding Operation of Distribution System with Distributed Generators". PhD Seminar on Detailed Modeling and Validation of Electrical Components and Systems 2010.

[29] Alley, S. (1993) "Generator Basics Applied to Field Problems". NETA World 1993

[30] Willis, H. , Scott, W. (2000). Distributed Power Generation: Planning and Evaluation Boca Raton: CRC Press, Taylor \& Francis Group 
[31] Cheung, H. , Wang, L. , Cheung, R. , Hamlyn, A. , Liu, W. , et al. (2008). "Adaptive active power line filter for interfacing wind-power dgs to distribution system". IEEE Power and Energy Society 2008 General Meeting: Conversion and Delivery of Electrical Energy in the 21st Century, PES

[32] Li, H. , \& Leite, H. (2008). "Increasing distributed generation using automatic voltage reference setting technique". IEEE Power and Energy Society 2008 General Meeting: Conversion and Delivery of Electrical Energy in the 21st Century, PES

[33] Network Protection \& Automation Guide, $1^{\text {st }}$ ed. Areva (2005)

[34] Wu, J. (2009). "Control technologies in distributed generation system based on renewable energy". 2009 3rd International Conference on Power Electronics Systems and Applications, PESA 2009, 2009

[35] Berg, A. , Krahl, S. , \& Paulun, T. (2008). "Cost-efficient integration of distributed generation into medium voltage networks by optimized network planning". IET Seminar Digest,2008(12380)

[36] Kazemi, A. , \& Sadeghi, M. (2009). "Distributed generation allocation for loss reduction and voltage improvement". 2009 Asia-Pacific Power and Energy Engineering Conference, APPEEC 2009 - Proceedings

[37] Dai, C. , \& Baghzouz, Y. (2004). "Impact of distributed generation on voltage regulation by Itc transformer". 2004 11th International Conference on Harmonics and Quality of Power

[38] Deng, W. , Pei, W. , \& Qi, Z. (2008). "Impact and improvement of distributed generation on voltage quality in micro-grid". 3rd International Conference on Deregulation and Restructuring and Power Technologies, DRPT 2008

[39] Fuel Cells for Distributed Generation: A Technology and Marketing Summary. March, 2000 Report 193-1. Energy Center of Wisconsin

[40] "Biomass for Power Generation and CHP" (2007). IEA Energy Technology Essentials January, 2007. OECD/IEA

[41] Yingyuan, Z. , Liuchen, C. , Meiqin, M. , \& Ming, D. (2008). "Study of energy management system for distributed generation systems". 3rd International Conference on Deregulation and Restructuring and Power Technologies, DRPT 2008

[42] Ipakchi, A. , \& Albuyeh, F. (2009). "Grid of the future". IEEE Power and Energy Magazine, 7(2), 52-62.

[43] Bhowmik, A. , Schatz, J. , Maitra, A. , \& Halpin, S. (2003). "Determination of allowable penetration levels of distributed generation resources based on harmonic limit considerations". IEEE Transactions on Power Delivery, 18(2), 619624. 
[44] Deng, W. , Pei, W. , \& Qi, Z. (2008). “Impact and improvement of distributed generation on voltage quality in micro-grid". 3rd International Conference on Deregulation and Restructuring and Power Technologies, DRPT 2008, .

[45] Céspedes, M. , \& Sun, J. (2009). "Renewable energy systems instability involving grid-parallel inverters". Conference Proceedings - IEEE Applied Power Electronics Conference and Exposition - APEC, 1971-1977.

[46] Orságová, J. , \& Toman, P. (2008). "Evaluation of negative effect of distributed generation”. PQ 2008: 6th International Conference - 2008 Power Quality and Supply Reliability, Conference Proceedings, 2008.

[47] Zhang, X. (2008). "A framework for operation and control of smart grids with distributed generation". IEEE Power and Energy Society 2008 General Meeting: Conversion and Delivery of Electrical Energy in the 21st Century, PES, .

[48] Koutroumpezis, G. , \& Safigianni, A. (2009). "Optimum distributed generation penetration in a distribution network". 2009 IEEE Bucharest PowerTech: Innovative Ideas Toward the Electrical Grid of the Future, .

[49] Seo, H. , Park, M. , Kim, G. , Yu, I. , \& Ali, M. (2007). "A study on the performance analysis of the grid-connected pv-af system". WProceeding of International Conference on Electrical Machines and Systems, ICEMS 2007.

[50] Jin, X. , Zhao, J. , \& Wang, H. (2006). "On-line stability control of power systems integrated with distributed generation systems". 41st International Universities Power Engineering Conference, UPEC 2006, Conference Procedings, 2.

[51] Liu, Z. , Guo, Z. , Zeng, X. , \& Tan, S. (2004). "A novel scheme of stability control for distributed generation systems”. 2004 International Conference on Power System Technology, POWERCON 2004, 2, .

[52] Yamaguchi, K. , Lee, K. , \& Kurokawa, K. (2008). "Study on voltage regulation method in the power distribution system". 7th Internatonal Conference on Power Electronics, ICPE'07, .

[53] Mäki, K. , Repo, S. , \& Järventausta, P. (2004). "Effect of wind power based distributed generation on protection of distribution network". IEEE Conference Publication, 1, 327-330.

[54] Benato, R. , \& Caldon, R. (2006). "Distribution line carrier: Analysis procedure and applications to DG". Proceedings of the IEEE Power Engineering Society Transmission and Distribution Conference

[55] 2008 Update of the Profiling and Mapping of Intelligent Grid R\&D Programs. EPRI, Palo Alto, CA and EDF - R\&D, Clamart Cedex, France: 2008. 1016931.

[56] Samuelson, S. (2009). "Development and Analysis of a Progressively Smarter Distribution System". CSI RD\&D Grant Solicitation Package: PV Grid Integration. UC-Irvine Advanced Power and Energy Program / PG\&E 


\section{APPENDIX A - CAL POLY YEARLY METERING DATA, 2008-2009}

The following graphs show metering data collected by the Cal Poly Facilities department from July 2008 through June 2009. Data for the $S$ and T feeders that service Poly Canyon Village from the Middle Substation were not operational during this timeframe, so data for those feeders is not presented here. Some incongruencies exist on these graphs due to abnormal operations; zero value points were omitted in the calculations of average, maximum, and minimum load demands.
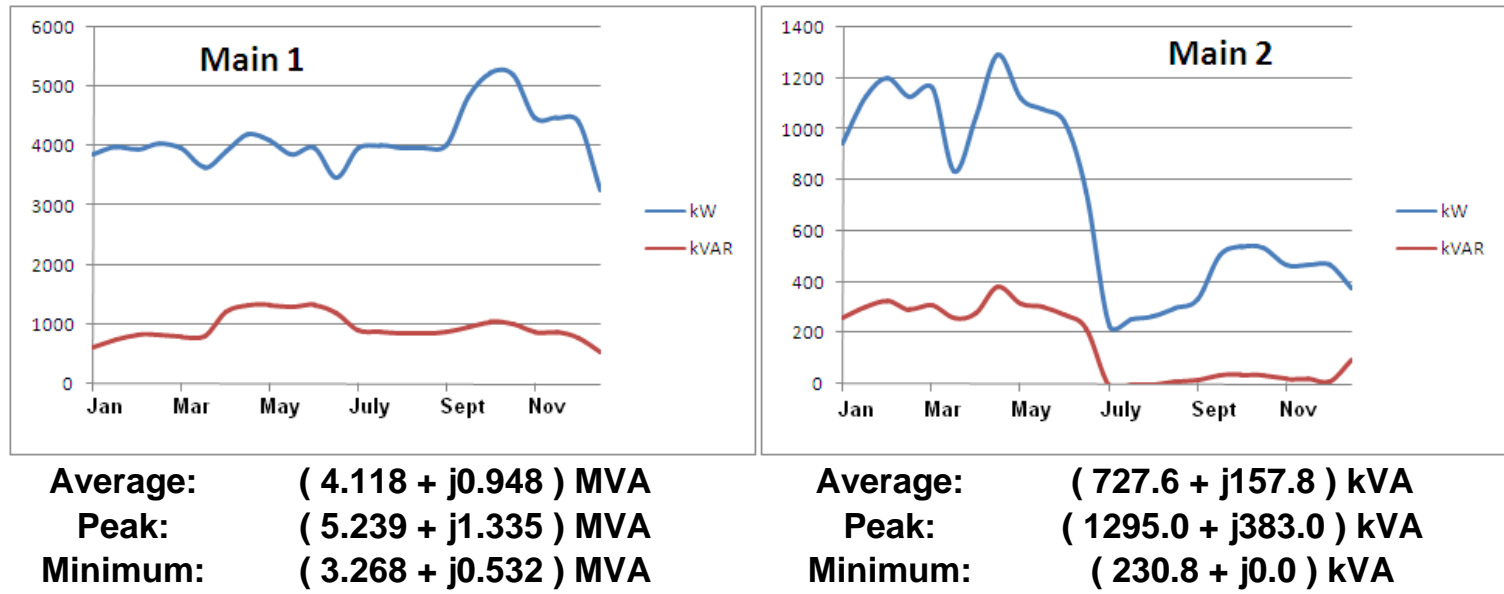

Minimum
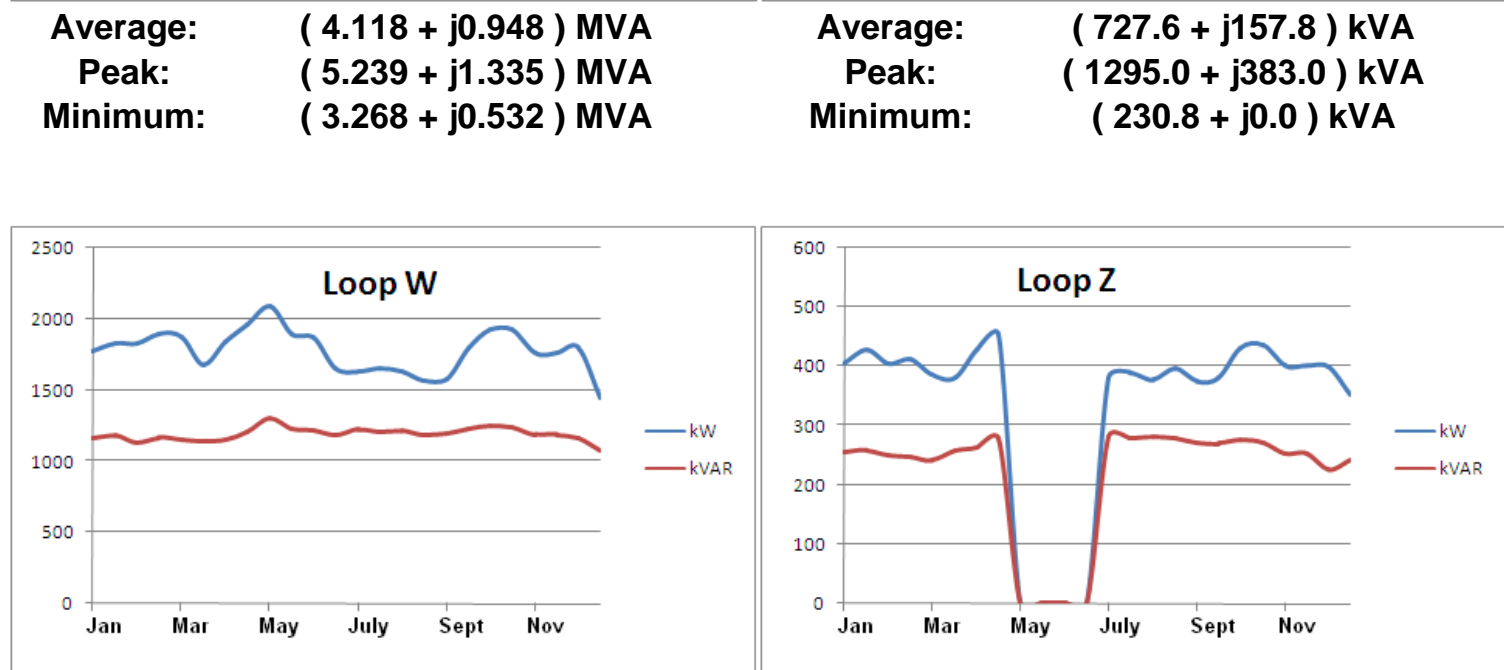

$\begin{array}{cl}\text { Average: } & (1.778+\mathrm{j} 1.192) \text { MVA } \\ \text { Peak: } & (2.091+\mathrm{j} 1.306) \text { MVA } \\ \text { Minimum: } & (1.446+\mathrm{j} 1.074) \text { MVA }\end{array}$

$\begin{array}{cl}\text { Average: } & (401.0+\mathrm{j} 262.3) \mathrm{kVA} \\ \text { Peak: } & (453.8+\mathrm{j} 282.9) \mathrm{kVA} \\ \text { Minimum: } & (352.8+\mathrm{j} 226.4) \mathrm{kVA}\end{array}$



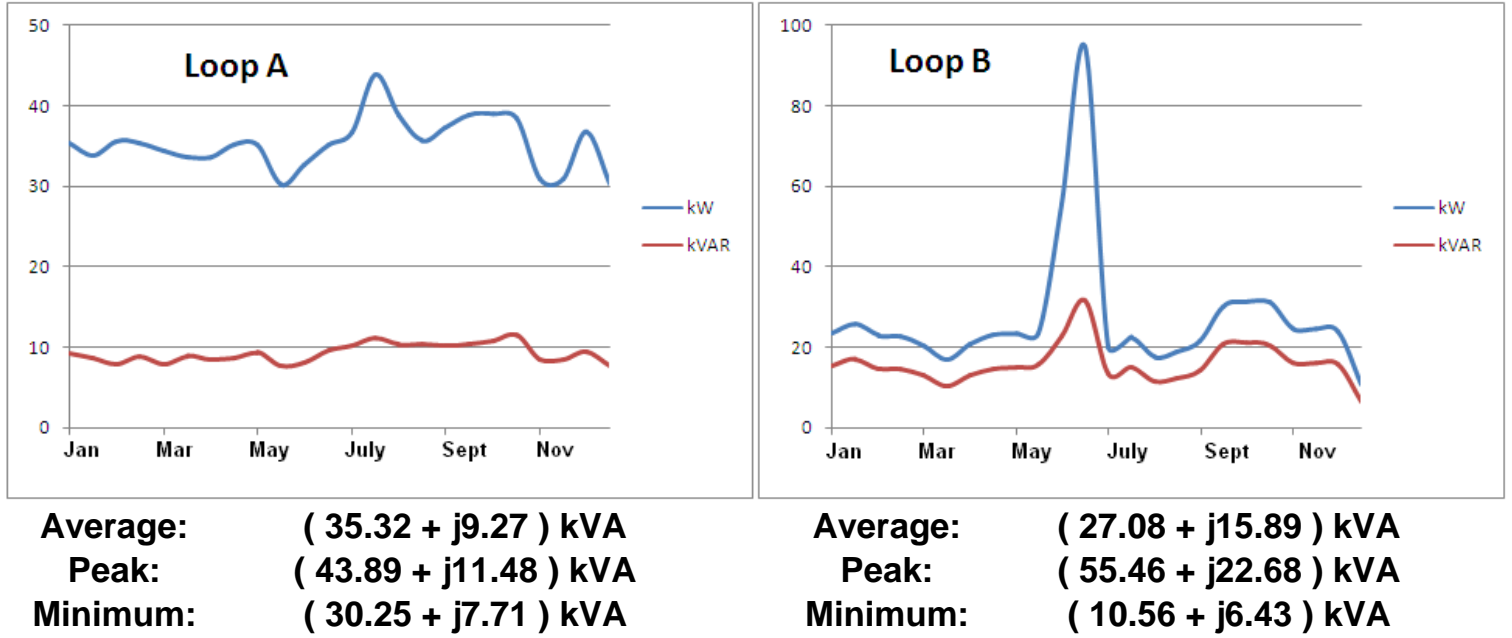

Minimum: $\quad(10.56+j 6.43) \mathrm{kVA}$
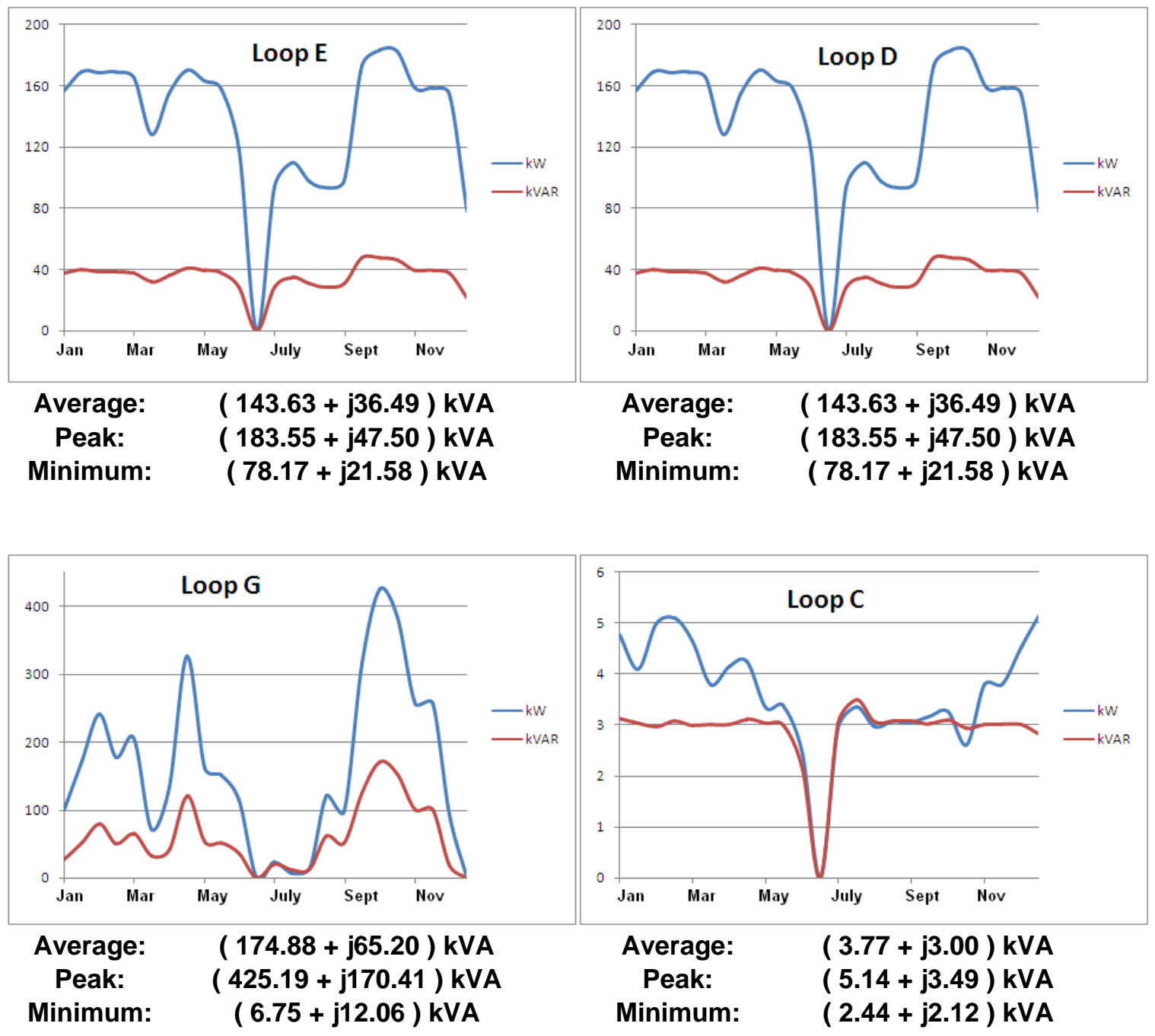


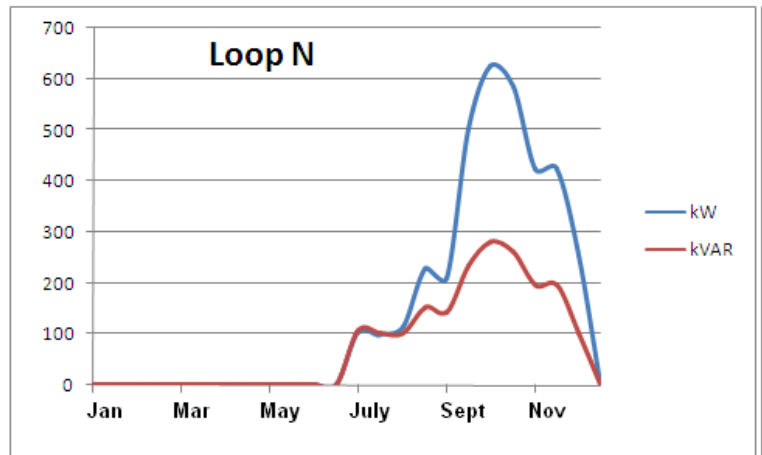

$$
\begin{array}{cc}
\text { Average: } & (324.7+\mathrm{j} 170.8) \mathrm{kVA} \\
\text { Peak: } & (625.7+\mathrm{j} 281.0) \mathrm{kVA} \\
\text { Minimum: } & (99.3+\mathrm{j} 101.7) \mathrm{kVA}
\end{array}
$$

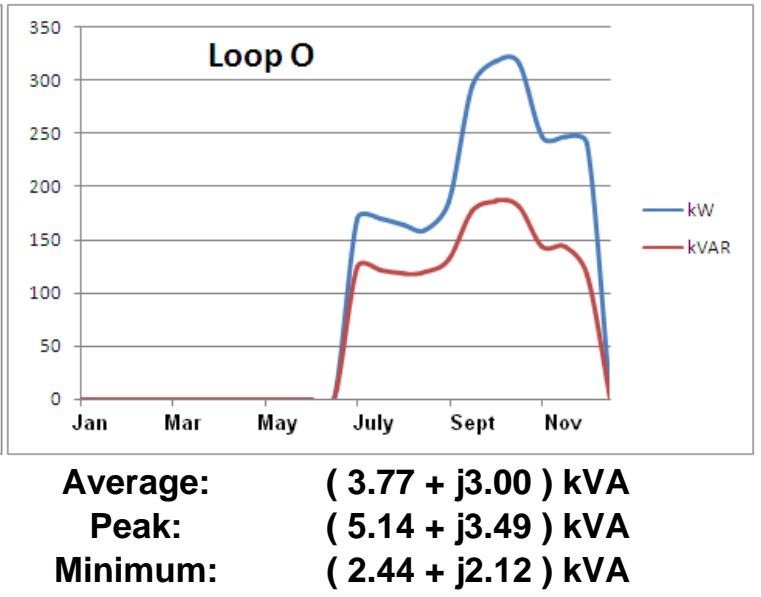




\section{APPENDIX B - CONDUCTOR \& TRANSFORMER MODELING DATA}

\begin{tabular}{|c|c|c|c|c|c||}
\hline Cable & Size & Length $[\mathbf{f t}]$ & $\begin{array}{c}\text { Quantity } \\
\text { per phase }\end{array}$ & $\begin{array}{c}\text { Resistance } \\
{[\mathbf{\Omega} / \mathbf{1 0 0 0 f t}]^{*}}\end{array}$ & $\begin{array}{c}\text { Reactance } \\
{[\mathbf{\Omega} / \mathbf{1 0 0 0 f t}]^{*}}\end{array}$ \\
\hline CBL-39 & 500 & 50 & 2 & 0.02840 & 0.0351 \\
\hline CBL-40 & 750 & 100 & 2 & 0.02030 & 0.0332 \\
\hline CBL-45 & 350 & 30 & 1 & 0.03750 & 0.0375 \\
\hline CBL-46 & 350 & 30 & 1 & 0.03750 & 0.0375 \\
\hline CBL-48 & 1250 & 30 & 1 & 0.01812 & 0.0710 \\
\hline CBL-53 & 1250 & 30 & 1 & 0.01812 & 0.0710 \\
\hline CBL-55 & 350 & 500 & 1 & 0.04387 & 0.0830 \\
\hline CBL-58 & 750 & 40 & 2 & 0.02030 & 0.0332 \\
\hline CBL-68 & 500 & 3 & 1 & 0.02760 & 0.0311 \\
\hline CBL-72 & $4 / 0$ & 50 & 1 & 0.06330 & 0.0332 \\
\hline CBL-Sierra & 2 & 200 & 1 & 0.19934 & 0.1040 \\
\hline \hline
\end{tabular}

*Impedance values given are in ohms per 1000 feet per conductor

\begin{tabular}{||c|c|c|c||}
\hline \hline Transformer & $\begin{array}{c}\text { MVA } \\
\text { rating }\end{array}$ & $\begin{array}{c}\mathbf{\% Z} \\
\text { impedance }\end{array}$ & X/R ratio \\
\hline A & 0.300 & 4.40 & 4.70 \\
\hline CS & 1.000 & 5.82 & 5.79 \\
\hline Din & 0.500 & 6.05 & 5.10 \\
\hline Main1 & 10.000 & 8.79 & 15.50 \\
\hline Main2 & 10.000 & 8.79 & 15.50 \\
\hline N & 3.750 & 5.73 & 11.41 \\
\hline O & 3.750 & 5.54 & 11.41 \\
\hline PAC AA & 1.000 & 5.62 & 5.79 \\
\hline PV & 0.500 & 5.20 & 5.10 \\
\hline Sierra & 0.500 & 4.59 & 4.70 \\
\hline
\end{tabular}

